\title{
Effect of Microstructure on Retained Austenite Stability and Tensile Behaviour In AN Aluminum-Alloyed TRIP Steel
}

\author{
by

\section{Jasmine Sheree Chiang}

\author{
A thesis submitted to the \\ Department of Mechanical and Materials Engineering \\ in conformity with the requirements for \\ the degree of Master of Applied Science
}

\author{
Queen's University \\ Kingston, Ontario, Canada
}

September 2012

Copyright (C) Jasmine Sheree Chiang, 2012 


$$
\begin{aligned}
& \text { Tomorrow may rain, } \\
& \text { so J'll follow the sum. } \\
& \text { - Tobe boatles }
\end{aligned}
$$




\section{Abstract}

Transformation-induced plasticity (TRIP) steels have excellent strength, ductility and work hardening behaviour, which can be attributed to a phenomenon known as the TRIP effect. The TRIP effect involves a metastable phase, retained austenite (RA), transforming into martensite as a result of applied stress or strain. This transformation absorbs energy and improves the work hardening rate of the steel, delaying the onset of necking.

This work describes two distinct TRIP steel microstructures and focuses on how microstructure affects the RA-to-martensite transformation and the uniaxial tensile behaviour. A two-step heat treatment was applied to an aluminum-alloyed TRIP steel to obtain a microstructure consisting of equiaxed grains of ferrite surrounded by bainite, martensite and RA - the equiaxed microstructure. The second microstructure was produced by first austenitizing and quenching the steel to produce martensite, followed by the two-step heat treatment. The resulting microstructure (labelled the lamellar microstructure) consisted of elongated grains of ferrite with bainite, martensite and RA grains. Both microstructural variants had similar initial volume fractions of RA. A series of interrupted tensile tests and ex-situ magnetic measurements were

conducted to examine the RA transformation during uniform elongation. Similar 
tests were also conducted on an equiaxed microstructure and a lamellar microstructure with similar ultimate tensile strengths.

Results show that the work hardening rate is directly related to the RA transformation rate. The slower transformation rate, or higher RA stability, that was observed in the lamellar microstructure enables sustained work hardening at high strains. In contrast, the equiaxed microstructure has a lower RA stability and thus exhibits high values of work hardening at low strains, but the effect is quickly exhausted. Several microstructural factors that affect RA stability were examined, including RA grain size, aspect ratio, carbon content and spatial distribution of the phases. Two of these factors were characteristic of only the lamellar microstructures and led to higher RA stabilities: elongated RA grains and RA grains being primarily surrounded by bainite. The results were also compared with previous work on a silicon-alloyed TRIP steel to show that the aluminum-alloyed compositions could achieve similar, if not better, combinations of strength and ductility. 


\section{Acknowledgements}

I would like to express my sincerest appreciation to my supervisors Dr. Keith Pilkey and Dr. Doug Boyd. This work would not have been possible without their guidance and encouragement.

Mr. Charlie Cooney deserves a lot of thanks for his assistance with equipment and lending his expertise in the lab. I would also like to thank the McLaughlin Hall machine shop technicians, especially Andy Bryson, for their help with mechanical testing sample preparations.

Many thanks to Dr. Anirban Chakraborty and Dr. Joe McDermid from McMaster University for the generous use of equipment for retained austenite magnetic measurements.

I would like to acknowledge the financial support of Queen's University, AUTO21 Network Centres of Excellence and the Ontario Graduate Scholarship. I also thank Dr. Jerry Wang and U.S. Steel Canada for providing the steel that was used in this research.

Most of all, a special thanks to my family and friends for all their love and support. I am really lucky to have you all in my life. 


\section{Table of Contents}

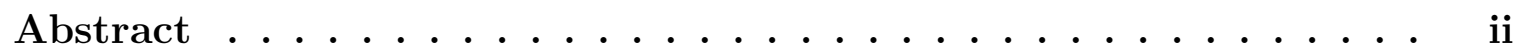

Acknowledgements .................. iv

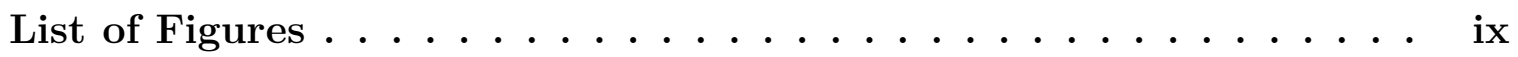

List of Tables $\ldots \ldots \ldots \ldots \ldots \ldots \ldots \ldots \ldots \ldots \ldots \ldots \ldots \ldots \ldots$

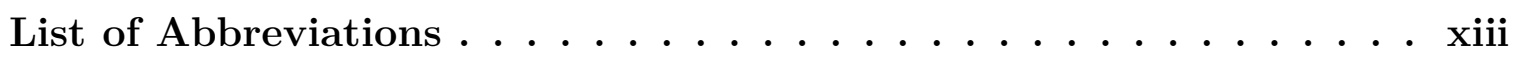

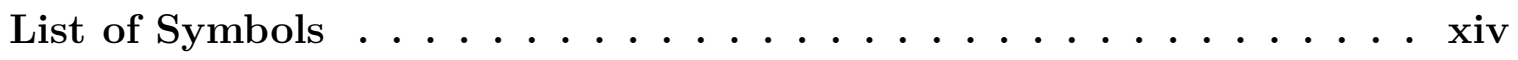

Chapter 1: Introduction $\ldots \ldots \ldots \ldots \ldots \ldots \ldots$

1.1 Motivation . . . . . . . . . . . . . . . . . 1

1.2 Research Objectives . . . . . . . . . . . . . . . . . 4

1.3 Outline of Thesis $\ldots \ldots \ldots \ldots \ldots \ldots \ldots$

Chapter 2: Literature Review . . . . . . . . . . . 7

2.1 The TRIP Effect $\ldots \ldots \ldots \ldots \ldots \ldots \ldots \ldots \ldots \ldots$

2.2 Chemical Composition . . . . . . . . . . . . . 8

2.3 Heat Treatment Processing . . . . . . . . . . . . . . . . 11

2.4 Retained Austenite Stability . . . . . . . . . . . . . . . 16 
2.4 .1 Grain Size . . . . . . . . . . . . . . . . . . . . . . 17

2.4 .2 Grain Shape . . . . . . . . . . . . . . . . . . 18

2.4.3 Spatial Distribution of Surrounding Phases . . . . . . . . . 20

2.4.4 Carbon Content . . . . . . . . . . . . . . . . . 20

2.5 Mechanical Properties and Work Hardening Behaviour . . . . . . . 21

2.6 Characterization Techniques . . . . . . . . . . . . . . . . . 23

2.6 .1 X-Ray Diffraction . . . . . . . . . . . . . . . . . . . 23

2.6.2 Magnetic Measurements . . . . . . . . . . . . . 25

Chapter 3: Experimental Methods . . . . . . . . . . . . 27

3.1 Experimental Material . . . . . . . . . . . . . . . . . . . 27

3.1.1 Details of Heat Treatments . . . . . . . . . . . . . . . 28

3.2 Characterization Techniques . . . . . . . . . . . . . . . 31

3.2 .1 Metallography . . . . . . . . . . . . . . . . 31

3.2.2 Scanning Electron Microscopy (SEM) . . . . . . . . . . 32

3.2 .3 Optical Microscopy . . . . . . . . . . . . . . . . . . . . 33

3.2 .4 Image Analysis $\ldots \ldots \ldots \ldots$. . . . . . . . . . . . . 34

3.2.5 Magnetic Measurements . . . . . . . . . . . . 35

3.2 .6 X-Ray Diffraction (XRD) $\ldots \ldots \ldots \ldots \ldots$

3.3 Uniaxial Tensile Tests . . . . . . . . . . . . . . . . . . . . 41

Chapter 4: Results ................... 44

4.1 Variants with Similar Volume Fractions of Retained Austenite . . . . 44

4.1.1 Microstructure Characterization . . . . . . . . . . . . 45

4.1.2 Tensile Behaviour and Work Hardening Response . . . . . . 53

4.1.3 Retained Austenite Transformation Behaviour . . . . . . . . 58 
4.2 Variants with Similar Ultimate Tensile Strengths _ . . . . . . . . . . 62

4.2.1 Microstructure Characterization ............. 63

4.2.2 Tensile Behaviour and Work Hardening Response . . . . . . . 70

4.2.3 Retained Austenite Transformation Behaviour . . . . . . . . . 73

$4.3 \mathrm{UTS} \times \mathrm{El}$ Values . . . . . . . . . . . . . . . . . . . . . 78

Chapter 5: Discussion . . . . . . . . . . . . . 80

5.1 Microstructural Evolution . . . . . . . . . . . . . . . 80

5.1.1 Equiaxed-875 Microstructure............... 81

5.1.2 Lamellar-875 Microstructure . . . . . . . . . . . . . . 81

5.1.3 Equiaxed-750 Microstructure................ 83

5.1.4 Lamellar-925 Microstructure . . . . . . . . . . . . . 84

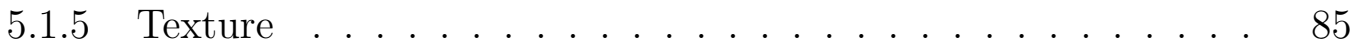

5.2 Retained Austenite Volume Fraction Measurement Techniques . . . . 86

5.3 Tensile Behaviour and RA Transformation Behaviour . . . . . . . . . 89

5.3.1 Variants with Similar Volume Fractions of RA . . . . . . . . 89

5.3.2 Variants with Similar Ultimate Tensile Strengths . . . . . . . 94

5.4 Microstructural Effects on Retained Austenite Stability . . . . . . . . 96

5.4.1 Variants with Similar Volume Fractions of RA . . . . . . . . 96

5.4.2 Variants with Similar Ultimate Tensile Strengths . . . . . . . 100

5.5 Aluminum- versus Silicon-Alloyed TRIP Steel . . . . . . . . . . . . . 102

Chapter 6: Conclusions and Recommendations . . . . . . . . 107

6.1 Conclusions . . . . . . . . . . . . . . . . . . . 108

6.2 Recommendations for Future Work . . . . . . . . . . . . . . . . 110 
Appendix A: Optimizing Heat Treatment Parameters . . . . . . 125

Appendix B: Heat Treatments to Produce Similar UTS Values . . 130

Appendix C: Calibration of Heat Treatment Equipment $\ldots \ldots \ldots 135$

C.1 Heating Rates . . . . . . . . . . . . . . . . . . . . . . . 135

C.2 Temperature Gradients . . . . . . . . . . . . . . 136 


\section{List of Figures}

1.1 "Banana curve" diagram . . . . . . . . . . . . . . . . . . . . 2

1.2 Stress-strain curves of three classes of steel . . . . . . . . . . . 3

2.1 Standard heat treatment path for TRIP steels . . . . . . . . . . 12

$2.2 \quad$ Fe-C phase diagram . . . . . . . . . . . . . . . . . . . . . . . . . . . 13

2.3 Effects of alloying elements on transformation behaviour . . . . . 15

2.4 Effect of aspect ratio and grain size on RA stability . . . . . . . 19

2.5 Bragg diffraction $\ldots \ldots \ldots \ldots \ldots \ldots \ldots \ldots$

3.1 Schematic of heat treatments _ . . . . . . . . . . . . . . . . . . . . 29

3.2 Drawing of heat treated coupon $\ldots \ldots \ldots \ldots \ldots \ldots$

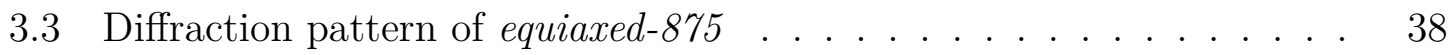

3.4 Deconvolution of a diffraction peak . . . . . . . . . . . 39

3.5 Engineering drawing of tensile specimen $\ldots \ldots \ldots \ldots$

4.1 SEM micrographs of equiaxed-875 and lamellar-875 . . . . . . 46

4.2 Magnified view of martensite and RA grains . . . . . . . . 47

4.3 Optical micrographs of equiaxed-875 and lamellar-875 . . . . . 48

$4.4 \quad \mathrm{M} / \mathrm{RA}$ grain sizes for equiaxed-875 and lamellar-875 $\ldots \ldots \ldots 51$

$4.5 \mathrm{M} / \mathrm{RA}$ grain aspect ratios for equiaxed-875 and lamellar-875 $\ldots . .51$

4.6 Magnified view of M/RA grains in equiaxed-875 and lamellar-875 . . 52 
4.7 Masked micrographs of equiaxed-875 and lamellar-875 . . . . . . 53

4.8 Tensile curves for equiaxed-875 and lamellar-875 . . . . . . . . 55

4.9 Work hardening rate of equiaxed-875 and lamellar-875 . . . . . . 56

$4.10 n_{\text {inst }}$ of equiaxed-875 and lamellar-875 . . . . . . . . . . . 57

4.11 RA transformation behaviour for equiaxed-875 and lamellar-875 . . . 59

4.12 SEM micrographs of equiaxed-750 and lamellar-925 . . . . . . . 64

4.13 Optical micrographs of equiaxed-750 and lamellar-925 . . . . . 65

$4.14 \mathrm{M} / \mathrm{RA}$ grain sizes for equiaxed-750 and lamellar-925 . . . . . . 68

$4.15 \mathrm{M} / \mathrm{RA}$ grain aspect ratios for equiaxed-750 and lamellar-925 . . . . 68

4.16 Magnified view of M/RA grains in equiaxed-750 and lamellar-925 . . 69

4.17 Masked micrographs of equiaxed-750 and lamellar-925 . . . . . 69

4.18 Tensile curves for equiaxed-750 and lamellar-925 . . . . . . . . 71

4.19 Work hardening rate of equiaxed-750 and lamellar-925 . . . . . . 72

$4.20 n_{\text {inst }}$ of equiaxed-750 and lamellar-925 . . . . . . . . . . 74

4.21 RA transformation behaviour for equiaxed-750 and lamellar-925 . . 75

$4.22 \mathrm{UTS} \times \mathrm{El}$ as it varies with $\% \mathrm{RA} \ldots \ldots . \ldots . \ldots . \ldots 79$

5.1 XRD pattern for equiaxed-750 and lamellar-925 . . . . . . . 86

5.2 RA fraction as a function of applied strain for different $\eta \quad \ldots . . . .91$

5.3 RA transformation and $n_{\text {inst }}$ for equiaxed-875 and lamellar-875 . . 93

5.4 RA transformation and $n_{\text {inst }}$ for equiaxed-750 and lamellar-925 . . 95

5.5 Magnified view of M/RA grains . . . . . . . . . . . . . . 98

5.6 Tensile curves for an Al TRIP and a Si TRIP . . . . . . . . . . . . . 104

5.7 RA transformation behaviour in an Al TRIP and a Si TRIP steel . . 106

A.1 Effect of heat treatment parameters on RA volume fraction . . . . . 128 
B.1 Tensile curves for different intercritical annealing temperatures . . . . 132

B.2 UTS vs. intercritical annealing temperature . . . . . . . . . . . 134

C.1 Heating rate in the tube furnace . . . . . . . . . . . . . . 137

C.2 Temperature gradient in tube furnace . . . . . . . . . . . . . . . . 137 


\section{List of Tables}

3.1 Chemical composition of material . . . . . . . . . . . 28

3.2 Samples for interrupted tensile tests . . . . . . . . . . . . . 43

4.1 Volume fractions of phases in equiaxed-875 and lamellar-875 . . . 50

4.2 Austenite carbon content of equiaxed-875 and lamellar-875 . . . . 53

4.3 Tensile properties of equiaxed-875 and lamellar-875 . . . . . . 55

4.4 Interrupted tensile test samples for equiaxed-875 . . . . . . . 60

4.5 Interrupted tensile test samples for lamellar-875 . . . . . . . . 61

4.6 Volume fractions of phases in equiaxed-750 and lamellar-925 . . . 66

4.7 Austenite carbon content of equiaxed-750 and lamellar-925 . . . . 70

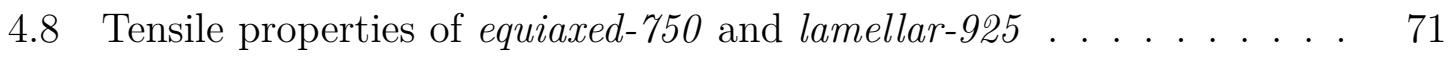

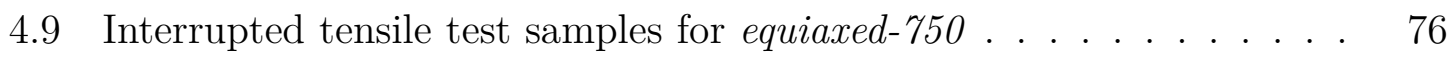

4.10 Interrupted tensile test samples for lamellar-925 . . . . . . . 77

5.1 Tensile properties of an Al TRIP and a Si TRIP . . . . . . . . . . 104

A.1 Parameters tested in preliminary heat treatments . . . . . . 126

B.1 UTS of samples with different intercritical annealing temperatures . . 133 


\section{List of Abbreviations}

$\begin{array}{ll}\text { AHSS } & \text { advanced high-strength steel } \\ \text { M/RA } & \text { martensite and/or retained austenite } \\ \text { MSAT } & \text { magnetic saturation } \\ \text { ND } & \text { normal direction of sheet } \\ \text { OM } & \text { optical microscopy } \\ \text { RA } & \text { retained austenite } \\ \text { RD } & \text { rolling direction of sheet } \\ \text { SEM } & \text { scanning electron microscopy } \\ \text { TEM } & \text { transmission electron microscopy } \\ \text { TRIP } & \text { transformation-induced plasticity } \\ \text { UTS } & \text { ultimate tensile strength } \\ \text { UTS } \times \text { El } & \text { product of ultimate tensile strength and total percent elongation } \\ \text { XRD } & \text { X-ray diffraction }\end{array}$




\section{List of Symbols}

$\begin{array}{ll}\alpha & \text { ferrite } \\ \alpha^{\prime} & \text { martensite } \\ \alpha_{B} & \text { bainite } \\ \gamma & \text { austenite } \\ \epsilon & \text { true strain } \\ \eta & \text { angle between the normal to the diffracting plane and } \\ \theta & \text { the direction of applied stress } \\ \lambda & \text { angle between the incident ray and the scattering planes } \\ \sigma & \text { wavelength of beam } \\ d \sigma / d \epsilon & \text { true stress } \\ a & \text { lattice parameter } \\ \mathrm{Ac}_{1} & \text { temperature at which austenite begins to form during heating } \\ \mathrm{Ac}_{3} & \text { temperature at which transformation of ferrite to austenite } \\ \mathrm{d} & \text { is completed during heating }\end{array}$


integrated intensity of a diffraction peak

$\mathrm{M}_{d}$ temperature below which martensitic transformation can be induced by mechanical deformation

$\mathrm{M}_{s} \quad$ temperature at which martensite begins to form on cooling $n_{\text {inst }}$ instantaneous work hardening exponent, or instantaneous $n$ $\mathrm{R}$ theoretical intensity of a diffraction peak 


\section{Chapter 1}

\section{Introduction}

\subsection{Motivation}

Increases in oil prices and the spread of environmental awareness have driven the automotive industry towards more fuel-efficient vehicles. One method of achieving this objective is by reducing the weight of the vehicle body, thereby reducing its fuel consumption and greenhouse gas emissions. Road vehicles, especially passenger cars, can potentially bring about the highest energy savings because they are the highest contributor to transport energy consumption due to the sheer number of these vehicles on the road [1].

Advanced high-strength steels (AHSS) have both high strength and high ductility in comparison to conventional steels. This can be seen in the classic "banana curve" diagram (Figure 1.1), which depicts the trade-off between strength and ductility in steels. Replacing conventional steels with grades that have higher strength and higher ductility means that thinner sheets can be used for components while still maintaining structural integrity. Consequently, the weight of the car body can be reduced. With 


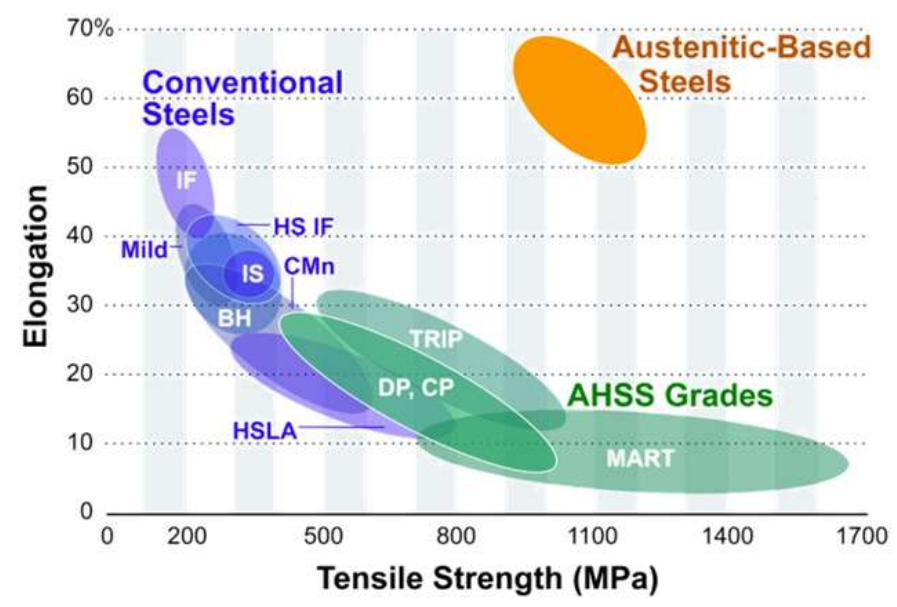

Figure 1.1: "Banana curve" diagram that compares classifications of steel with respect to strength and elongation. Modified from [2].

the use of AHSS, sheet thicknesses can be reduced by about $20 \%$ without loss of performance [3]. Additionally, the steels have the capacity to be formed into complex shapes so a single, more complex component could take the place of multiple parts [4]. A $25 \%$ mass savings can be realized for the body-in-white by replacing conventional steel with AHSS, resulting in a total vehicle weight reduction of about $9 \%$. For a typical five passenger family car, this means a reduction of $117 \mathrm{~kg}$. The power train in turn can then be downsized, giving a fuel savings about $5.1 \%$ and a lifetime carbon dioxide savings of 2.2 tonnes, which is a savings that is greater than the amount of carbon dioxide emitted during production of the steel [5].

To truly reduce a vehicle's footprint on the environment, consideration must also be given to factors beyond fuel efficiency - the entire life cycle of the vehicle should be analyzed. This includes the material production, parts production and end-of-life phases. Unlike steels, competing materials like aluminum and magnesium produce harmful greenhouse gases such as fluorocarbons and sulphur hexafluoride during material production, which are more detrimental to the environment than carbon dioxide 
alone [5]. These emissions severely detract from the savings achieved through the use of aluminum and magnesium components. Furthermore, steel is fully recyclable so the production phase uses less energy when compared to these other light metals $[5,6]$. When its relatively low cost is also considered, steel remains competitive as a material for automotive purposes.

Transformation-induced plasticity (TRIP) steels are a class of AHSS that were first developed by Zackay [7]. TRIP steels have a better combination of strength, ductility and work hardening properties than other first generation AHSS. Figure 1.2 is a plot of the engineering stress-strain curves of three classes of steel: conventional high-strength low-alloy steel, dual-phase steel and TRIP steel. In comparison to the other two, the TRIP steel exhibits much higher values of uniform elongation and a higher ultimate tensile strength (UTS). TRIP steels also exhibit superior formability, making them an excellent candidate for automotive applications [8]. Structural components can then

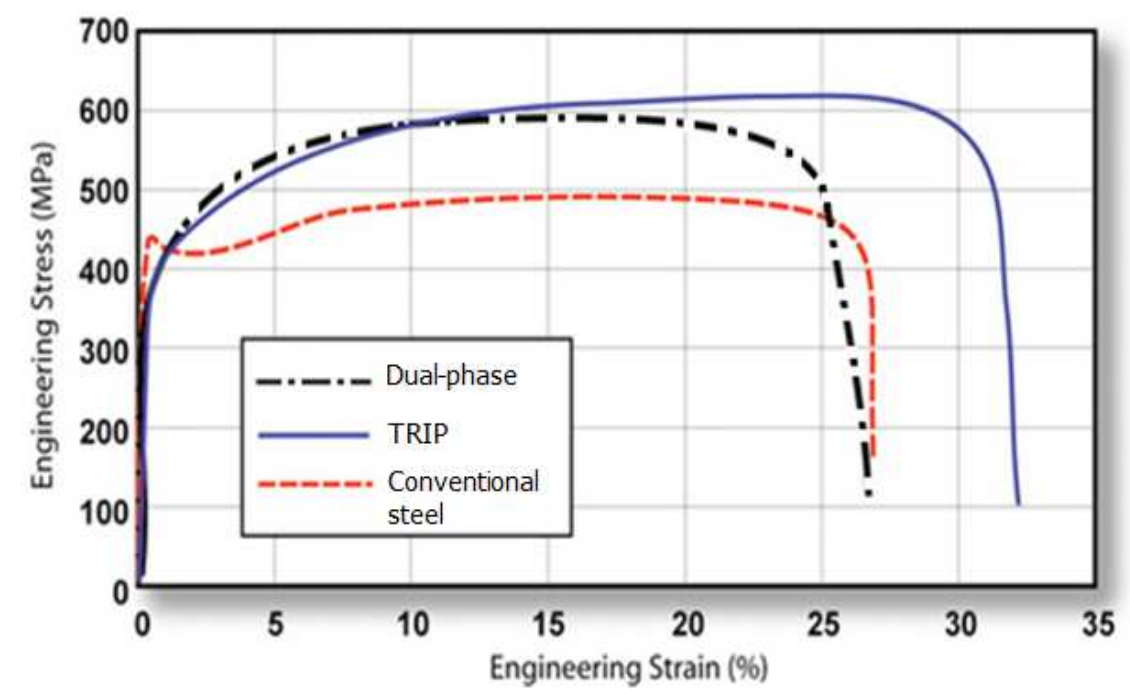

Figure 1.2: A comparison of engineering stress-strain curves for conventional, dualphase and TRIP steels. Modified from [2]. 
be made thinner because the steel has the ductility to withstand high deformation processes such as stamping and bending, while still having the strength necessary to meet safety regulations.

In addition to the benefits of using TRIP steel for reducing vehicle weight, their energy absorption behaviour is ideal for improving the passive and active safety of vehicles [9]. The excellent energy absorption characteristics and high work hardening response better distributes strain during crash deformation, which improves the crash management, or crashworthiness, of a vehicle $[2,10]$.

Currently, there are strong geographic differences between Europe and North America in terms of the use and production of TRIP steels. The development and use of TRIP steels has proceeded quite rapidly in Europe whereas North American steelmakers and car manufacturers still strongly promote the use of dual-phase steels instead [3]. Consequently, a relatively new composition of TRIP steel has been introduced with aluminum as the main alloying component. The aim of this composition is to achieve improved galvanizing and coating properties over the traditional silicon-

alloyed TRIP steels [11]. Galvanized automotive components are important in North America because of the common use of road salt and its deteriorating effect on vehicles. The better coating makes the aluminum-alloyed composition of TRIP steel a more practical option for the North American market than other compositions.

\section{$1.2 \quad$ Research Objectives}

This thesis aims to investigate the microstructure and mechanical properties of a TRIP steel that is alloyed with aluminum to produce the TRIP effect. Specifically, the scope of this thesis will compare two distinct microstructural variants. Investigation 
of the different microstructural variants was used to gain a better understanding of the aluminum-alloyed TRIP steel in terms of processing steps and the resulting properties. One of the microstructural variants is widely-used in industry and is obtained via a two-step heat treatment. This variant will herein be referred to as the equiaxed microstructure, named for the equiaxed grains of ferrite that make up the matrix. The other variant is a less common alternative that exhibits promising mechanical properties according to a few previous studies using silicon-alloyed TRIP steels. This variant will be referred to as the lamellar microstructure, also named for the morphology of the grains in the matrix.

- Experimental work was conducted to characterize the retained austenite (RA) transformation behaviour and the uniaxial tensile properties of the two microstructural variants.

- The RA-to-martensite transformation behaviour is an important characteristic of the TRIP steel, and will therefore be examined in greater detail. In particular, the relationship between this behaviour and specific microstructural features of the equiaxed and lamellar microstructures will be discussed.

- Results will also be compared with previous work in a silicon-alloyed TRIP steel to determine if aluminum-alloyed TRIP steels are a suitable replacement for the silicon compositions.

This thesis will provide valuable insight for the lamellar microstructural variant and for aluminum-alloyed TRIP steels, especially in terms of the relationship between transformation behaviour, mechanical properties and microstructure. 


\subsection{Outline of Thesis}

The remainder of this thesis is divided into the following chapters:

- Chapter 2 provides a literature review that introduces background information and the previous work on TRIP steels.

- Chapter 3 details the experimental material, processing steps, characterization techniques and mechanical testing procedures.

- Chapter 4 presents the results of the experiments. The microstructure of each variant is described, as well as the RA transformation behaviour and uniaxial tensile behaviour.

- Chapter 5 discusses the results and their significance with respect to existing literature.

- Chapter 6 summarizes the findings of this thesis and provides suggestions for future work in this field. 


\section{Chapter 2}

\section{Literature Review}

\subsection{The TRIP Effect}

TRIP steels have a multi-phase microstructure consisting of four phases: ferrite, bainite, martensite and retained austenite (RA). The presence of retained austenite in the microstructure makes TRIP steels unique and gives rise to their good mechanical properties. Their excellent properties can be attributed to the transformation associated with RA, a phenomenon known as the TRIP effect, which is the transformation of the metastable austenite phase into a hard, brittle martensite phase as a result of applied stress or strain. This transformation absorbs energy and improves the work hardening capacity of the steel, thus delaying the onset of localized necking and improving the uniform elongation. The transformation to martensite is considered to be a displacive transformation, which is a diffusionless structural change brought about by a coordinated movement of atoms relative to their neighbours [12]. Typically, partially transformed grains are rarely observed, suggesting that the austenite-tomartensite transformation is (quasi-)instantaneous [13]. In order for the TRIP effect 
to take place, the steel must be deformed in the temperature range above the martensite start $\left(\mathrm{M}_{s}\right)$ temperature and below the martensite deformation $\left(\mathrm{M}_{d}\right)$ temperature. The $\mathrm{M}_{s}$ temperature is the temperature at which martensite begins to form upon cooling [10] and the $\mathrm{M}_{d}$ temperature is the point below which martensitic transformation can be initiated by mechanical deformation [14]. It is within this temperature range that the $\mathrm{RA}$ is considered to be metastable [15].

\subsection{Chemical Composition}

TRIP steels that are used in the automotive industry are low-alloy TRIP steels, which are different from the original highly-alloyed TRIP steel reported by Zackay [16]. Key alloying elements are added to the steel composition to prevent cementite precipitation, which is a type of carbide $\left(\mathrm{Fe}_{3} \mathrm{C}\right)$ that is commonly found in steels [17]. Suppression of cementite formation allows the carbon content of the austenite phase to be increased, which increases its thermal stability such that the austenite can be retained in the microstructure at room temperature [18]. In other words, the austenite phase is more resistant to martensitic transformation because a higher carbon content decreases the $\mathrm{M}_{s}$ temperature. The steel chemistry is determined based on several factors, including the need for realistic processing paths, high carbon levels in the austenite, low cost and good surface properties [4]. Furthermore, the degree of alloying is limited by its feasibility for mass production; less-alloyed compositions are favoured for ease of production and for economic reasons [15].

One of the most important alloying elements in TRIP steels is carbon. Carbon acts as an austenite stabilizer, which means that it slows the transformation of austenite to ferrite or bainite [10]. It also slows the transformation to martensite by lowering 
the $\mathrm{M}_{s}$ temperature and thereby increasing the austenite's thermal stability. In other words, an increased amount of carbon in the steel would allow for more austenite to be retained in the microstructure. However, TRIP steels are limited to compositions at or below $0.2 \mathrm{wt} . \% \mathrm{C}$ because of weldability concerns, as large amounts of carbon make the steel difficult to weld [3]. Manganese is another austenite stabilizer that is commonly found in all AHSS compositions. It improves the potential for carbon enrichment by increasing the solubility of carbon in the austenite phase and helps to solid-solution strengthen the steel [3]. On the other hand, manganese also promotes carbide formation, so the manganese content should be limited [17]. Furthermore, manganese contents above $2.5 \mathrm{wt} . \% \mathrm{Mn}$ also tend to form an undesired banded morphology in the microstructure and lead to over-stabilized retained austenite grains that do not transform under load, and therefore, do not contribute to the overall ductility through the TRIP effect [19].

Other common alloying elements in TRIP steels include several ferrite stabilizers that are generally used to delay carbide precipitation. Elements that fall into this category include silicon, aluminum, phosphorus and chromium. Traditionally, silicon is used to delay carbide precipitation during the formation of bainite when heat treating. Preventing carbide formation ensures that the carbon is available for stabilizing the remaining austenite [20]. If the silicon content is too low, cementite precipitation occurs and causes austenite decomposition [21]. Silicon also solid-solution strengthens the ferrite matrix, which helps to improve the overall strength of the steel [22, 23]. However, the high silicon levels typically used in TRIP steels (usually ranging between 1.5 to $2.5 \mathrm{wt} . \% \mathrm{Si}$ ) cause difficulties for hot-rolling and galvanizing [11]. The silicon produces silicon oxides during the heat treatment process, which tend to segregate to the steel surface $[24,25]$. These surface oxides reduce surface quality and also hinder 
the formation of an inhibition layer, which in turn does not allow zinc to wet the steel surface during galvanizing, resulting in poor quality coatings with many bare patches [26]. In order to overcome this issue, new compositions of TRIP steel have been investigated in which silicon is either partially or fully replaced by another element such as aluminum or phosphorus. Phosphorus can be used in conjunction with additions of silicon or aluminum to retard carbide precipitation and to enhance the strength. Only small amounts of less than $0.1 \mathrm{wt} . \% \mathrm{P}$ should be used though because high phosphorus contents lead to phosphorus segregation at the grain boundaries and a deterioration in the strength [10]. Aluminum appears to be the forerunner as an alternative to silicon compositions. Similar to silicon, aluminum is insoluble in cementite and is able to suppress carbide formation [27]. Aluminum also increases the potential maximum carbon concentration that can be reached by increasing the carbon solubility in austenite, thereby further stabilizing the austenite phase [7]. The main advantage of using aluminum is that it does not form surface oxides, which is better for coatability and galvanizing properties [25]. Moreover, aluminum accelerates bainite formation, which is beneficial for industrial practices such as continuous galvanizing lines, where there is a limited time window for the heat treatment process to be carried out $[3,28]$. On the other hand, there are a few drawbacks to compositions that fully substitute silicon with aluminum. Aluminum offers less solidsolution strengthening of the ferrite matrix so aluminum-alloyed TRIP steels exhibit a marked deterioration in strength compared to silicon-alloyed TRIP steels [29, 30]. Aluminum also raises the transformation temperatures of the steel, including the $\mathrm{M}_{s}$ temperature, which acts to destabilize the austenite [10]. 


\subsection{Heat Treatment Processing}

In order to obtain the typical multi-phase TRIP steel microstructure, a two-step heat treatment is required. This standard heat treatment is tailored specifically to enrich the austenite phase with carbon so that austenite can be stabilized down to room temperature. The heat treatment path consists of intercritical annealing followed by a bainite hold and a quench to room temperature. Typically, the initial condition of the material is cold-rolled, although other starting conditions have also been considered. The standard heat treatment is shown schematically in Figure 2.1 along with diagrams depicting the microstructure development over the course of the heat treatment. This heat treatment path and the chemical composition are designed to promote the formation of carbon-saturated austenite which can be retained in the microstructure when the steel is quenched to room temperature [31].

The annealing temperature for the first step of the heat treatment is chosen such that it lies within the intercritical region of the Fe-C phase diagram (shown as the region labelled $\gamma+\alpha$ in Figure 2.2). This is the temperature range in which both ferrite $(\alpha)$ and austenite $(\gamma)$ are present in the microstructure. The intercritical region is bound by the transformation temperatures $\mathrm{Ac}_{1}$ and $\mathrm{Ac}_{3} . \mathrm{Ac}_{1}$ is the lower transformation temperature, where austenite begins to form during heating of the steel. $\mathrm{Ac}_{3}$ is the upper boundary of the intercritical region and it is the temperature at which the transformation of ferrite to austenite is completed upon heating. These two temperatures can be estimated from the chemical composition of the steel using two

equations. The Andrews formula is commonly used to calculate the $\mathrm{Ac}_{1}$ temperature for low alloys steels with less than $0.6 \mathrm{wt} . \% \mathrm{C}$. 


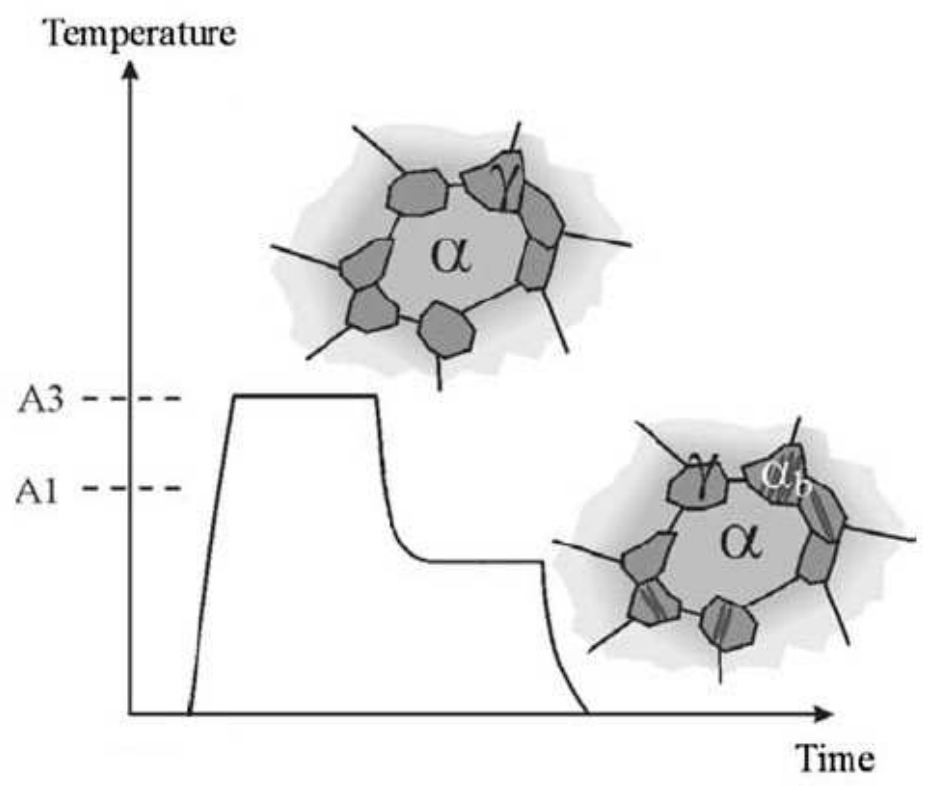

Figure 2.1: Schematic of the standard heat treatment path for TRIP steels and the microstructure development at each stage. $\gamma$ is austenite, $\alpha$ is ferrite, and $\alpha_{b}$ is bainite. Modified from [31].

The formula for $\mathrm{Ac}_{1}$ is given as [32]:

$$
\begin{aligned}
A c_{1}= & 723-16.9(w t . \% N i)+29.1(w t . \% S i)+6.38(w t . \% W) \\
& -10.7(w t . \% M n)+16.9(w t . \% C r)+290(w t . \% A s) .
\end{aligned}
$$

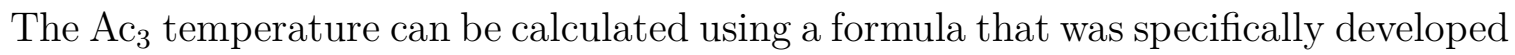
for TRIP steels, called the Park formula [33]:

$$
\begin{aligned}
A c_{3}= & 955-350(w t . \% C)-25(w t . \% M n)+51(w t . \% S i)+106(w t . \% N b) \\
& +100(w t . \% T i)+68(w t . \% A l)-11(w t . \% C r)-33(w t . \% N i) \\
& -16(w t . \% C u)+67(w t . \% M o) .
\end{aligned}
$$

During this intercritical annealing step, nearly carbon-free ferrite and carbonenriched austenite form (refer to Figure 2.1). The volume fractions of intercritical ferrite and retained austenite in the resulting microstructure are strongly influenced 


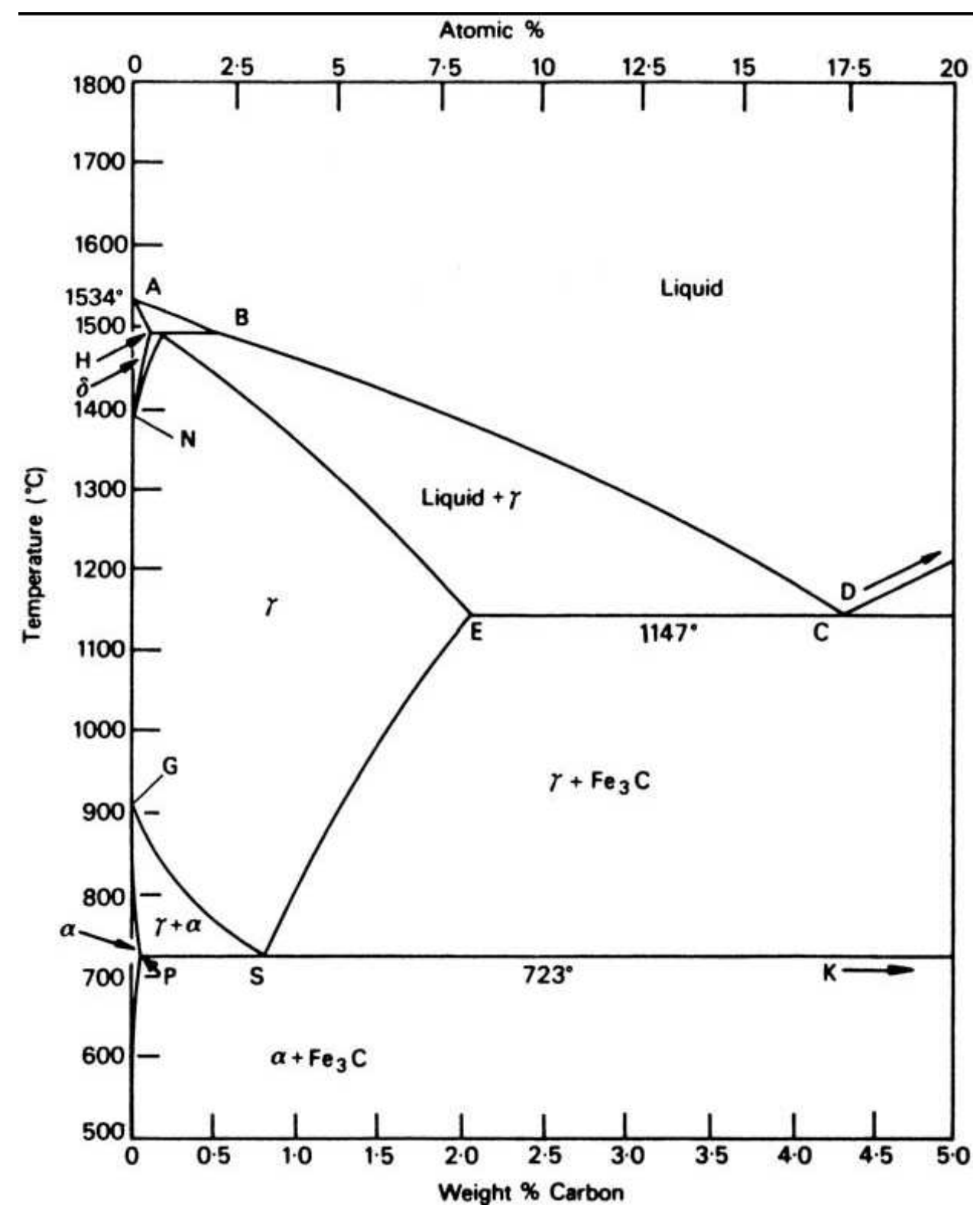

Figure 2.2: Iron-carbon equilibrium phase diagram. $\alpha$ is ferrite, $\gamma$ is austenite, and $\mathrm{Fe}_{3} \mathrm{C}$ is cementite [17]. 
by the temperature at this step. At lower annealing temperatures, there are higher volume fractions of ferrite and smaller amounts of austenite that form. Lower annealing temperatures tend to result in higher volume fractions of $\mathrm{RA}$ in the final microstructure because the small amount of austenite that forms is more carbonenriched. However, austenite that has too high a carbon content becomes susceptible to cementite precipitation, so an optimum annealing temperature must be found that promotes the best carbon-enrichment levels in the austenite [19, 34].

Intercritical annealing alone does not sufficiently enrich the austenite with carbon to prevent martensitic transformation during quenching. If the steel were to be quenched directly after the intercritical annealing step, a dual-phase microstructure of ferrite and martensite would be observed. Hence, a second step is needed for further carbon-enrichment [31]. The bainite hold is an isothermal heat treatment in the bainite formation temperature range (about $250^{\circ} \mathrm{C}-550^{\circ} \mathrm{C}$ ) [17]. As bainite is formed, carbon is partitioned into the surrounding austenite, which decreases its $\mathrm{M}_{s}$ temperature and thermally stabilizes the austenite [21,35]. After a minimum bainite hold time, the austenite is sufficiently stabilized so as to not transform into martensite during quenching to room temperature [36]. The volume fraction of RA is expected to increase for lower bainite hold temperatures because more bainite is able to form, and hence, more carbon is partitioned into the austenite [37]. Lower bainite hold temperatures also help to limit carbide precipitation [38]. There is also an optimum bainite hold time in which a maximum volume fraction of RA can be achieved. An increase in the time leads to more bainite being formed and more carbon-enrichment of the austenite, but too long of a hold can lead to the precipitation of carbides, which destabilizes the austenite phase $[39,40]$.

The optimal heat treatment temperatures and times for a given TRIP steel are 
dependent on its chemical composition because the alloying elements affect the transformations that occur in the steel during heat treatment. Figure 2.3 summarizes how individual alloying elements affect the transformation temperatures and times over the course of the standard two-step heat treatment, including the $\mathrm{Ac}_{1}, \mathrm{Ac}_{3}$ and bainite-formation temperatures.

This two-step heat treatment produces a microstructural variant labelled as the equiaxed microstructure and it is the conventional thermal processing path used in industry for TRIP steels. By changing the heat treatment parameters, the morphology and distribution of the phases within the microstructure can be altered. One such microstructural variant, called the lamellar microstructure, involves adding an extra heat treatment step in which the steel is first austenitized and quenched before the

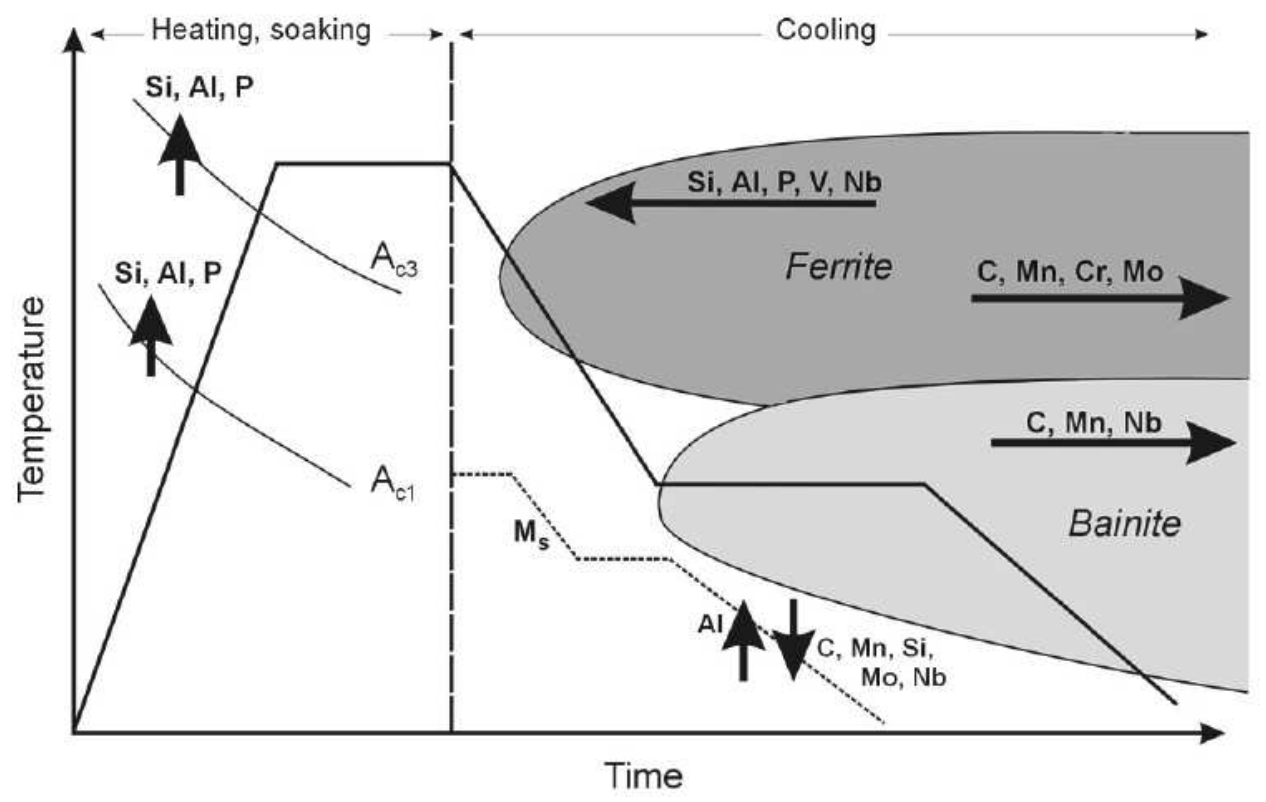

Figure 2.3: Effects of alloying elements on transformation behaviour during heat treatment $[10]$. 
two-step heat treatment. Essentially, this changes the initial condition of the steel, such that the structure before the two-step heat treatment is martensite instead of the deformed ferrite/pearlite structure that is used for the equiaxed microstructure. The lamellar microstructure was first introduced by Sugimoto et al. [41] and has been studied in silicon-alloyed TRIP steels $[4,42,43]$. Similar microstructures using martensite as the starting microstructure have also been studied in dual-phase steels [44]. This microstructural variant has been shown to exhibit good ductility due to its fine uniform lath structure and its RA transformation behaviour [43].

\subsection{Retained Austenite Stability}

The optimum TRIP effect is obtained by ensuring continuous transformation of RA to martensite throughout deformation, which produces the best mechanical properties. Typically, higher initial volume fractions of RA are related to better mechanical properties [4]. That is, the higher the amount of RA in the steel, the more RA available for transformation, and hence, a better combination of strength and elongation. However, the mechanical properties of the steel also depend on the RA stability, which refers to its resistance to mechanically-induced martensitic transformation [45]. The RA stability dictates the austenite-to-martensite transformation rate, which in turn, affects the strength-ductility balance of the TRIP steel [31]. The mechanical stability of the RA controls two main mechanisms: the work hardening capacity and thus the steel's ability to delay necking, and the nucleation mechanism for damage because damage nucleates from the transformed martensite [46]. However, the scope of this thesis is focused on RA stability and its effects on work hardening response; it does not address damage mechanisms in TRIP steels. 
The stability of the RA varies from grain to grain, which is why some grains are observed to transform completely during deformation and some do not transform at all [47]. Several factors affect the RA stability, including the grain size, grain shape, carbon content and spatial distribution of other phases within the microstructure $[48,49]$. The carbon content and the grain size are considered the most influential factors of RA stability for grains below a grain volume of $14 \mu \mathrm{m}^{3}$. On the other hand, the stability of larger RA grains is mostly influenced by the carbon content [50].

\subsubsection{Grain Size}

Smaller RA grains are more resistant to transformation and are thus more stable for several reasons. A smaller grain has a lower $\mathrm{M}_{s}$ temperature than a larger grain, which helps to thermally stabilize the RA $[48,51]$. In the case where a small austenite grain does transform, it would transform into many small martensite laths as martensite laths are unable to cross grain boundaries or areas with a high concentration of dislocations $[12,17]$. Consequently, the interfacial energy component for martensite formation is significantly increased, which in turn, decreases the $\mathrm{M}_{s}$ temperature [48]. Moreover, a high number of nucleation sites would be required for this transformation to occur, and smaller RA grains have fewer defects and thus fewer nucleation sites to begin with [52]. As seen in Figure 2.4b, the volume fraction of RA grains smaller than $1 \mu \mathrm{m}$ does not change with increasing applied tensile deformation, indicating that this is the critical grain size below which the RA does not actively contribute to improving the steel's mechanical properties by means of the TRIP effect $[52,53]$. There have also been studies that show similar size effects, but with a lower critical grain size of about $0.1 \mu \mathrm{m}[48]$. These very small RA grains will not transform during 
mechanical deformation because they are over-stabilized. On the other hand, RA grains that are too large will not contribute to the work hardening response either because they will transform into martensite upon quenching from the bainite hold or during application of very small stress [48].

\subsubsection{Grain Shape}

Retained austenite can be found in the TRIP steel microstructure in one of two morphologies: isolated RA islands and thin films along prior martensite or bainite lath boundaries. Previous studies have found that RA thin films do not significantly contribute to the TRIP effect, and therefore, hardly influence the deformation behaviour, so the focus has been mainly on isolated RA islands [41, 54]. In the case of RA islands, the aspect ratios of these grains affect their stability. Although elongated particles tend to experience higher stresses and stress concentrations, studies have found that retained austenite grains with larger aspect ratios tend to be more stable. Figure 2.4a shows the volume fractions of RA grains as they change with tensile deformation. It can be seen that the volume fraction of grains with aspect ratios larger than 4 remain unchanged with increasing amounts of deformation, demonstrating that these elongated RA grains are more stable than those with lower aspect ratios $[52,53]$. Transformation of an elongated austenite grain would require the formation of many small martensite laths to compensate for the morphology of the grain because the laths are unable to cross grain boundaries [17]. This transformation would result in a high interfacial area for the new martensite in comparison to the volume, thus increasing the interfacial energy component of the energy required for transformation, making elongated RA grains more stable [55]. 


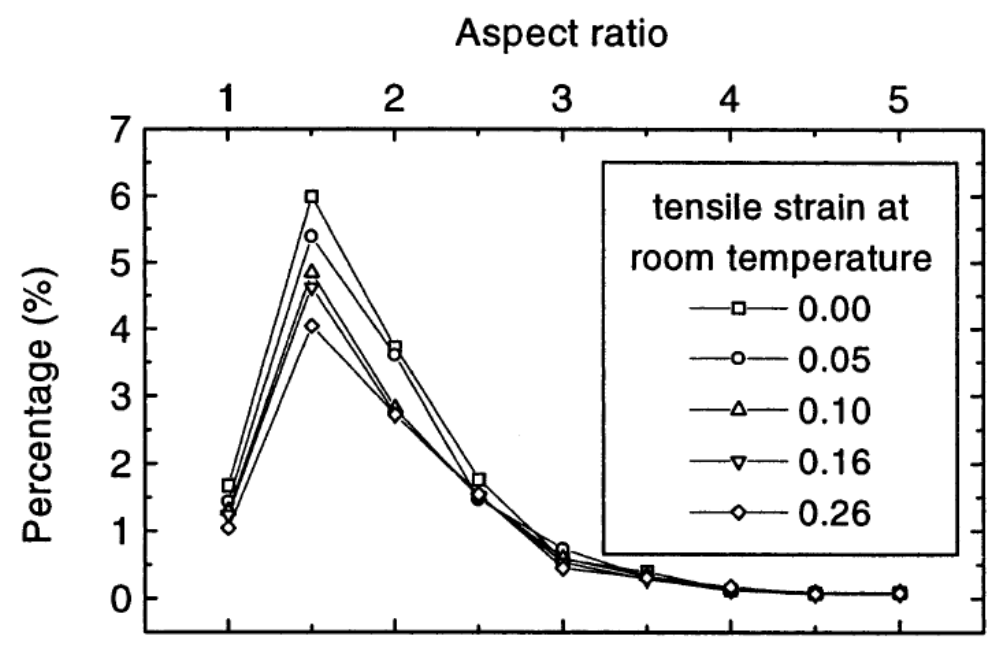

(a)

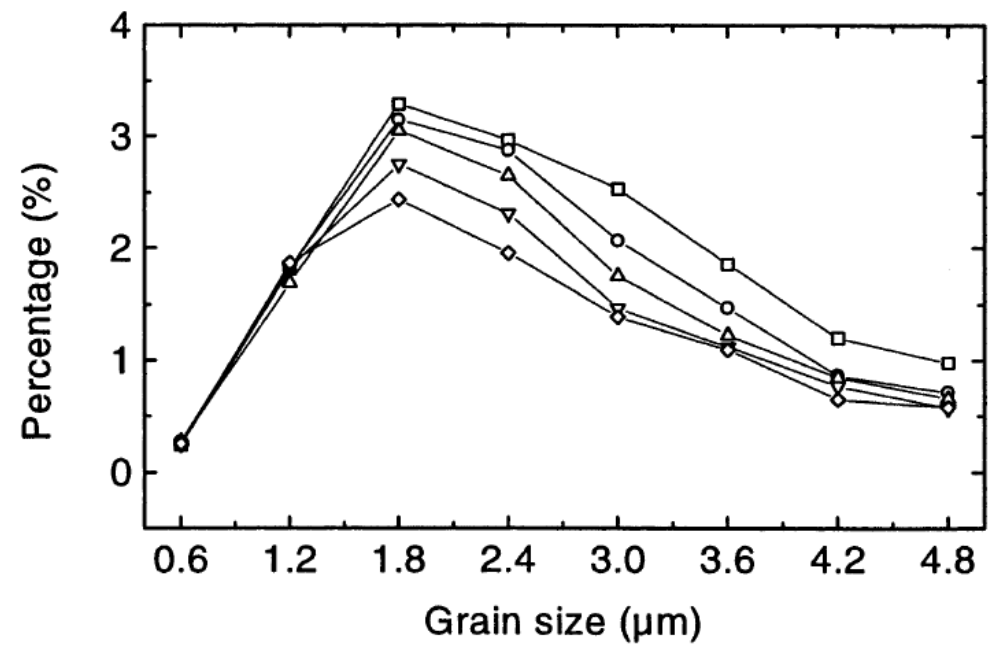

(b)

Figure 2.4: Effect of (a) aspect ratio and (b) grain size of RA on its stability [52]. 


\subsubsection{Spatial Distribution of Surrounding Phases}

The spatial distribution of the phases around the RA grains affects the stresses and strains that individual RA grains experience, and therefore, affects the RA stability. The relative hardness of each of the four phases - ferrite, RA, martensite and bainite are different and thus affect the stress distribution in the microstructure accordingly. Ferrite is the softest phase, followed by bainite, austenite, and finally martensite is the hardest $[18,23]$. Under normal circumstances, austenite is considered a soft phase; however, RA has been found to be harder due to its unusually high carbon content [56]. A RA grain that is surrounded by ferrite grains will transform at relatively low strains because the soft ferrite matrix will yield at low strains and subsequently shed load onto the RA, leading to earlier RA transformation [56]. In comparison, a RA grain that is surrounded by bainite will experience less load than if it were surrounded by ferrite due to a stress shielding effect, and therefore, transform later in the deformation process [57]. Stress shielding occurs because bainite is stronger than ferrite due to its higher carbon content and higher dislocation density [58].

\subsubsection{Carbon Content}

The enrichment of carbon is considered to be one of the most important mechanisms for retaining austenite in the TRIP microstructure because the carbon content affects the thermodynamics of the martensitic transformation. That is, RA grains with very low levels of carbon $(<0.6 \mathrm{wt} . \% \mathrm{C})$ are susceptible to martensitic transformation at low levels of strain [59] and RA grains with very high levels of carbon ( $>1.8$ wt.\%C) do not transform at all [60]. Increasing the carbon content of RA lowers the 
$\mathrm{M}_{s}$ temperature, thereby increasing its thermal stability $[48,61]$. Therefore, the mechanical driving force required for martensitic transformation increases with a higher carbon content, which means a higher carbon content of RA corresponds to higher stability [53].

\subsection{Mechanical Properties and Work Hardening Behaviour}

Engineering stress-strain curves of TRIP steels typically exhibit continuous yielding, high UTS values and high values of uniform elongation. Most TRIP steels exhibit continuous yielding; however, discontinuous yielding may arise due to certain processing conditions. This phenomenon has been observed and studied in greater detail in dual-phase steels. According to these studies, discontinuous yielding occurs when there is a low density of mobile dislocations in the ferrite matrix before deformation $[62,63]$. The transformation of unstable RA during the initial stages of tensile de-

formation may also affect discontinuous yielding behaviour, although the details are unclear as there are many associated factors to consider [19]. The mobile dislocations that promote continuous yielding are usually present in the ferrite matrix as a result of the volume change related to the austenite-to-martensite transformation [62, 64].

The mechanical performance of TRIP steels is often characterized using the product of the ultimate tensile strength and the total percent elongation $(\mathrm{UTS} \times \mathrm{El})$. TRIP steels combine high strength with high elongation, and this product describes the balance between the two. Typical UTS $\times$ El values for conventional silicon-alloyed TRIP steels are about 20000MPa\%-24000MPa\%, whereas values for aluminum-alloyed TRIP 
steels are slightly lower, roughly 20000MPa\%-23000MPa\% [61,65]. Good mechanical properties are generally related to high initial volume fractions of RA, and hence, so are high UTS $\times$ El values [66]. Some studies have also shown that the RA transformation rate is related to the UTS $\times \mathrm{El}$, where a higher RA stability improves the $\mathrm{UTS} \times \mathrm{El}$ value $[67]$.

Furthermore, TRIP steels typically have pronounced work hardening rates that persist to higher strains compared to that of other steels, which contributes to delaying the onset of local necking and allows for higher uniform elongation values [68, 69]. This sustained work hardening rate is generally attributed to the RA-to-martensite transformation, because the hard martensite phase is continuously being created in the microstructure and dislocations are generated in the ferrite matrix due to the associated volume expansion $[8,22]$. However, the increase of dislocation density cannot entirely explain the high strength values that are exhibited by TRIP steels. Another important contributing factor is the composite nature of the multi-phase microstructure $[31,70]$. The ferrite matrix contributes to the high elongation values because it is the most ductile phase while the harder phases improve the strength levels [71].

The work hardening rate of a TRIP steel varies throughout a tensile test and it is commonly expressed in terms of the slope of the true stress-true strain curve $(d \sigma / d \epsilon)$ or as a series of instantaneous work hardening exponents $\left(n_{\text {inst }}\right)$. A set of instantaneous $n$ values are used in place of a single value because the work hardening rate is not constant over the entire range of uniform strain and is therefore better represented by a progression of $n_{\text {inst }}$ values [72]. The instantaneous $n$ value has been widely used as an indication of formability in sheet materials, where sheet formability increases with an increasing value of $n[2,45,57,72,73]$. Generally, higher $n_{\text {inst }}$ values 
are a result of a larger amounts of RA transforming into martensite [60]. The value of $n_{\text {inst }}$ is derived from the power law hardening rule that relates true stress $(\sigma)$ and true strain $(\epsilon)$ :

$$
\sigma=K \epsilon^{n}
$$

and is defined as:

$$
n_{\text {inst }}=\frac{\ln \left(\sigma_{m} / \sigma_{m-1}\right)}{\ln \left(\epsilon_{m} / \epsilon_{m-1}\right)}
$$

where $\sigma_{m}$ and $\epsilon_{m}$ are discrete points of true stress and true strain.

\subsection{Characterization Techniques}

Many experimental techniques have been used in previous studies to quantify the amount of retained austenite in TRIP steels. These include methods such as microscopy, magnetic measurements, X-ray diffraction (XRD), neutron diffraction, Mössbauer spectroscopy and dilatometry. Of these techniques, X-ray diffraction is the most frequently used because the facilities are widely available and it is also able to measure the crystallographic texture and the stress state in the material [18].

Three of the above characterization methods were used in this thesis: XRD, magnetic measurements and microscopy.

\subsubsection{X-Ray Diffraction}

Planes of atoms within a material will diffract beams of X-rays at specific angles, and these diffracted beams are commonly used to characterize various material properties. There are two properties associated with the diffracted beams that are used: the angle between the incident and diffracted beams $(2 \theta)$ and the intensity of the 
diffracted beam (I).

There is a simple relationship that relates the angle $\theta$, the wavelength of the beam $(\lambda)$ and the spacing between the planes of atoms in the material (d):

$$
n \lambda=2 d \sin \theta
$$

where $n$ is an integer. Equation 2.5 is known as the Bragg law and is shown schematically in Figure 2.5 [74]. Furthermore, the intensity of a given diffracted beam is proportional to the volume of material that has planes spaced and oriented for diffraction in that particular direction. This means that the relative volumes of phases within a polycrystalline material can be estimated from the relative intensities of the diffracted beams.

Generally, in diffraction experiments, a specimen is placed in a monochromatic beam of X-rays. A detector measures the intensity of the diffracted beam (I) as a

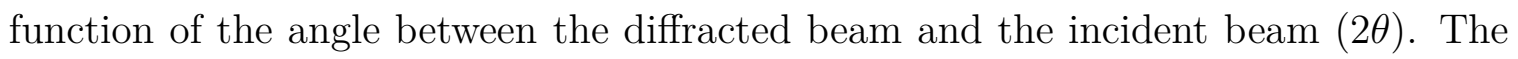
results appear as a distribution of a high number of counts centred on the angles as defined by the Bragg law, also known as diffraction peaks. The intensity of this diffracted beam corresponds to the integrated area under its diffraction peak.

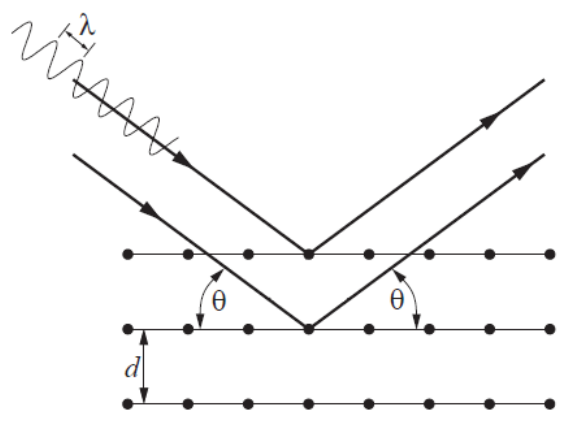

Figure 2.5: Schematic representation of Bragg diffraction of crystallographic planes. 
XRD is commonly used for determining the volume fraction of RA because facilities are widely available and only a small volume of material is required for the measurements [75]. Furthermore, the average carbon content in the RA can also be estimated from the same diffraction pattern. However, there are a few drawbacks associated with XRD. The measurements are carried out at the surface of the sample because the radiation can only penetrate to a depth of $2 \mu \mathrm{m}$ in a steel sample [74], which means that sample surface preparation is critical for accurate results [18]. XRD diffraction peaks are also affected by texture, but there are several ways to mitigate this effect, which will be discussed in Section $5.2[41,61,76]$.

\subsubsection{Magnetic Measurements}

Magnetic measurements can also be used to measure the volume fraction of RA. It provides information about the bulk properties and produces very reproducible results $[75,77,78]$. This technique is based on the different magnetic properties of retained austenite versus the magnetic properties of the other phases in the TRIP steel. Retained austenite is paramagnetic, so it does not retain magnetic properties in the absence of an externally applied magnetic field. In comparison, the other phases (ferrite, martensite and bainite) are ferromagnetic and can therefore form permanent magnets, staying magnetized even when the applied magnetic field is removed $[79,80]$.

This technique involves measuring the magnetic saturation of a sample in an applied magnetic field and comparing it to a theoretical sample composed of $100 \%$ ferrite. The resulting ratio represents the volume fraction of the paramagnetic RA phase [81]. Essentially, these magnetic measurements assume that the microstructure is made up of only austenite and ferrite. The assumption that the ferrite, martensite 
and bainite phases have the same magnetic saturation leads to an inherent error in this method because their magnetic saturations do vary slightly [82]. The amount of cementite in the microstructure is also assumed to be negligible as the addition of aluminum (or silicon) in the TRIP steel significantly suppresses the formation of cementite during heat treatment [75]. While cementite is also ferromagnetic, only the presence of a significant amount of cementite would lead to inaccurate results because the magnetic saturation of cementite is noticeably lower than that of ferrite, at $0.99 \times 10^{6} \mathrm{Am}^{-1}$ as opposed to $1.714 \times 10^{6} \mathrm{Am}^{-1}[75]$. 


\section{Chapter 3}

\section{Experimental Methods}

This chapter describes the material used for the experiments and the heat treatment steps used to produce the specific microstructure variants. The procedure for conducting and analyzing data from the microscopy, X-ray diffraction, magnetic measurements and uniaxial tensile tests are also provided.

\subsection{Experimental Material}

All thermo-mechanical processing and experimental work was conducted on hotrolled TRIP steel provided by U.S. Steel Canada with a base composition of Fe-0.17C2.19Mn-1.60Al. The complete chemical composition of the steel is given in Table 3.1. The steel was hot-rolled from $230 \mathrm{~mm}$ down to $3 \mathrm{~mm}$ with a finishing temperature of $904^{\circ} \mathrm{C}$ and a coiling temperature of $635^{\circ} \mathrm{C}$. The hot-band material was then cold-rolled on a laboratory-sized rolling mill at Queen's University, reducing the thickness from $3 \mathrm{~mm}$ to a nominal thickness of $1 \mathrm{~mm}$ in 15 passes for a reduction of $67 \%$, where the sheet thickness varied between $0.9 \mathrm{~mm}$ and $1.2 \mathrm{~mm}$. Ideally, the cold-rolling would be 
Table 3.1: Chemical composition of material, wt.\%.

\begin{tabular}{ccccccc}
\hline $\mathrm{C}$ & $\mathrm{Mn}$ & $\mathrm{Al}$ & $\mathrm{P}$ & $\mathrm{S}$ & $\mathrm{Cr}$ & $\mathrm{N}$ \\
0.17 & 2.19 & 1.60 & 0.013 & 0.003 & 0.11 & 0.004 \\
\hline
\end{tabular}

conducted in just one or two passes to simulate industrial-scale processes; however, the small size of the rolling mill limited the amount of reduction per pass for such a high strength steel.

\subsubsection{Details of Heat Treatments}

Because alloying additions alter the transformation temperatures of a steel, two equations were used to estimate the temperature at which austenite begins to form $\left(\mathrm{Ac}_{1}\right)$ and the temperature at which the transformation of ferrite to austenite is completed $\left(\mathrm{Ac}_{3}\right)$. The Andrews formula (Equation 2.1) was used to calculate $\mathrm{Ac}_{1}$ and the Park formula (Equation 2.2) was used to calculate $\mathrm{Ac}_{3}$ [32, 33]. These formulae were chosen because they take most of the main alloying elements in this TRIP steel into account. The calculated values were used as a guideline for a set of preliminary heat treatments, which are detailed in Appendix A.

The final heat treatment parameters were chosen based on the combination of temperatures and times that retained the maximum volume fraction of RA in the room temperature microstructure and have similar volume fractions of RA in both microstructural variants. This heat treatment schedule involved an intercritical anneal of $875^{\circ} \mathrm{C}$ for $300 \mathrm{~s}$, rapid cooling to $450^{\circ} \mathrm{C}$ and a hold for $100 \mathrm{~s}$, and subsequent quenching in ice water. These heat treatment parameters were used to produce microstructural variants, herein labelled as the equiaxed-875 and lamellar-875 microstructures. The first part of the name refers to the morphology of the respective ferrite grains and the numbers refer to the intercritical annealing temperature. The 
main difference between the heat treatments employed for these two microstructures is their initial condition. The equiaxed-875 microstructure is derived from the intercritical anneal and bainite hold heat treatment with an initial cold-rolled microstructure consisting of deformed ferrite and pearlite. The lamellar-875 microstructure follows the same two-stage heat treatment, except that the starting condition is a martensitic microstructure obtained by austenitizing at $1100^{\circ} \mathrm{C}$ for 1800 s and then quenching in ice water. This austenitizing temperature was chosen because it was well above the $\mathrm{Ac}_{3}$ temperature. Both of these heat treatment schedules are shown in the schematic in Figure 3.1.

For a better comparison of mechanical properties, the heat treatment parameters were altered to produce microstructural variants with similar UTS values. Because there are a multitude of ways the heat treatments could be altered, only the intercritical annealing temperature was varied to simplify the experimental process. A set

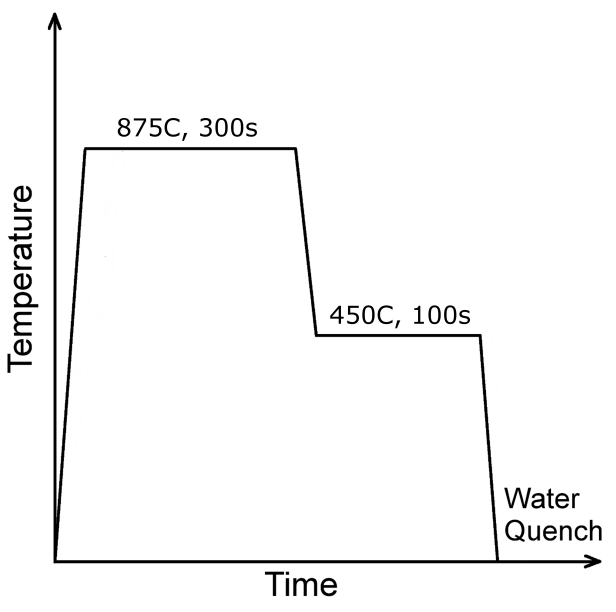

(a)

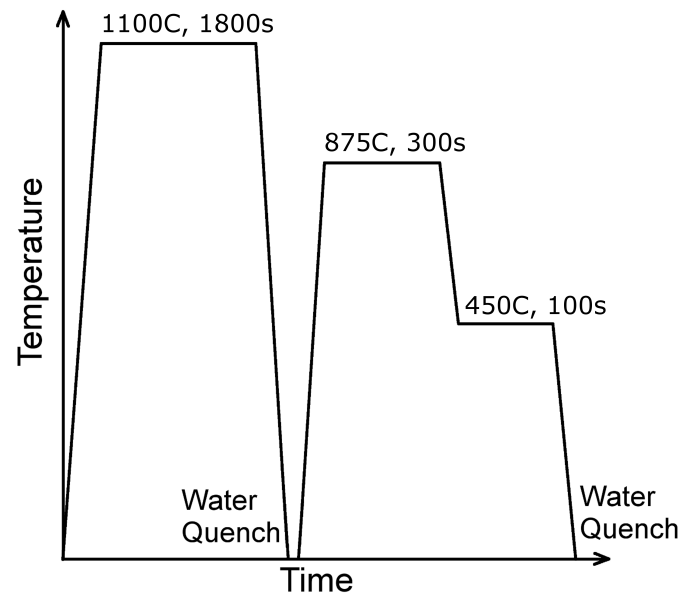

(b)

Figure 3.1: Schematic of the heat treatment path for (a) equiaxed-875 and (b) lamellar-875 microstructures. 
of heat treatments were conducted with different intercritical annealing temperatures ranging from $750^{\circ} \mathrm{C}$ to $925^{\circ} \mathrm{C}$ for the equiaxed microstructure and from $825^{\circ} \mathrm{C}$ to $950^{\circ} \mathrm{C}$ for the lamellar microstructure. Each of these heat treated samples were then tested in uniaxial tension to determine the average UTS for each heat treatment. The details and results of this mini-study are described in Appendix B. Consequently, the intercritical annealing temperature was decreased to $750^{\circ} \mathrm{C}$ for the equiaxed microstructure heat treatment and the intercritical annealing temperature for the lamellar microstructure was increased to $925^{\circ} \mathrm{C}$. This set of microstructural variants was termed the equiaxed-750 and lamellar-925 microstructures, once again named for the morphology of the ferrite grains and for the intercritical temperature.

A Lindberg tube furnace was used for the intercritical anneal in all of the heat treatments. The tube furnace was also used for austenitizing the samples for the lamellar microstructure. An inert atmosphere was maintained within the tube furnace using argon gas to prevent significant oxidation of the steel samples. The heat treatment temperatures were measured using a thermocouple located where the centre of the sample was placed in the tube furnace. Temperature measurements were taken before each sample was inserted to ensure that the heat treatment temperatures were consistent. The error associated with this thermocouple was $\pm 0.4 \%$ [83]. The heating rates and temperature gradient in this furnace were also measured and are presented in Appendix C.

A custom-built salt bath which contained a draw salt consisting of potassium nitrate and sodium nitrite was used for the bainite hold. It should be noted that this composition of draw salt will react with the steel sample, thereby hardening the surface. Consequently, a calculation was carried out to determine how far the nitriding effect would extend into the sample [84]. It was found that the effect of 
nitriding is negligible because of the relatively low temperature and short time span of the bainite hold. Moreover, the surfaces of the samples were sanded after heat treatment to remove any oxide layers, further reducing any surface effects of the nitriding. The bainite hold temperature was monitored using a thermocouple with a $0.4 \%$ limit of error [83]. The temperature gradient in the salt bath was also measured, and the results are presented in Appendix C.

\subsection{Characterization Techniques}

Several different techniques were used to characterize the two microstructural variants produced in the TRIP steel, including microscopy, magnetic measurements and X-ray diffraction. Samples were sectioned from a $110 \mathrm{~mm} \times 20 \mathrm{~mm}$ coupon that was initially sheared from the cold-rolled sheet and then heat treated. Figure 3.2 is a diagram showing the heat treatment coupon with the individual samples for tensile testing, magnetic measurements, X-ray diffraction and microscopy highlighted. One of the magnetic measurement samples was taken from the heat treatment coupon for an undeformed specimen and one of the samples was taken from the tensile specimen after it had been deformed.

\subsubsection{Metallography}

All metallographic samples of heat treated steel (for both scanning electron microscopy and optical microscopy) were further tempered at $200^{\circ} \mathrm{C}$ for 2 hours in the tube furnace. This tempering was carried out to darken the martensite for better distinction between the martensite and the RA [85]. Samples were then sectioned longitudinally from the heat treated coupons such that the plane containing the 


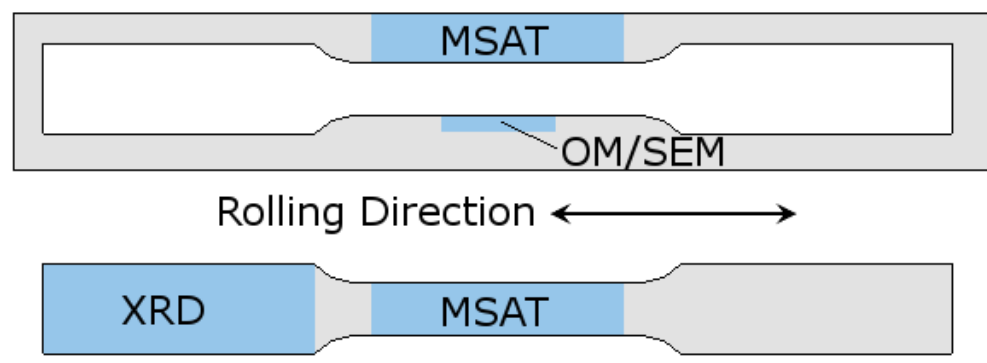

Figure 3.2: Drawing showing how each of the specimens were cut out of the heat treated coupon. MSAT is for magnetic measurements, OM/SEM is for optical or scanning electron microscopy, XRD is for X-ray diffraction.

rolling direction (RD) and the normal direction (ND) could be examined metallographically. The samples were cut using an Accutome wafer cutter to ensure minimal deformation was imparted during the cutting process. These samples were mounted in Bakelite using a mounting press. The heat produced during this process was not expected to affect the microstructures of the TRIP steel. The mounted samples were then ground successively using finer grits of silicon carbide paper, starting with 220 grit and finishing with 800 grit. Diamond polish was then used to polish the sample surface starting with $6 \mu \mathrm{m}$ diameter diamond particles, followed by $1 \mu \mathrm{m}$ and finally $0.25 \mu \mathrm{m}$, being careful to rinse the sample with soap and a cotton ball between each of these steps.

\subsubsection{Scanning Electron Microscopy (SEM)}

The microstructures for each of the heat treated samples were examined using scanning electron microscopy (SEM). After the standard surface grinding and polishing procedure outlined in Section 3.2.1, the surface was etched with $2 \%$ Nital for 7 seconds. These etched samples were then sputter coated with gold for 90s to improve 
the conductivity and thus the contrast in the SEM image. Copper tape was used to electrically ground the sample and then the puck was slotted into a holder in the JEOL-JSM840 SEM sample chamber. Secondary electron imaging was used with an emission current of $80 \mu \mathrm{A}$ and an accelerating voltage of $20 \mathrm{kV}$. Following this method, the ferrite phase appears dark, and the bainite, martensite and retained austenite appear light.

\subsubsection{Optical Microscopy}

Each of the heat treated samples was also examined using optical microscopy to better distinguish among the non-ferritic phases, namely bainite, martensite and retained austenite. Optical microscopy samples were prepared following the metallographic procedure outlined in Section 3.2.1 and a LePera tint etch was employed [86]. This tint etch colours the ferrite phase tan, the bainite dark brown, retained austenite white, and the martensite off-white. The etchant uses two solutions: $4 \%$ Picral and $1 \%$ aqueous sodium metabisulfite. Equal volumes of these two solutions were mixed immediately before use and the samples were immersed in the etchant and held vertically for $25 \mathrm{~s}$. The volumes of these two solutions were adjusted slightly by $1 \mathrm{~mL}$ or $2 \mathrm{~mL}$ depending on the resulting tint [85]. The tint etchant was adjusted for each heat treated sample to provide the best visual contrast between the phases. A solution of $1 \%$ zephiran chloride was added to the Picral to act as a wetting agent and improve the etch rate and uniformity [87]. This Picral solution was then aged for at least a week before use whereas the sodium metabisulfite solution was freshly mixed before etching. It was found that this preparation procedure provided the best and most consistent results for optical microscopy. 
A Zeiss Axioskop 2 MAT light microscope equipped with an Olympus Evolution MP Colour CCD camera was used to capture the colour images for each specimen. A 100x Zeiss Epiplan-NEOFLUAR oil-immersion lens was used during micrograph acquisition. Care was taken to acquire all of the micrographs at one time because the LePera tint etch can be affected if the oil were to be applied to the surface of the specimen and subsequently wiped off.

\subsubsection{Image Analysis}

A Java-based image processing program, ImageJ, was used in conjunction with the optical micrographs to quantify the characteristics of the RA grains, including size and aspect ratio. ImageJ has the ability to analyze particles within a binary image, which includes providing data such as the size and aspect ratio of each recognized particle. First, thresholding must be carried out to convert the colour micrograph to a binary image. Colour thresholding for an HSB stack was used and the hue filter was adjusted so that only the martensite/retained austenite (M/RA) grains were selected. Because the martensite and retained austenite were so similar in colour, the two phases could not be separated for the purposes of this analysis. Micrographs that had a field of view of approximately $40 \mu \mathrm{m} \times 27 \mu \mathrm{m}$ were used for this analysis because

of the steel's fine microstructure. Fifteen images of each microstructural variant were used to obtain a representative average for the M/RA grains. 


\subsubsection{Magnetic Measurements}

The main method employed for determining the volume fraction of RA in the TRIP steel samples was magnetic measurements using a Metis MSAT retained austenite measurement instrument. This instrument consists of sensor coils to produce a magnetic field and a fluxmeter to measure the magnetic moment of the sample. The sample dimensions were chosen such that the volume of each sample was $200 \mathrm{~mm}^{3}$ to provide a sample that was sufficiently large so that bulk properties could be measured while still being within the specifications of the MSAT instrument. There is a critical sample size below which the results are skewed due to variations within the microstructure and the assumptions inherent in the MSAT instrument software. Therefore, the sample dimensions were chosen to be larger than this critical sample size.

The magnetic moment of each of the samples was measured ten times within the magnetic field and the calculated volume fraction of RA was averaged to give the final value. This volume fraction is based on a calculated theoretical magnetic saturation of a steel sample with the same chemical composition consisting of $100 \%$ ferrite. The density of a plain carbon steel $\left(7.85 \mathrm{~g} / \mathrm{cm}^{3}\right)$ was used in this calculation while assuming that the other alloying elements do not contribute significantly to the density [88].

The magnetic measurements gave values of RA that were extremely precise and consistent if the same sample were to be measured repeatedly. The difference in the measured volume fraction of RA varied by only about $\pm 0.4 \%$. The largest error associated with the RA measurement comes from the spatial variation within the 
microstructure where samples with the same heat treatment have some sample-tosample variation. Additionally, the accuracy of the measurement is affected by the inherent assumptions that are made in this method (see Section 2.6.2), introducing a systematic error in the technique.

\subsubsection{X-Ray Diffraction (XRD)}

The TRIP steel samples were also characterized using X-ray diffraction (XRD), primarily to determine the carbon content of the RA grains, but also to validate the RA volume fraction measurements that were determined magnetically. RA carbon content and volume fraction values can be determined from the locations of the diffraction peaks and their integrated intensities, respectively.

Sample preparation for XRD measurements focuses on the surface of the sample because the X-rays only penetrate to a depth of $2 \mu \mathrm{m}$ from the sample surface [74]. Hence, care needs to be taken to ensure that the surface is deformation free. The samples were first ground to the centre of the sheet thickness using coarse silicon carbide paper. The metallographic procedure (Section 3.2.1) was then followed and subsequent etching was carried out using $2 \%$ Nital for 5 s to remove any deformation imparted by the polishing procedure.

Measurements were conducted on a Rigaku DMAX-1100 diffractometer with a copper source and a nickel filter. Monochromated $\mathrm{Cu} \mathrm{K} \alpha$ radiation was used at $40 \mathrm{kV}$ and $36 \mathrm{~mA}$. The specified $2 \theta$ range was from $42^{\circ}$ to $102^{\circ}$ with a step size of $0.02^{\circ}$. This wide $2 \theta$ range was chosen so that as many peaks as possible could be captured to take the effect of texture into account. Eight diffraction peaks were captured in 
total, four ferrite $(\alpha)$ peaks and four austenite $(\gamma)$ peaks. A typical diffraction pattern for a TRIP steel is shown in Figure 3.3.

The deconvolution of the XRD data is shown in Figure 3.4. Two curves were fit to each diffraction peak because there are two wavelengths associated with the $\mathrm{K} \alpha$ radiation $-\mathrm{K} \alpha_{1}$ and $\mathrm{K} \alpha_{2}$. A pseudo-Voigt profile was used for deconvolution of the data because it best describes the line intensity distribution [89-91]. It was expected that the maximum values for the $\mathrm{K} \alpha_{1}$ peaks were about twice as large as for the $\mathrm{K} \alpha_{2}$ peaks, and the fitting was adjusted to take this into account. After deconvolution, the integrated intensity and the position of the $\mathrm{K} \alpha_{1}$ peaks were used for determining the carbon content and volume fraction of RA.

The carbon content in RA can be determined from the lattice parameters according to the austenite peak positions in the diffraction pattern. A combination of two approaches (Dyson and Holmes [92] and Ruhl and Cohen [93]) was used to compensate for the effect of manganese and aluminum additions on the lattice parameter $(a)$. Taking this into account, the average carbon content in the retained austenite lattice parameter could be calculated from [94]:

$$
\begin{aligned}
a= & 3.572+0.0012(w t . \% M n)-0.00157(w t . \% \text { Si }) \\
& +0.0056(w t . \% A l)+0.033(w t . \% C)
\end{aligned}
$$

where the values for manganese, silicon and aluminum are from the chemical composition of the steel (given in Table 3.1).

This value for carbon content is the average within the RA phase; however the distribution of carbon within the RA is not homogeneous so there is an error inherent in this analysis. It should be noted that the X-ray analysis was conducted for relative comparisons of the carbon content in RA between different microstructural variants, and not for the purposes of providing an absolute value for local carbon content. 


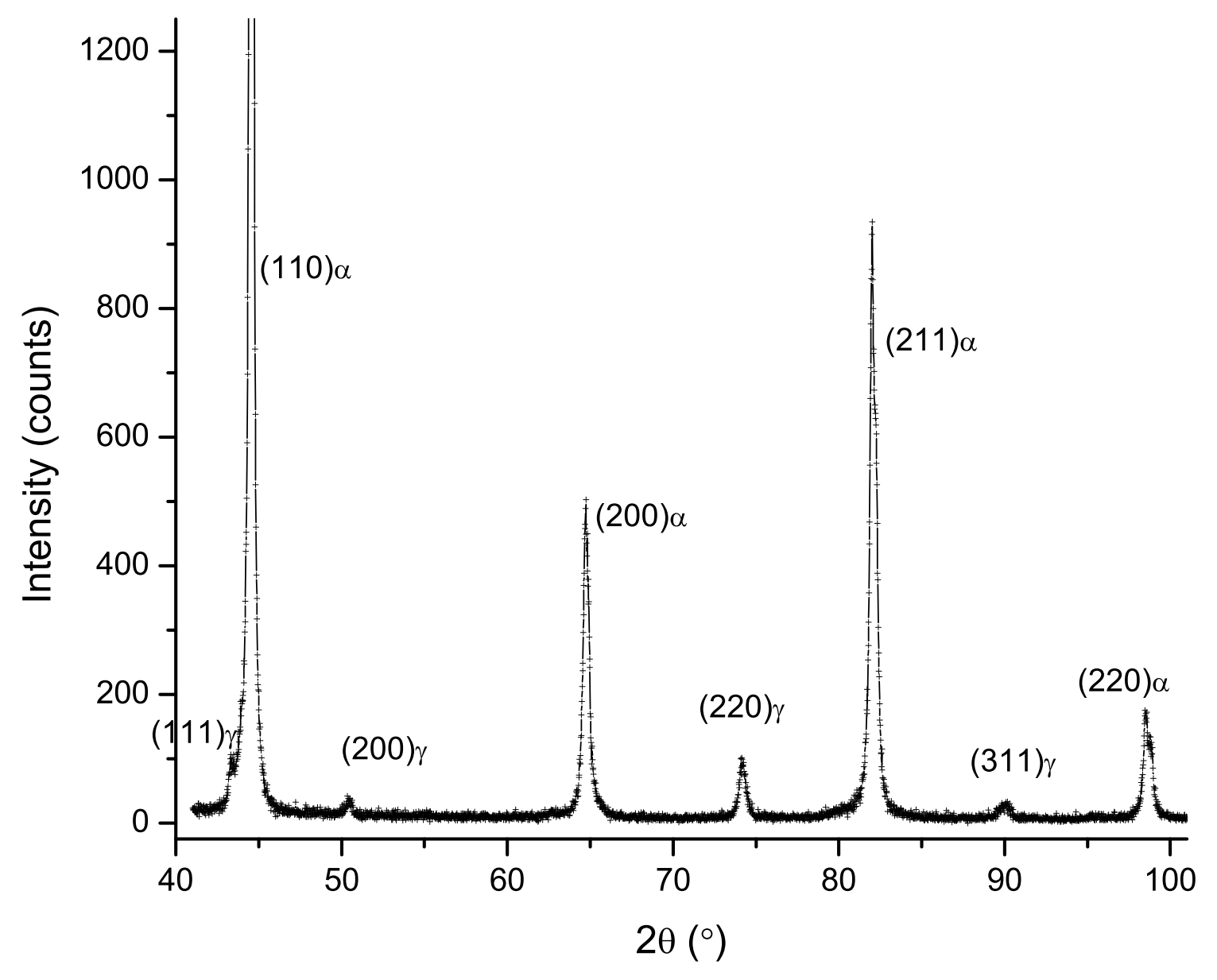

Figure 3.3: X-ray diffraction pattern of the equiaxed-875 microstructure. 


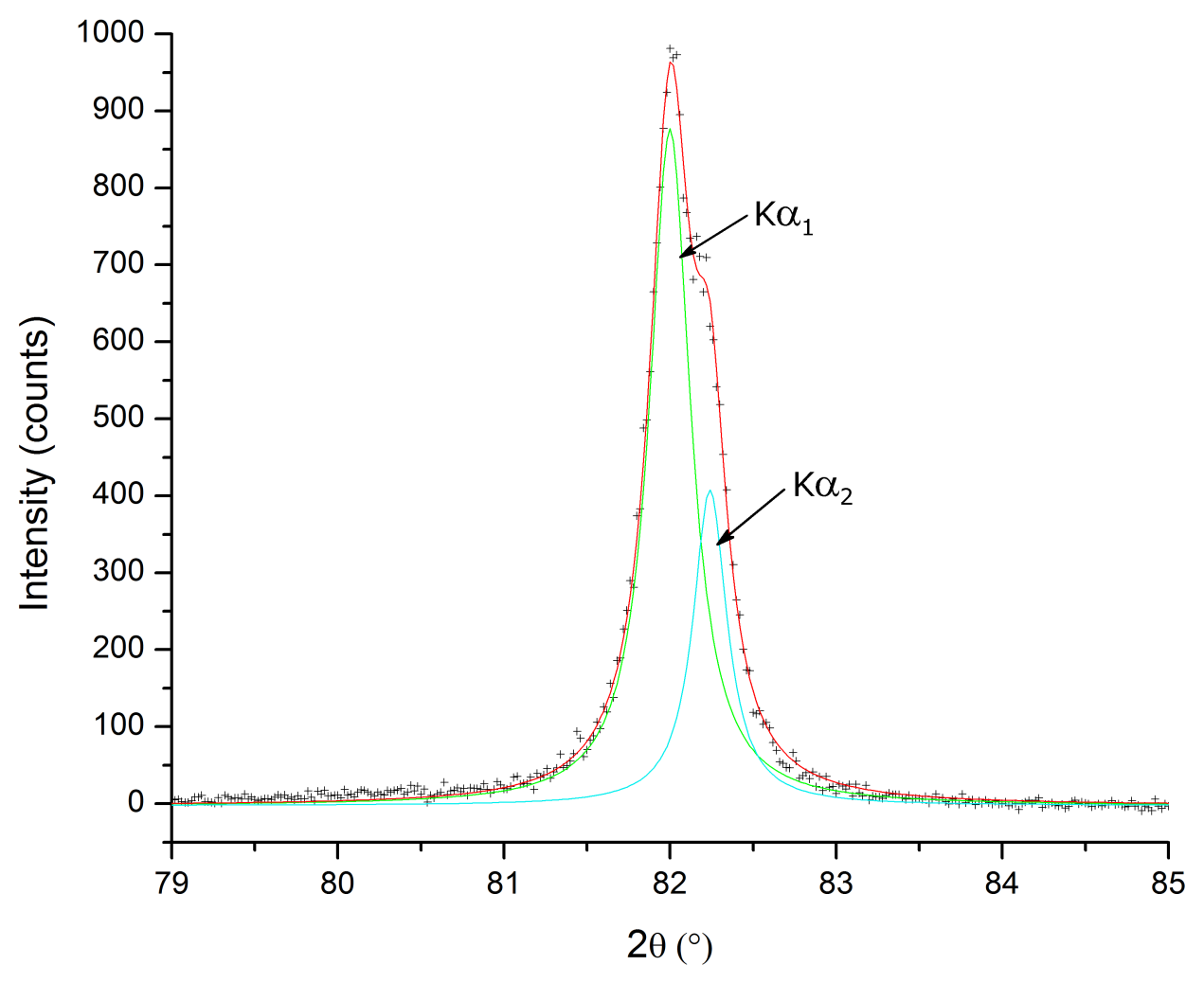

Figure 3.4: Deconvolution of a (211) $\alpha$ peak separating the $\mathrm{K} \alpha_{1}$ and $\mathrm{K} \alpha_{2}$ peaks in the diffraction pattern. 
There are several different formulae that can be used to relate the austenite lattice parameter to its carbon content, so the accuracy of the carbon content measurement may differ from the actual value by amounts on the order of several tenths of wt.\% [95]. However, for a comparison of carbon content values between specimens using the same formula, the main source of error originates from the differences in intergranular stress.

The volume fraction of RA can also be calculated from the diffraction pattern via the direct comparison method described by Cullity [74] and the ASTM standard E975-03 [96]. This method involves comparing the integrated intensity of the austenite phase to the intensity of the ferrite phase, which is essentially finding the fraction of the diffracted intensity that is due to austenite planes. The integrated intensity is also normalized against a theoretical intensity value that is calculated from various machine parameters and characteristic values of the diffracting plane, such that:

$$
R A=\frac{\sum I_{\gamma}^{h k l} / \sum R_{\gamma}^{h k l}}{\sum I_{\alpha}^{h k l} / \sum R_{\alpha}^{h k l}+\sum I_{\gamma}^{h k l} / \sum R_{\gamma}^{h k l}}
$$

where $I$ is the integrated intensity for each ferrite $(\alpha)$ or austenite $(\gamma)$ peak and $R$ is the theoretical intensity. The integrated intensity is calculated using a constant interval size of $\mathrm{d} \theta=0.02^{\circ}$ with the background subtracted, given by:

$$
I=\sum I\left(\theta_{i}\right) \Delta \theta
$$

The theoretical intensity is calculated as:

$$
R=\frac{1}{U^{2}}|F|^{2} m \frac{1+\cos ^{2} 2 \theta}{\sin ^{2} \theta \cos \theta} e^{-2 M}
$$

where $U$ is the unit cell volume, $F$ is a structure factor, $m$ is the multiplicity, $\theta$ is the diffraction angle and $e^{-2 M}$ is a temperature factor. Each of these values were taken from Cullity [74]. 
The largest source of error for these RA volume fraction measurements is the texture of the sample. Because certain diffraction peaks are larger than others, the calculated volume fractions from each of these peaks will correspondingly be larger or smaller. Thus, the results of four austenite peaks and three ferrite peaks were averaged to mitigate this effect.

\subsection{Uniaxial Tensile Tests}

Uniaxial tensile tests were conducted to determine the macroscopic mechanical properties of the TRIP steel. Essentially, the main parameters that are determined from the stress-strain curves of each sample are the $0.2 \%$ yield strength, ultimate tensile strength (UTS), strain at UTS and work hardening rates of the material.

The sub-sized tensile specimens were cut out of the heat treated coupons using a water-jet cutter following the dimensions given in the ASTM standard E8M-09 [97]. The specimens were oriented such that the loading direction would be parallel to the RD of the sheet. The tensile specimens had a nominal thickness of $1 \mathrm{~mm}$ and the dimensions are shown in Figure 3.5. These samples were subsequently sanded using silicon carbide sandpaper to smooth the surfaces before mechanical testing. Measurements of the width and thickness were taken at three different points along the gauge region and averaged to determine the gauge cross-sectional area for each tensile specimen.

A hydraulic Instron testing machine with a $100 \mathrm{kN}$ load cell was used for tensile testing with a constant cross-head speed of $0.625 \mathrm{~mm} / \mathrm{min}$. This speed produced an initial nominal strain rate of $0.025 \mathrm{~min}^{-1}\left(0.0004167 \mathrm{~s}^{-1}\right)$ in the gauge region of the sample. The macroscopic strain in the samples was monitored using a contact 


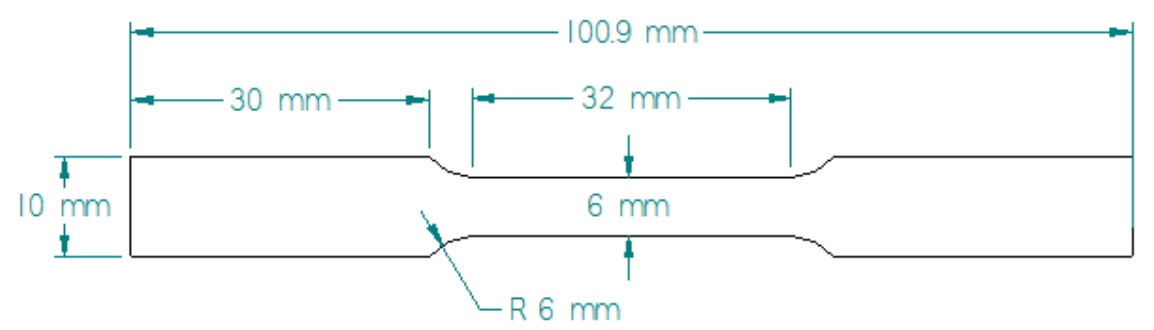

Figure 3.5: Engineering drawing of sub-sized uniaxial tensile specimen.

extensometer with a gauge length of $25 \mathrm{~mm}$. Three samples were tested to failure and a set of interrupted tensile tests were also conducted, where the specimen was deformed to a given strain before the test was halted. Table 3.2 shows a list of the strains that were considered. The interrupted test samples were subject to ex-situ RA measurements to provide insight on the RA-to-martensite transformation behaviour at various stages during uniaxial loading. Samples for magnetic measurements were cut from the gauge region of deformed samples as shown in Figure 3.2.

Engineering stress-strain curves were calculated from the uniaxial tension test data and the work hardening rate was examined using the slope of the true stresstrue strain curve $(d \sigma / d \epsilon)$ as it varies with true strain $(\epsilon)$ and the instantaneous work hardening exponent $\left(n_{\text {inst }}\right)$. 
Table 3.2: List of samples that were tested in the interrupted tensile tests.

\begin{tabular}{|c|c|c|}
\hline Heat Treatment & Deformation Strain & Number of Samples \\
\hline \multirow{10}{*}{ Equiaxed-875 } & 0.025 & 3 \\
\hline & 0.05 & 3 \\
\hline & 0.075 & 3 \\
\hline & 0.10 & 3 \\
\hline & 0.125 & 3 \\
\hline & 0.15 & 3 \\
\hline & 0.175 & 3 \\
\hline & 0.20 & 3 \\
\hline & 0.225 & 3 \\
\hline & Failure & 3 \\
\hline \multirow{10}{*}{ Lamellar-875 } & 0.025 & 3 \\
\hline & 0.05 & 3 \\
\hline & 0.075 & 3 \\
\hline & 0.10 & 3 \\
\hline & 0.125 & 3 \\
\hline & 0.15 & 3 \\
\hline & 0.175 & 3 \\
\hline & 0.20 & 3 \\
\hline & 0.225 & 3 \\
\hline & Failure & 3 \\
\hline \multirow{8}{*}{ Equiaxed-750 } & 0.025 & 3 \\
\hline & 0.05 & 3 \\
\hline & 0.075 & 3 \\
\hline & 0.10 & 3 \\
\hline & 0.125 & 3 \\
\hline & 0.15 & 3 \\
\hline & 0.175 & 3 \\
\hline & Failure & 3 \\
\hline \multirow{8}{*}{ Lamellar-925 } & 0.025 & 3 \\
\hline & 0.05 & 3 \\
\hline & 0.075 & 3 \\
\hline & 0.10 & 3 \\
\hline & 0.125 & 3 \\
\hline & 0.15 & 3 \\
\hline & 0.175 & 3 \\
\hline & Failure & 3 \\
\hline
\end{tabular}




\section{Chapter 4}

\section{Results}

The results in this chapter are presented in three sections. The first focuses on a set of equiaxed and lamellar microstructures with similar volume fractions of retained austenite and the second compares two microstructural variants with similar values of ultimate tensile strength. The third section describes the mechanical performance of the microstructural variants in terms of their $\mathrm{UTS} \times \mathrm{El}$ values.

\subsection{Variants with Similar Volume Fractions of Retained Austenite}

The heat treatments detailed in Section 3.1.1 resulted in two microstructural variants with similar volume fractions of RA of about 16\%: the equiaxed-875 microstructure and the lamellar-875 microstructure. By comparing two microstructural variants with the same volume fractions of RA, the effects of microstructure on the RA transformation behaviour can be better isolated and observed. 


\subsubsection{Microstructure Characterization}

The equiaxed-875 and the lamellar-875 microstructures are distinctly different despite originating from the same cold-rolled material. The microstructures are presented in Figure 4.1 as SEM micrographs at two different magnifications. In these micrographs, the ferrite is the dark phase and martensite and retained austenite $(\mathrm{M} / \mathrm{RA})$ are light islands. Bainite appears as a light, irregular phase adjacent to M/RA islands. On closer inspection in Figure 4.2, the retained austenite can be differentiated from the martensite because it is smooth whereas the martensite is slightly etched, showing the substructure. This substructure becomes apparent after the tempering process detailed in Section 3.2.1 because of carbide precipitation in the martensite [98].

Optical micrographs (shown in Figure 4.3) were also acquired to help make a clear distinction between the bainite and M/RA phases. The LePera tint etchant provided colour contrast between all four phases in the TRIP microstructure, revealing ferrite as tan, bainite as a dark brown, and M/RA as white. The martensite can be somewhat distinguished from the retained austenite by its slightly off-white colour arising from the tempering process, but the etch is usually not uniform enough to be able to make this distinction consistently.

The equiaxed-875 microstructure consists of equiaxed grains of intercritical ferrite surrounded by discrete particles of M/RA and bainite. By contrast, the lamellar-875 microstructure has elongated grains of ferrite separated by M/RA and bainite. The M/RA islands in the equiaxed-875 microstructure are equiaxed and are located either at ferrite grain boundaries or between bainite clusters, whereas the M/RA islands in the lamellar-875 microstructure are more needle-like and primarily surrounded by 


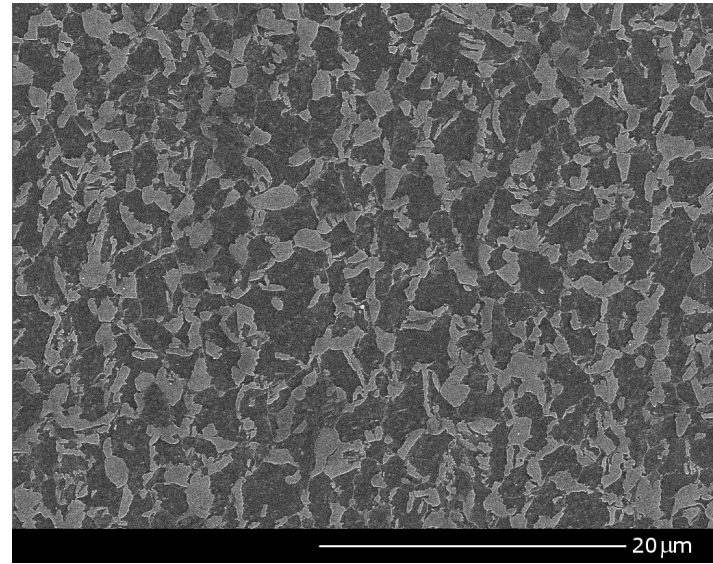

(a)

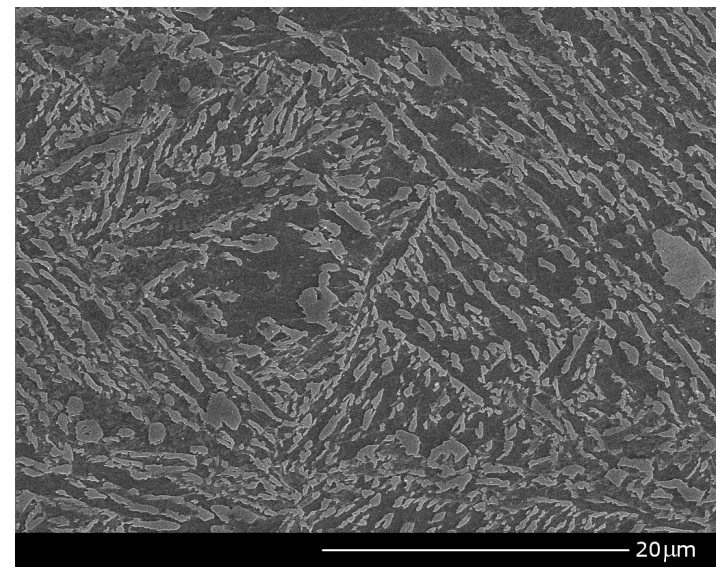

(c)

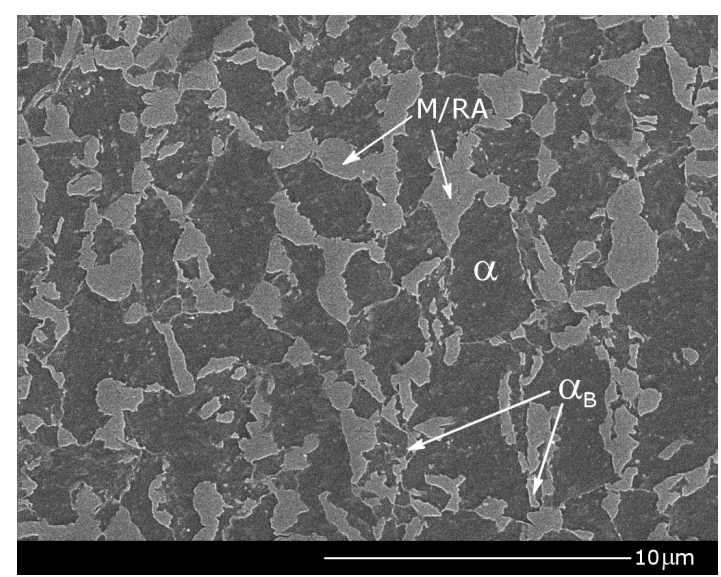

(b)

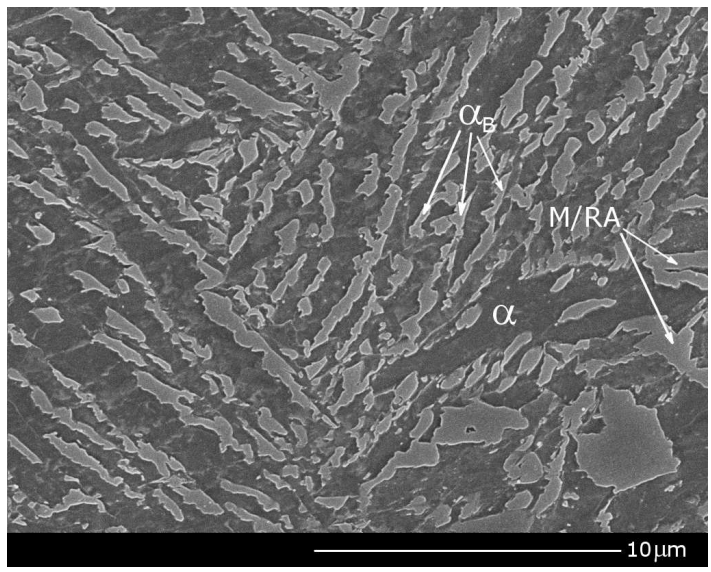

(d)

Figure 4.1: SEM micrographs of equiaxed-875 microstructure at (a) lower and (b) higher magnification and of lamellar-875 microstructure at (c) lower and (d) higher magnification. $\alpha$ is ferrite, $\alpha_{B}$ is bainite, and M/RA is martensite and retained austenite. 


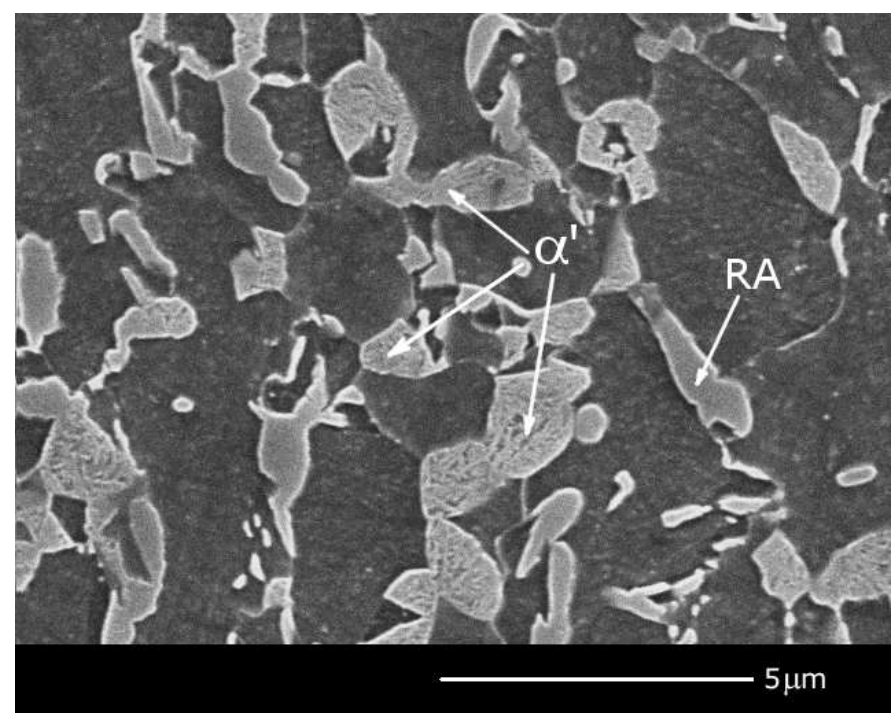

Figure 4.2: Magnified SEM micrograph showing the differences between martensite and RA grains in the tempered equiaxed-875 microstructure. $\alpha^{\prime}$ is martensite and RA is retained austenite.

bainite grains located at prior martensite lath boundaries. There are also a few larger M/RA grains that appear blocky and are generally located near ferrite grain boundaries.

The volume fractions of RA were measured in both microstructural variants using the magnetic method, and determined to be $16.5 \% \pm 3.2 \%$ (mean \pm standard deviation) in the equiaxed-875 microstructure and $16.3 \% \pm 2.4 \%$ for the lamellar-875 microstructure. The error is mostly associated with the spatial variation in the steel microstructure and less so with the reproducibility of the measurements from the equipment. In comparison, the volume fractions of RA as determined via XRD were calculated as $11.5 \% \pm 4.1 \%$ in the equiaxed-875 microstructure and $11.5 \% \pm 8.3 \%$ in the lamellar-875 microstructure. The uncertainty is given as the deviation from the average value, which comes from the use of four austenite peaks in the calculation, because the greatest source of error in XRD measurements arises from the texture of 


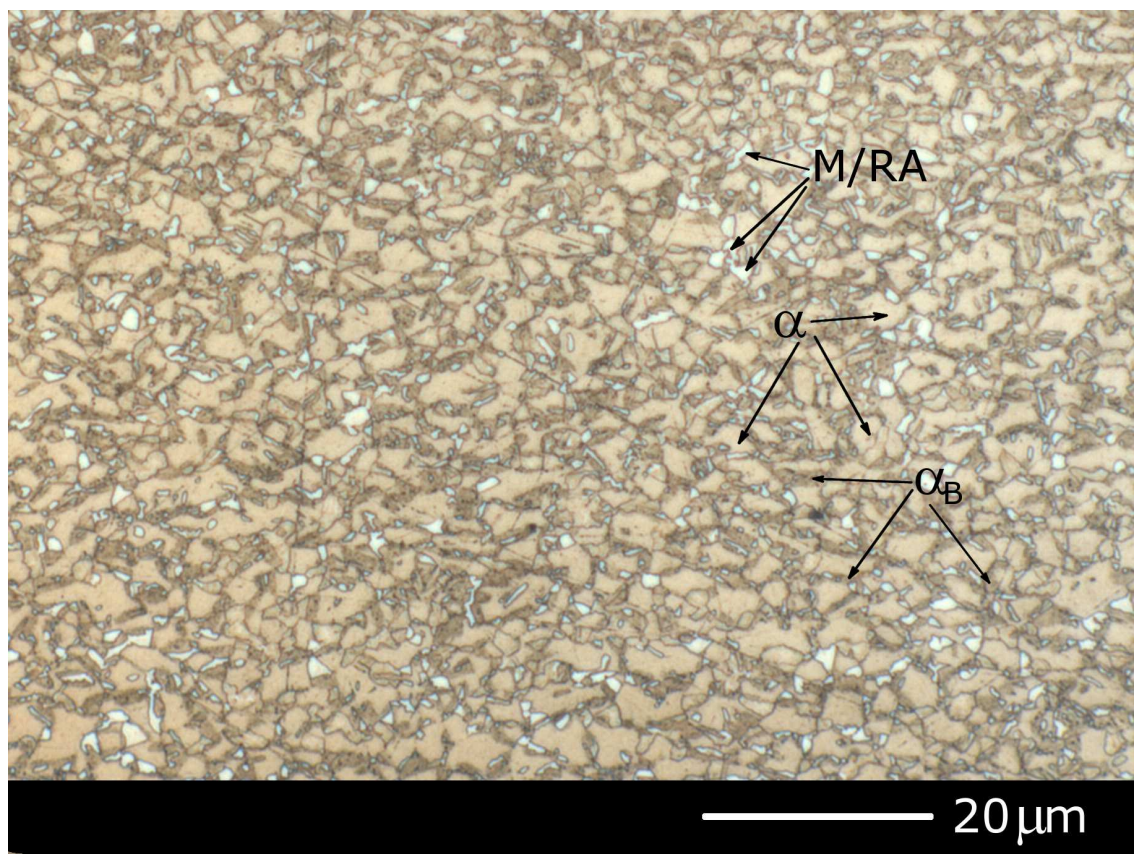

(a)

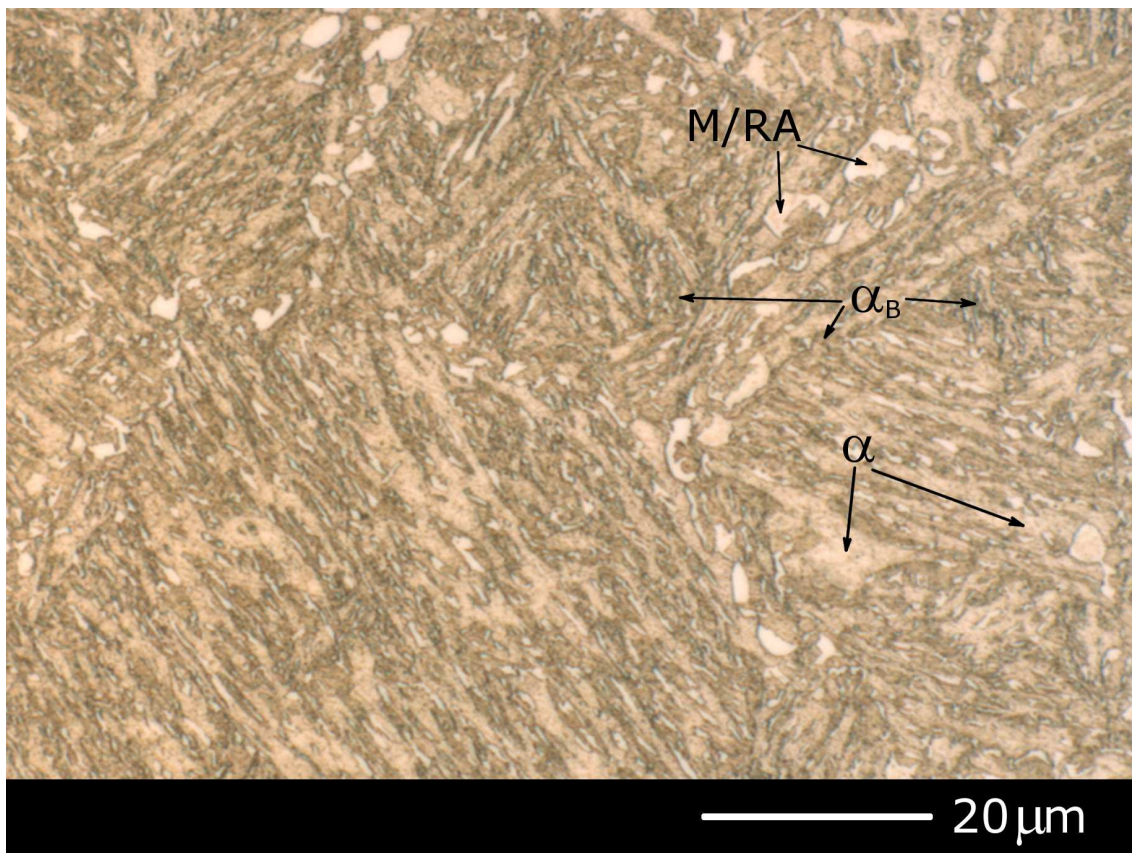

(b)

Figure 4.3: Optical micrographs of the (a) equiaxed-875 microstructure and the (b) lamellar-875 microstructure, prepared using LePera tint etch. $\alpha$ is ferrite, $\alpha_{B}$ is bainite, and M/RA is martensite and retained austenite. 
the samples. Certain ferrite and austenite diffraction peaks are consistently stronger than other reflections due to the texture of the steel (see Figure 3.3). For instance, the $(111) \gamma$ peak tends to be weaker than the $(200) \gamma$ peak and the (211) $\alpha$ peak is usually stronger than the (200) $\alpha$ peak in these samples. These differences in intensity create variations in the values of measured RA volume fraction. The measured volume fractions of RA are slightly higher when using magnetic measurements compared with XRD, but both techniques confirm that the equiaxed-875 and lamellar-875 microstructures have the same RA volume fractions.

The volume fractions of M/RA, bainite and ferrite were determined from the optical micrographs using image analysis. The equiaxed-875 microstructure was estimated to have $27 \% \pm 4 \%$ bainite and $12 \% \pm 4 \% \mathrm{M} / \mathrm{RA}$, and the lamellar-875 microstructure contained slightly more non-ferritic phase with $31 \% \pm 6 \%$ bainite and $17 \% \pm 4 \% \mathrm{M} / \mathrm{RA}$. The volume fraction of ferrite was determined as the remaining percentage from the non-ferritic phases. The uncertainties are given as the $95 \%$ confidence interval associated with the accuracy of thresholding the colour image and the variations in volume fractions observed between the 15 micrographs. According to these results, the lamellar-875 microstructure has about 5\% more M/RA than the equiaxed-875 microstructure, but the RA volume fraction measurements show that the two microstructures have the same volume fraction of RA. This difference between the measured values suggests that it is the martensite phase that produces this $5 \%$ difference. The volume fractions measurements of each constituent determined by magnetic methods, XRD and image analysis are summarized in Table 4.1. The volume fractions of RA as measured from the optical micrographs are in fact for the M/RA grains because the martensite and RA phases could not be clearly distinguished from one another. 
Table 4.1: Volume fractions of phases in equiaxed-875 and lamellar-875 microstructures as determined by different methods.

\begin{tabular}{lcccc}
\hline Microstructure & Phase & \multicolumn{3}{c}{ Volume fractions measured using different methods } \\
& & Magnetic & XRD & Optical micrographs \\
\hline \multirow{2}{*}{ Equiaxed-875 } & RA & $16.5 \% \pm 3.2 \%$ & $11.5 \% \pm 4.1 \%$ & $12 \% \pm 4 \%$ (M/RA) \\
& Bainite & - & - & $27 \% \pm 4 \%$ \\
& Ferrite & - & - & $61 \% \pm 4 \%$ \\
\hline \multirow{2}{*}{ Lamellar-875 } & RA & $16.3 \% \pm 2.4 \%$ & $11.5 \% \pm 8.3 \%$ & $17 \% \pm 4 \%(\mathrm{M} / \mathrm{RA})$ \\
& Bainite & - & - & $31 \% \pm 6 \%$ \\
& Ferrite & - & - & $52 \% \pm 6 \%$ \\
\hline
\end{tabular}

Image analysis was also used to determine the M/RA grain sizes in each microstructural variant. The equivalent grain diameter of a M/RA grain was calculated as the square root of the grain area, which is a method that is commonly used in grain size measurements [99]. The grain size distributions are shown in Figure 4.4. Although the lamellar-875 microstructure has more very large grains and very small grains, both of the microstructural variants generally have a very similar size distribution. The main source of error for these grain size measurements is the accuracy of the thresholding procedure.

The distribution of M/RA grain aspect ratios in the equiaxed-875 and lamellar-875 microstructures are shown in Figure 4.5. These aspect ratio measurements also have uncertainties that are associated with the accuracy of the thresholding procedure, although the measurements appear to be less affected by the thresholding than the grain size. It can clearly be seen that the lamellar-875 microstructure has more $\mathrm{M} / \mathrm{RA}$ grains with higher aspect ratios compared to the equiaxed-875 microstructure. This difference in aspect ratios can be also be qualitatively observed in the SEM micrographs of the two microstructures (Figure 4.6) where the M/RA grains in the lamellar-875 microstructure are thinner and more elongated. 


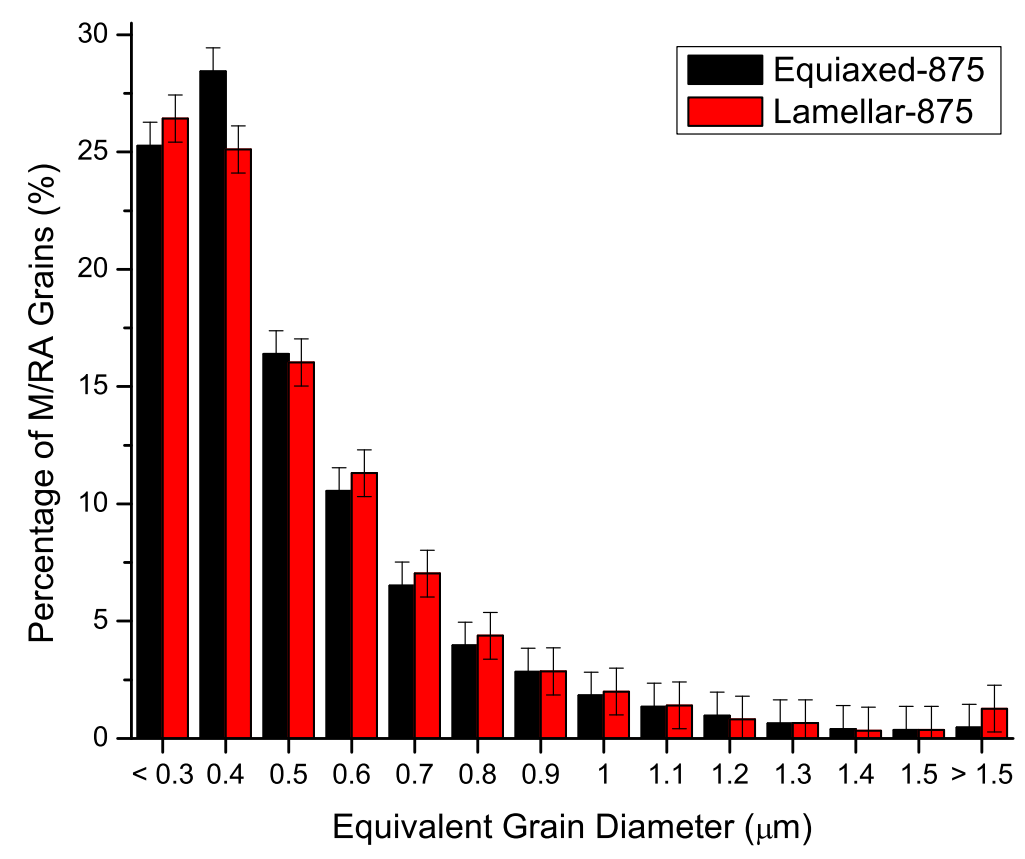

Figure 4.4: Size distribution of M/RA grains for equiaxed-875 and lamellar-875 microstructures.

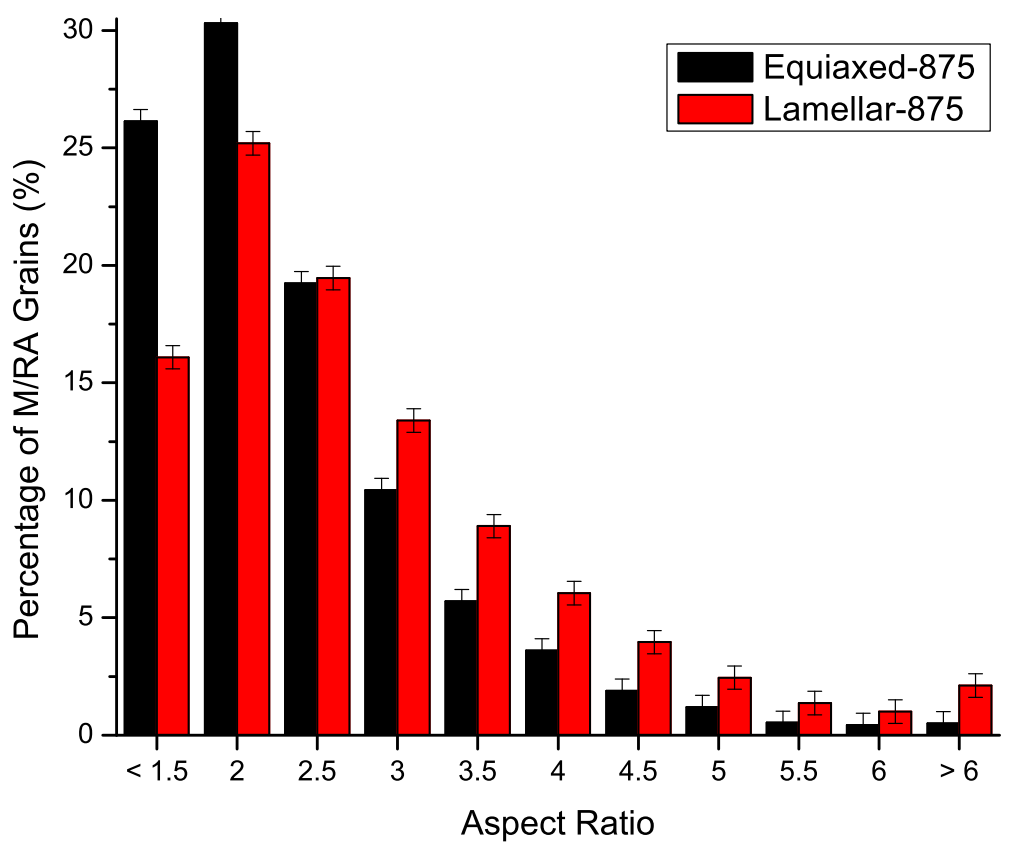

Figure 4.5: Aspect ratios of $\mathrm{M} / \mathrm{RA}$ grains for equiaxed-875 and lamellar-875 microstructures. 


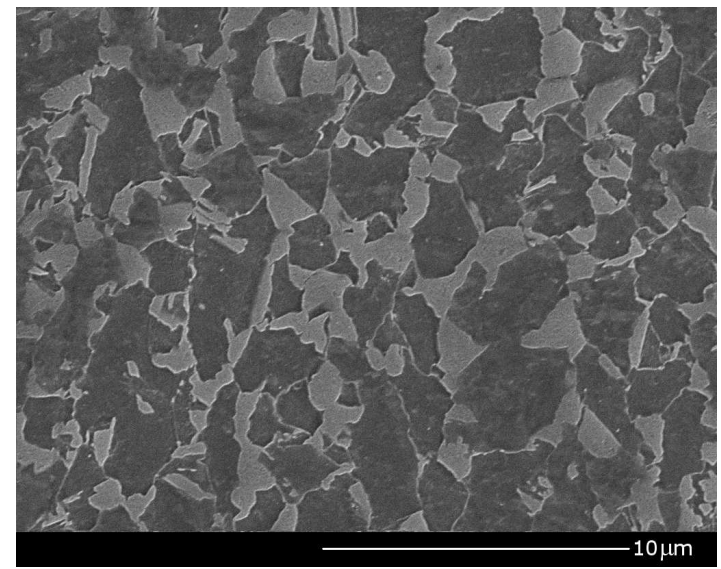

(a)

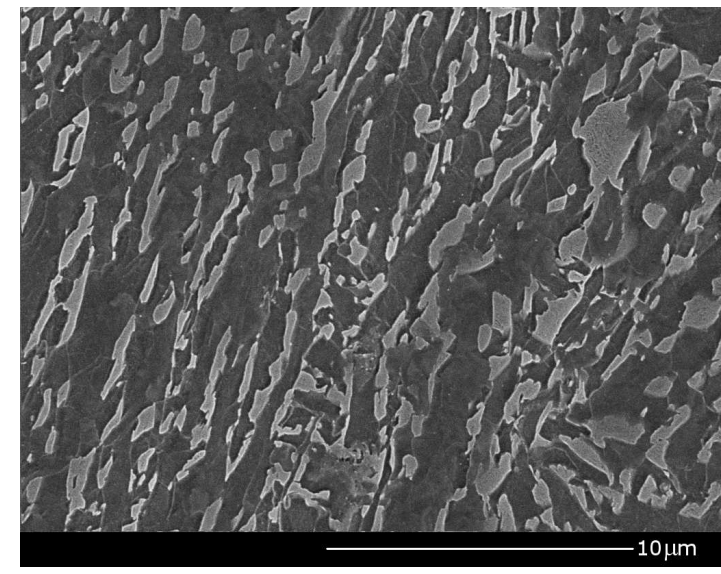

(b)

Figure 4.6: SEM micrographs of (a) equiaxed-875 microstructure with more blocky M/RA grains and (b) lamellar-875 microstructure with elongated M/RA grains.

The two microstructural variants also exhibit different spatial distributions of phases, specifically the bainite phase. Figure 4.7 shows two optical micrographs with the phases masked in solid colours to provide better contrast to compare the spatial distribution of phases. The M/RA grains are masked in white and the bainite in black. The equiaxed-875 microstructure has some M/RA grains that are surrounded by ferrite and some that are surrounded by bainite. On the other hand, the majority of the M/RA grains in the lamellar-875 microstructure are surrounded by bainite, particularly the grains that lie on prior martensite lath boundaries.

In order to compare the carbon content of the austenite phase in each microstructural variant, XRD measurements were conducted. The diffraction patterns of each microstructural variant look very similar to the one given in Figure 3.3. Because of the texture of the steel sample, the calculated carbon contents vary from peak to peak. Consequently, the results of this calculation that are provided in Table 4.2 are separated according to the individual diffraction peaks so that a better comparison can be 


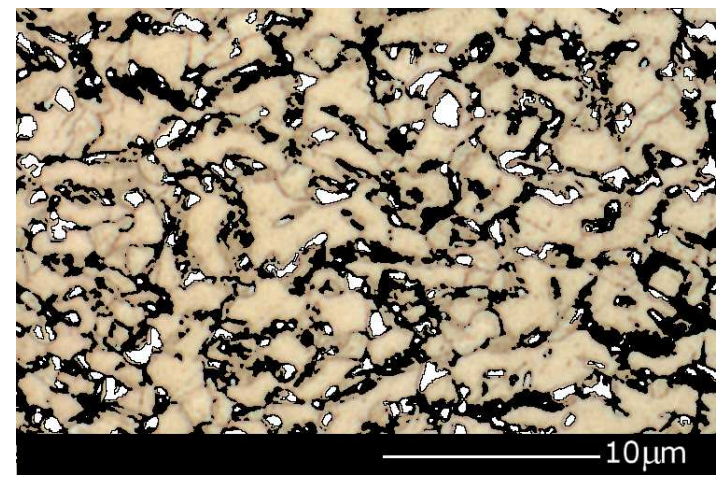

(a)

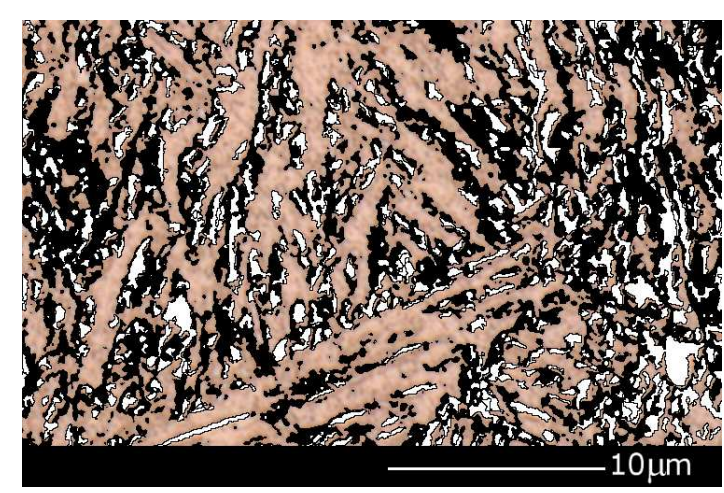

(b)

Figure 4.7: Optical micrographs of (a) equiaxed-875 and (b) lamellar-875 microstructures with phases masked. M/RA is white, bainite is black.

made between the two microstructural variants. The uncertainties are given as the 95\% confidence interval according to Dyson and Holmes [92]. Although each of the calculated carbon contents within a sample differ by a significant amount, each of the peaks show a similar trend between samples where the lamellar-875 microstructure has a distinctly higher carbon content than the equiaxed-875 microstructure.

Table 4.2: Carbon content in the austenite phase of equiaxed-875 and lamellar-875 microstructures.

\begin{tabular}{ccccc}
\hline & \multicolumn{4}{c}{ Carbon content by diffraction peak (wt.\%C) } \\
Sample & $(111) \gamma$ & $(200) \gamma$ & $(220) \gamma$ & $(311) \gamma$ \\
\hline Equiaxed-875 & $0.65 \pm 0.01$ & $1.33 \pm 0.01$ & $1.06 \pm 0.01$ & $1.03 \pm 0.01$ \\
Lamellar-875 & $1.23 \pm 0.01$ & $1.77 \pm 0.01$ & $1.25 \pm 0.01$ & $1.24 \pm 0.01$ \\
\hline
\end{tabular}

\subsubsection{Tensile Behaviour and Work Hardening Response}

Uniaxial tensile tests were conducted on the two microstructural variants to characterize their mechanical behaviour. Engineering stress-strain curves are shown in 
Figure 4.8 and values for individual tests are summarized in Table 4.3. The equiaxed875 microstructure exhibits a higher UTS but a lower value of uniform elongation (strain at which the UTS occurs) than the lamellar-875 microstructure. The lamellar875 microstructure also produces a higher value of $\mathrm{UTS} \times \mathrm{El}$, which is the product of the UTS and the total percent elongation. The higher UTS $\times$ El values indicate that the lamellar-875 microstructure has a better combination of strength and ductility than the equiaxed-875 microstructure.

The work hardening behaviour was investigated in greater detail for two representative samples using a plot of the work hardening rate $(d \sigma / d \epsilon)$ and the instantaneous $n$ values as a function of true strain. These two graphs are shown in Figures 4.9 and 4.10, respectively. The $d \sigma / d \epsilon$ plot shows the equiaxed-875 microstructure with very high work hardening values that gradually decrease to the point of necking. The lamellar-875 microstructure, on the other hand, exhibits a curve that is fairly close to a flat line that plateaus around 1000MPa. Because of this, the equiaxed-875 microstructure has a higher initial work hardening rate, but the lamellar-875 microstructure sustains the work hardening response at strains higher than 0.125 where the work hardening rate in the equiaxed-875 microstructure begins to diminish. The difference in work hardening behaviour is even more noticeable in Figure 4.10, the instantaneous $n$ plot. The equiaxed-875 microstructure has a high maximum $n_{\text {inst }}$ value of about 0.35 , and this value gradually drops as the sample is deformed. The lamellar-875 microstructure only has a maximum value of about 0.23 , but this value is sustained even at higher strains, such that the work hardening rate surpasses the equiaxed-875 at a strain of about 0.1 . 


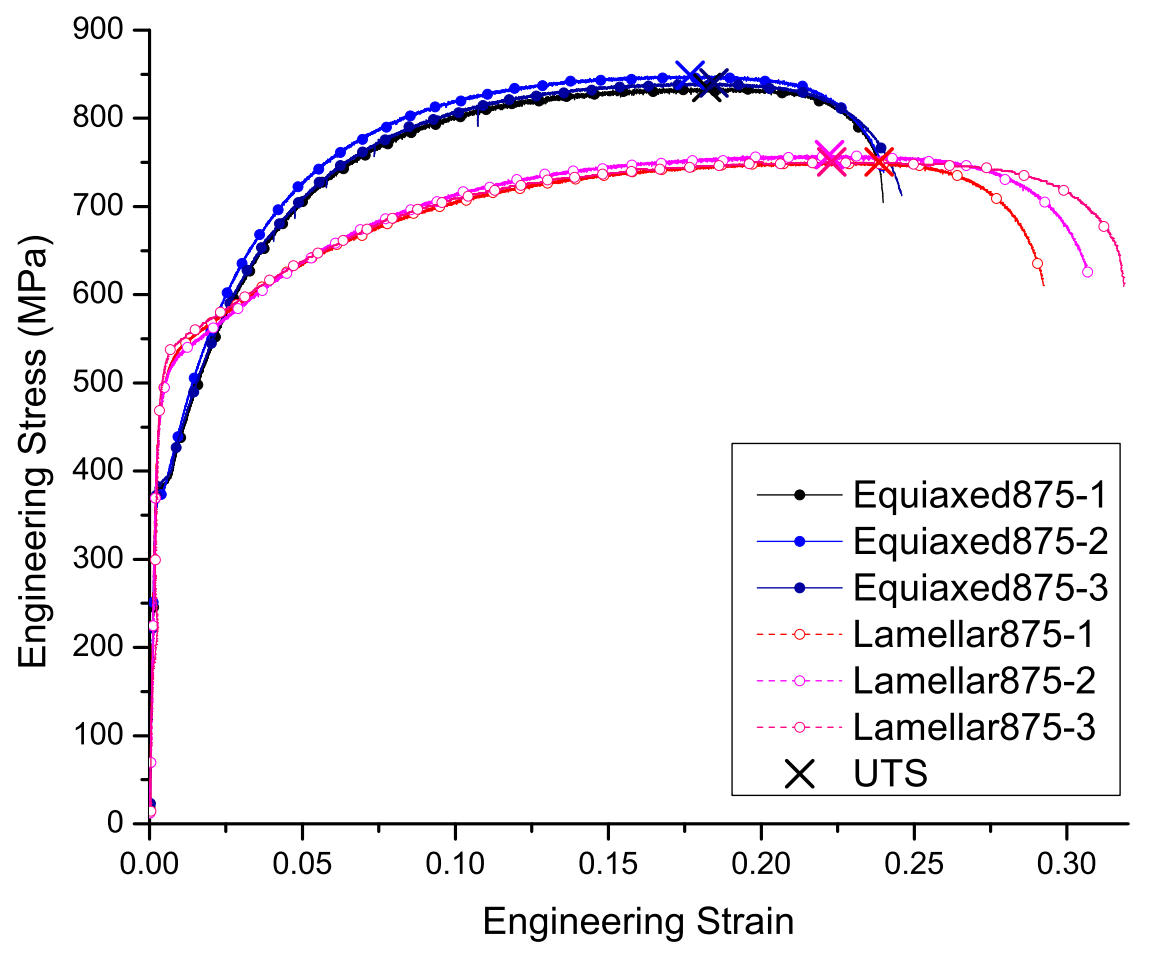

Figure 4.8: Engineering stress-strain curves for equiaxed-875 and lamellar-875 microstructures.

Table 4.3: Tensile properties of equiaxed-875 and lamellar-875 microstructures.

\begin{tabular}{ccccc}
\hline Sample & $\begin{array}{c}\text { Yield Strength } \\
(\mathrm{MPa})\end{array}$ & $\begin{array}{c}\text { UTS } \\
(\mathrm{MPa})\end{array}$ & $\begin{array}{c}\text { Engineering Strain } \\
\text { at UTS }\end{array}$ & $\begin{array}{c}\text { UTS } \times \text { El } \\
(\mathrm{MPa} \%)\end{array}$ \\
\hline Equiaxed875-1 & 384 & 835 & 0.182 & 20000 \\
Equiaxed875-2 & 372 & 849 & 0.177 & 20400 \\
Equiaxed875-3 & 388 & 840 & 0.184 & 20700 \\
Lamellar875-1 & 494 & 751 & 0.238 & 22000 \\
Lamellar875-2 & 493 & 758 & 0.222 & 23300 \\
Lamellar875-3 & 524 & 750 & 0.223 & 23900 \\
\hline
\end{tabular}




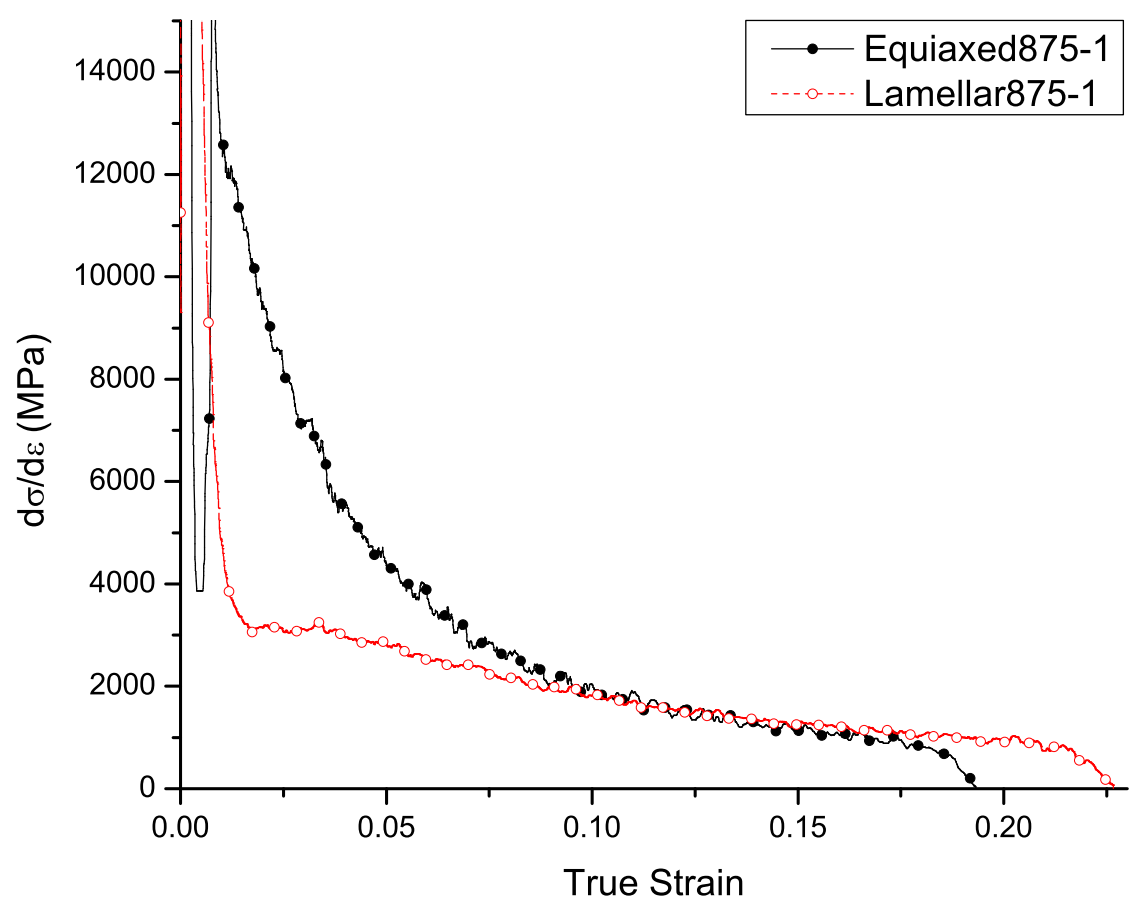

Figure 4.9: Work hardening rate of equiaxed-875 and lamellar-875 microstructures as it varies with true strain. 


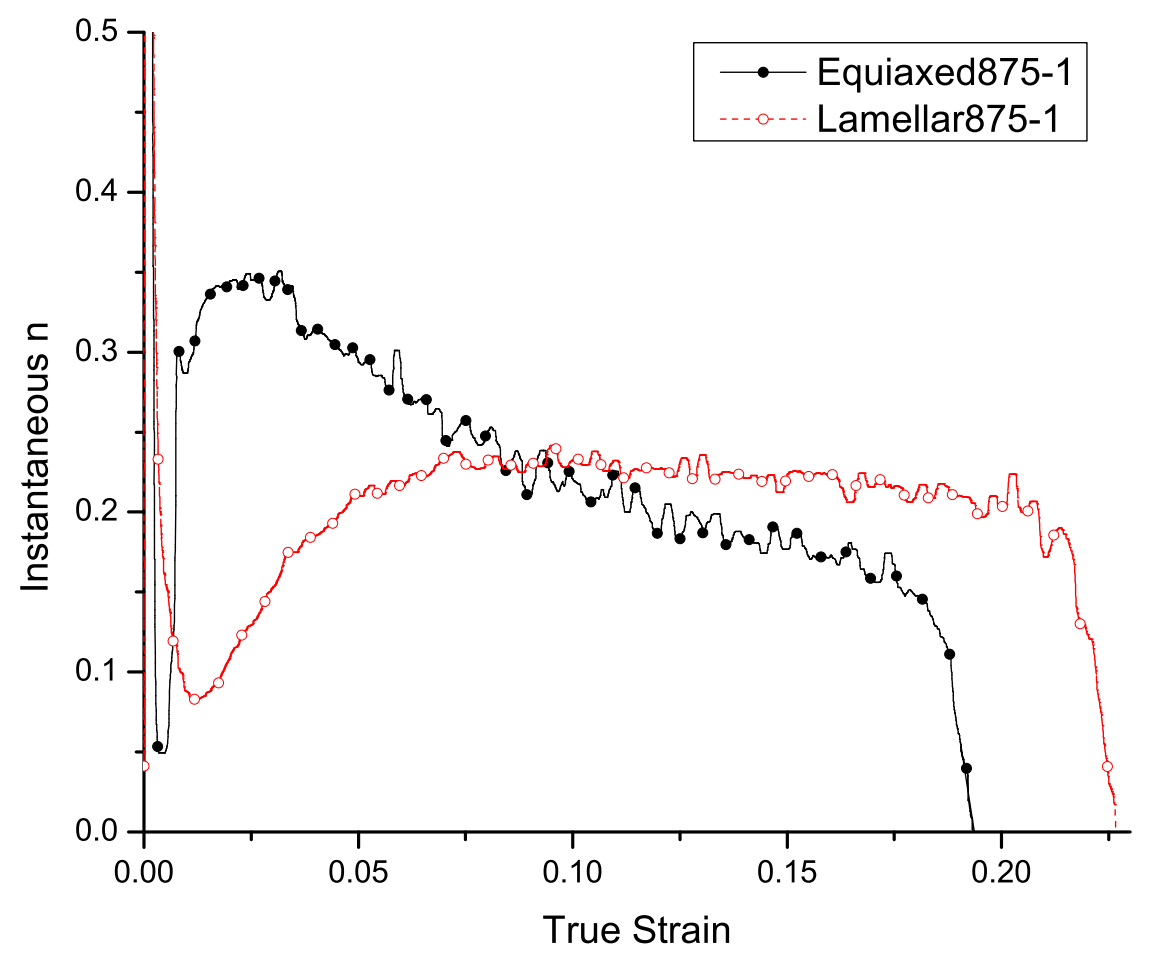

Figure 4.10: Instantaneous work hardening exponent for equiaxed-875 and lamellar-875 microstructures as it varies with true strain. 


\subsubsection{Retained Austenite Transformation Behaviour}

Ex-situ magnetic measurements were conducted on a series of interrupted tensile samples so that the transformation of the retained austenite throughout the deformation process could be determined. The volume fractions of RA were measured for each of the interrupted tensile samples and paired with a measurement from a sample that was taken from the same heat treatment coupon as the tensile specimen to provide an initial volume fraction measurement and a final volume fraction measurement after deformation. The value of transformed RA as compared to its original volume fraction was used to reduce the error associated with sample-to-sample variation. This variation corresponds to the standard deviation of the RA volume fraction measurements $( \pm 3.2 \%$ in the equiaxed-875 microstructure and $\pm 2.4 \%$ in the lamellar-875 microstructure). The results are given as the percentage of initial RA transformed as a function of true strain in Figure 4.11. The measurements for individual samples are provided in Table 4.4 and Table 4.5. The samples were named according to the nominal value of strain that it was deformed to. For instance, the equiaxed875e10-1 sample is specimen number 1 of the equiaxed-875 microstructure that was deformed to a nominal strain of 0.10 .

Both of the microstructures have transformation curves that are similar in shape. The transformation occurs quite rapidly during the initial stages of straining and then gradually reaches a plateau before failure. However, the two curves do exhibit different slopes and thus, different transformation rates. The RA in the equiaxed-875 microstructure transforms quickly, with almost all of the RA transformed by a strain of 0.1 . In contrast, only about $60 \%$ of the retained austenite in the lamellar-875 microstructure has transformed by this same value of strain, showing a more gradual 


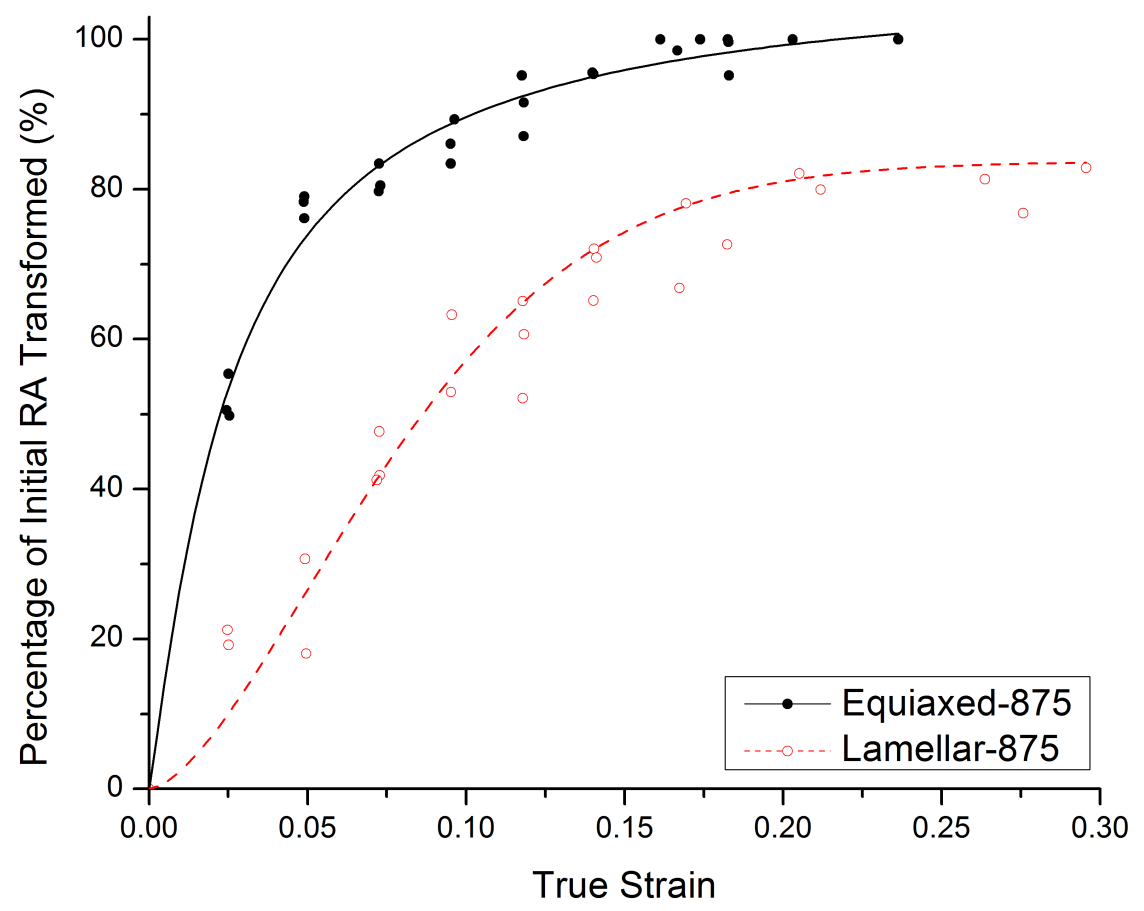

Figure 4.11: Percentage of initial RA transformed for equiaxed-875 and lamellar-875 microstructures as it varies with true strain. 
Table 4.4: Interrupted tensile test samples for the equiaxed-875 microstructure.

\begin{tabular}{lcc}
\hline Sample Name & True Strain & $\begin{array}{c}\text { Percentage of Initial } \\
\text { RA Transformed }(\%)\end{array}$ \\
\hline Equiaxed875e2.5-1 & 0.024 & 60.5 \\
Equiaxed875e2.5-2 & 0.024 & 55.4 \\
Equiaxed875e2.5-3 & 0.025 & 59.8 \\
\hline Equiaxed875e5-1 & 0.049 & 76.1 \\
Equiaxed875e5-2 & 0.049 & 79.0 \\
Equiaxed875e5-3 & 0.049 & 78.3 \\
\hline Equiaxed875e7.5-1 & 0.072 & 79.7 \\
Equiaxed875e7.5-2 & 0.073 & 83.4 \\
Equiaxed875e7.5-3 & 0.073 & 80.5 \\
\hline Equiaxed875e10-1 & 0.095 & 86.1 \\
Equiaxed875e10-2 & 0.095 & 83.4 \\
Equiaxed875e10-3 & 0.096 & 89.3 \\
\hline Equiaxed875e12.5-1 & 0.118 & 95.2 \\
Equiaxed875e12.5-2 & 0.118 & 91.6 \\
Equiaxed875e12.5-3 & 0.118 & 87.1 \\
\hline Equiaxed875e15-1 & 0.140 & 95.4 \\
Equiaxed875e15-3 & 0.140 & 95.5 \\
\hline Equiaxed875e17.5-1 & 0.167 & 98.5 \\
Equiaxed875e17.5-2 & 0.174 & 100 \\
Equiaxed875e17.5-3 & 0.161 & 100 \\
\hline Equiaxed875e20-1 & 0.182 & 100 \\
Equiaxed875e20-2 & 0.183 & 99.7 \\
Equiaxed875e20-3 & 0.183 & 95.2 \\
\hline Equiaxed875e22.5-2 & 0.203 & 100 \\
\hline Equiaxed875efail-1 & 0.236 & 100 \\
Equiaxed875efail-2 & 0.207 & 100 \\
Equiaxed875efail-3 & 0.203 &
\end{tabular}


Table 4.5: Interrupted tensile test samples for the lamellar-875 microstructure.

\begin{tabular}{lcc}
\hline Sample Name & True Strain & $\begin{array}{c}\text { Percentage of Initial } \\
\text { RA Transformed }(\%)\end{array}$ \\
\hline Lamellar875e2.5-1 & 0.025 & 19.2 \\
Lamellar875e2.5-3 & 0.025 & 21.2 \\
\hline Lamellar875e5-1 & 0.049 & 30.7 \\
Lamellar875e5-2 & 0.050 & 18.0 \\
\hline Lamellar875e7.5-1 & 0.073 & 47.7 \\
Lamellar875e7.5-2 & 0.073 & 41.8 \\
Lamellar875e7.5-3 & 0.072 & 41.2 \\
\hline Lamellar875e10-1 & 0.095 & 63.2 \\
Lamellar875e10-2 & 0.095 & 53.0 \\
\hline Lamellar875e12.5-1 & 0.118 & 52.1 \\
Lamellar875e12.5-2 & 0.118 & 65.1 \\
Lamellar875e12.5-3 & 0.118 & 60.6 \\
\hline Lamellar875e15-1 & 0.140 & 72.0 \\
Lamellar875e15-2 & 0.140 & 65.2 \\
Lamellar875e15-3 & 0.141 & 70.9 \\
\hline Lamellar875e17.5-1 & 0.167 & 66.8 \\
Lamellar875e17.5-3 & 0.169 & 78.1 \\
\hline Lamellar875e20-1 & 0.182 & 72.6 \\
\hline Lamellar875e22.5-1 & 0.205 & 82.1 \\
Lamellar875e22.5-2 & 0.212 & 79.9 \\
\hline Lamellar875efail-1 & 0.276 & 76.8 \\
Lamellar875efail-2 & 0.264 & 81.4 \\
Lamellar875efail-3 & 0.296 & 82.8 \\
\hline
\end{tabular}


transformation rate compared to the equiaxed-875 microstructure. Or, put another way, the RA in the lamellar microstructure can be said to be more stable. Moreover, the two microstructures differ with regards to the total percentage of RA that transforms. While $100 \%$ of the retained austenite in the equiaxed-875 microstructure transforms, only about $80 \%$ of the initial RA in the lamellar-875 microstructure is transformed even at failure.

\subsection{Variants with Similar Ultimate Tensile Strengths}

The comparison of two microstructures with similar volume fractions of RA provides some insight on the transformation behaviour, but it does not give a very clear comparison of the microstructures in terms of mechanical behaviour and formability. This is because the specimens exhibit the expected trade-off between strength and ductility, where a material with a higher UTS value (equiaxed-875 microstructure) has lower values of uniform elongation and vice versa. To better compare the formability of the two microstructures, the heat treatment paths were altered to produce variants that produced similar levels of ultimate tensile strength. Accordingly, values of UTS were achieved to within $30 \mathrm{MPa}$ of one another in the two additional microstructural variants, labelled as equiaxed-750 and lamellar-925. These UTS values can be considered the same because $30 \mathrm{MPa}$ is well within the variations in strength for repeated samples of a given heat treatment. 


\subsubsection{Microstructure Characterization}

The microstructures obtained from this second set of heat treatments are shown in the SEM and optical micrographs in Figures 4.12 and 4.13. These two microstructural variants show similar characteristics to the equiaxed-875 and the lamellar-875 microstructures. The lamellar-925 microstructure has elongated grains of ferrite with bainite and elongated M/RA grains located at prior martensite lath boundaries. In comparison, the equiaxed-750 microstructure has a matrix consisting of equiaxed ferrite with blocky M/RA islands located at ferrite grain boundaries. The most distinctive feature of the equiaxed-750 microstructure is that it does not have the expected multi-phase microstructure that is usually found in TRIP steels. There is a lack of any bainite phase and there are carbides present throughout the ferrite matrix. The carbides show up as light dots in the SEM micrographs and as dark dots in the optical micrographs. The appearance of carbides in the microstructure is most likely due to the very low intercritical annealing temperature of $750^{\circ} \mathrm{C}$, which makes the steel susceptible to carbide precipitation. The lamellar-925 microstructure is also slightly different from the lamellar-875 microstructure, where the lamellar-925 has a higher

volume fraction of bainite and a lower volume fraction of RA. Using image analysis, the lamellar-925 microstructure was estimated to have a bainite volume fraction of $47 \% \pm 5 \%$, which is significantly more than the $31 \%$ of bainite that was observed in the lamellar-875 microstructure. The reported error values are the $95 \%$ confidence interval associated with the threshold procedure accuracy and the variation between the 15 micrographs that were analyzed.

The equiaxed-750 microstructure had $12.4 \% \pm 4.4 \% \mathrm{RA}$ and the lamellar-925 microstructure had $14.0 \% \pm 1.3 \% \mathrm{RA}$ according to the magnetic measurements. XRD 


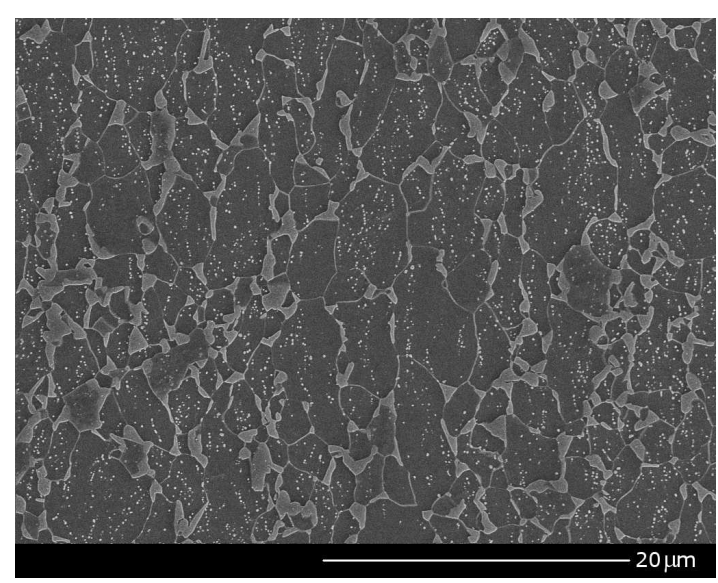

(a)

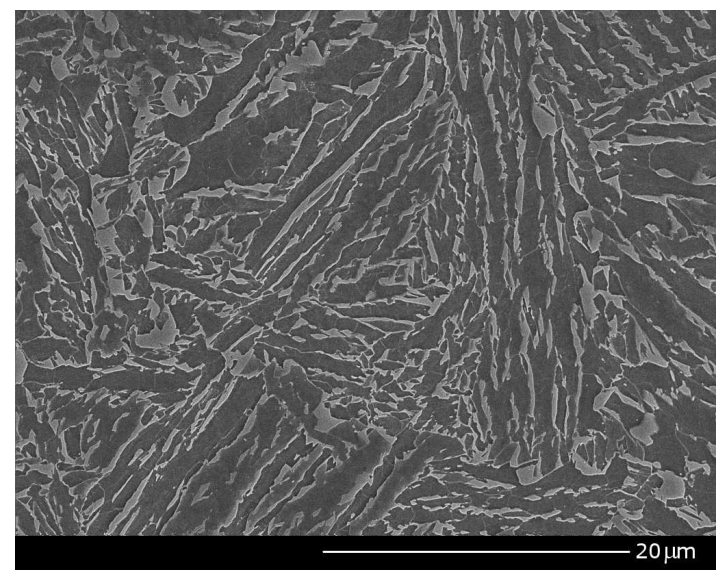

(c)

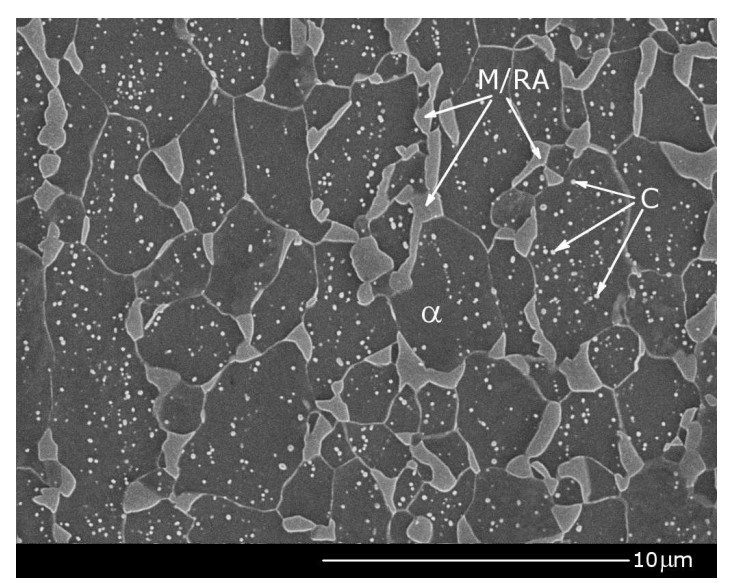

(b)

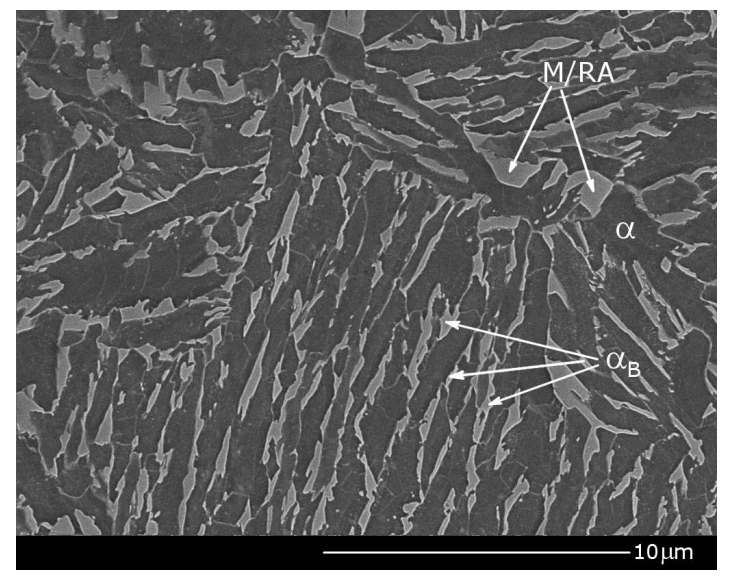

(d)

Figure 4.12: SEM micrographs of equiaxed-750 microstructure at (a) lower and (b) higher magnification and of lamellar-925 microstructure at (c) lower and $(\mathrm{d})$ higher magnification. $\alpha$ is ferrite, $\alpha_{B}$ is bainite, $\mathrm{C}$ are carbides, and $\mathrm{M} / \mathrm{RA}$ is martensite and retained austenite. 


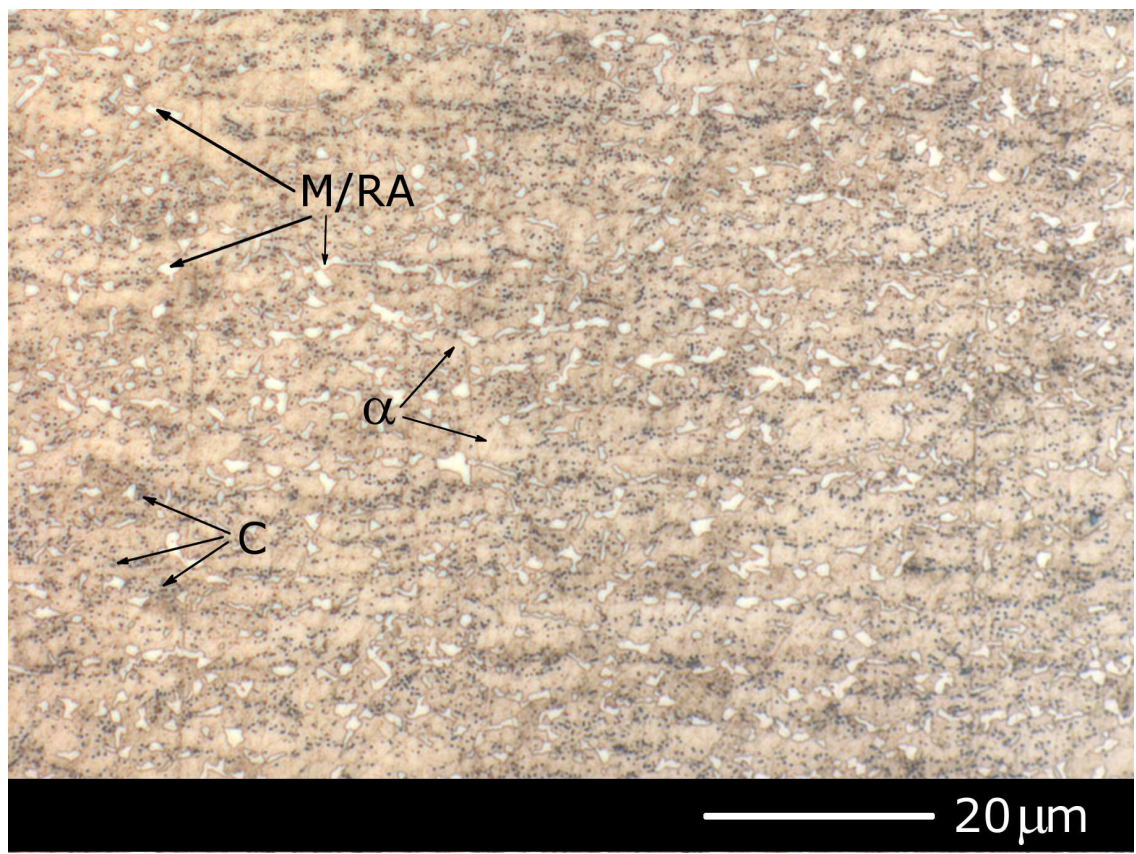

(a)

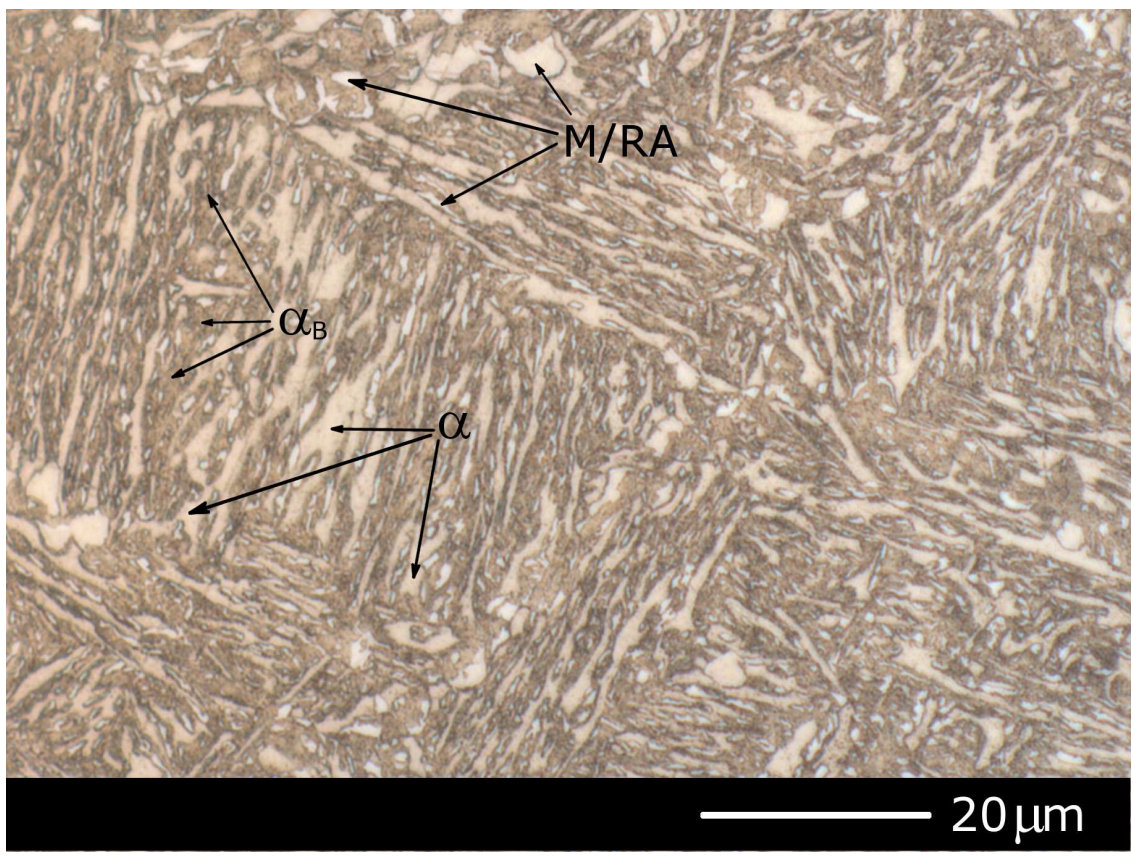

(b)

Figure 4.13: Optical micrographs of the (a) equiaxed-750 microstructure and the (b) lamellar-925 microstructure, prepared using LePera tint etch. $\alpha$ is ferrite, $\alpha_{B}$ is bainite, $\mathrm{C}$ are carbides, and M/RA is martensite and retained austenite. 
measurements were also used to confirm the volume fractions of RA and found to be $7.8 \% \pm 2.2 \%$ in the equiaxed-750 microstructure and $10.3 \% \pm 6.9 \%$ in the lamellar925 microstructure, respectively. Once again, the XRD measurements showed volume fractions of RA that are systematically lower than the data given by the magnetic measurements; however the measurements are able to confirm the trends that are seen in the comparison of the microstructural variants. Both of these microstructures have a lower volume fraction of RA as compared to the equiaxed-875 and the lamellar875 microstructures, with the equiaxed-750 microstructure having the lowest volume fraction of RA. The different measurements for the volume fractions of each phase are summarized in Table 4.6. It should be noted that the volume fractions of RA as measured from the optical micrographs are for the M/RA grains, and not just the RA phase, because the martensite and RA phases were so similar in colour in the optical micrographs.

The M/RA grain diameters in the equiaxed-750 and lamellar-925 microstructures are summarized in Figure 4.14 as determined using image analysis of optical micrographs. The lamellar-925 microstructure appears to have smaller M/RA grains than the equiaxed-750 microstructure, with the majority of the M/RA grains having a grain

Table 4.6: Volume fractions of phases in equiaxed-750 and lamellar-925 microstructures as determined by different methods.

\begin{tabular}{ccccc}
\hline Microstructure & Phase & \multicolumn{3}{c}{ Volume fractions measured using different methods } \\
& & Magnetic & XRD & Optical micrographs \\
\hline Equiaxed-750 & RA & $12.4 \% \pm 4.4 \%$ & $7.8 \% \pm 2.2 \%$ & $9 \% \pm 2 \%$ (M/RA) \\
& Ferrite & - & - & $91 \% \pm 2 \%$ \\
\hline \multirow{2}{*}{ Lamellar-925 } & RA & $14.0 \% \pm 1.3 \%$ & $10.3 \% \pm 6.9 \%$ & $11 \% \pm 3 \%(\mathrm{M} / \mathrm{RA})$ \\
& Bainite & - & - & $47 \% \pm 5 \%$ \\
& Ferrite & - & - & $42 \% \pm 5 \%$ \\
\hline
\end{tabular}


diameter less than $0.5 \mu \mathrm{m}$. The error values of the M/RA grain size measurements are associated with the accuracy of the thresholding procedure.

The aspect ratios were analyzed using image analysis, and the resulting histogram of aspect ratio distributions is shown in Figure 4.15. Figure 4.16 shows SEM micrographs of typical M/RA grains that are observed in the two microstructural variants. The shapes of the M/RA grains in the lamellar-925 microstructure are distinctly more elongated than those in the equiaxed-750 microstructure. The majority of the $\mathrm{M} / \mathrm{RA}$ grains in the equiaxed-750 microstructure have an aspect ratio between 1 and 2.5 , whereas most of the M/RA grains in the lamellar-925 microstructure have an aspect ratio larger than 2.5. Again, the error bars for the aspect ratio measurements are related to the thresholding procedure.

The equiaxed-750 and lamellar-925 microstructures have different phases present in the microstructure, as well as different spatial distribution of phases. All of the M/RA grains in the equiaxed-750 microstructure are located along ferrite grain boundaries, as there is no bainite present in the microstructure. In comparison, the M/RA grains in the lamellar-925 microstructure are predominantly surrounded by bainite. Two optical micrographs with the phases masked in a solid colour are shown in Figure 4.17 to show the locations of M/RA grains in reference to the ferrite and bainite phases. 


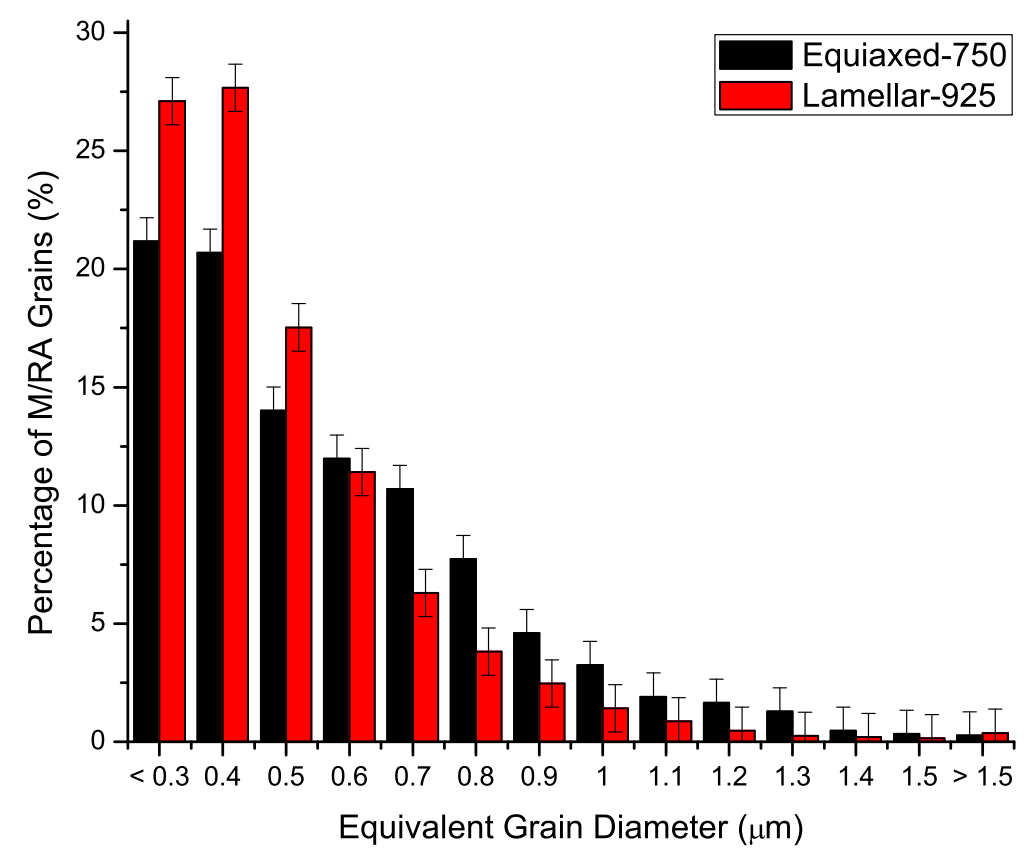

Figure 4.14: Size distribution of M/RA grains for equiaxed-750 and lamellar-925 microstructures.

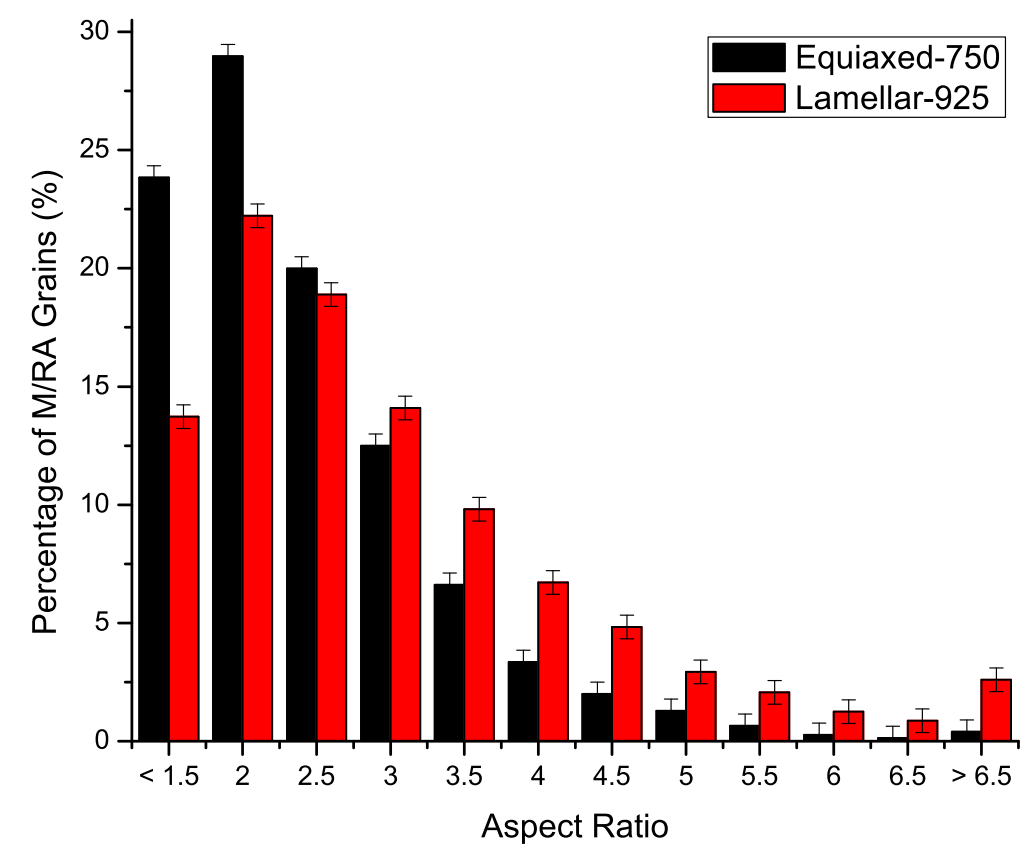

Figure 4.15: Aspect ratios of $\mathrm{M} / \mathrm{RA}$ grains for equiaxed-750 and lamellar-925 microstructures. 


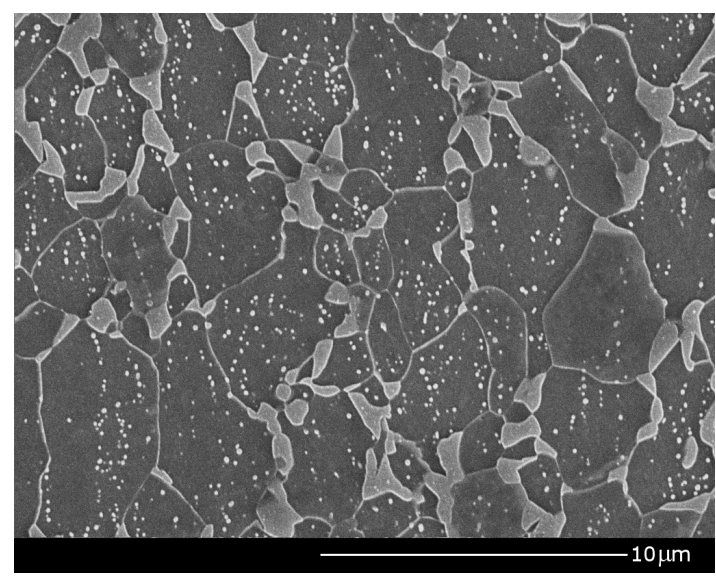

(a)

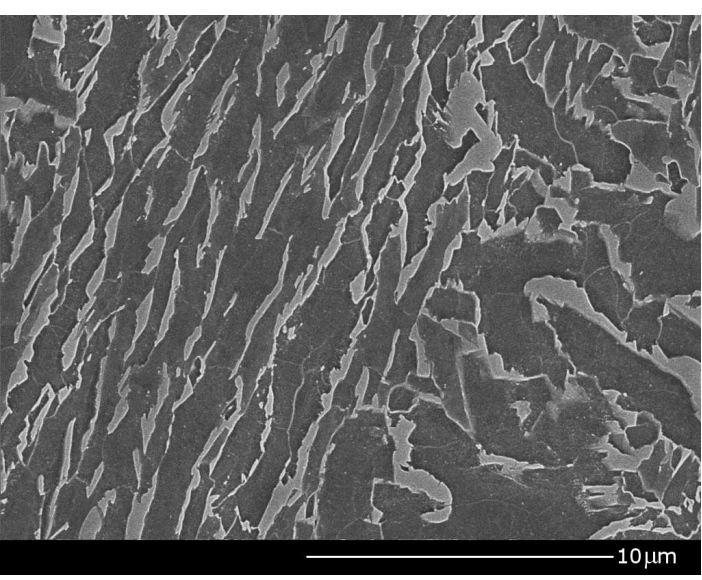

(b)

Figure 4.16: SEM micrographs of (a) equiaxed-750 microstructure with more blocky M/RA islands and (b) lamellar-925 microstructure with elongated $\mathrm{M} / \mathrm{RA}$ grains.

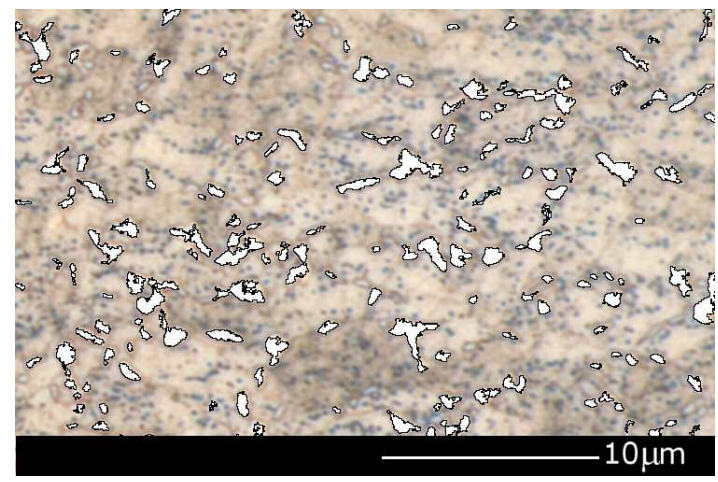

(a)

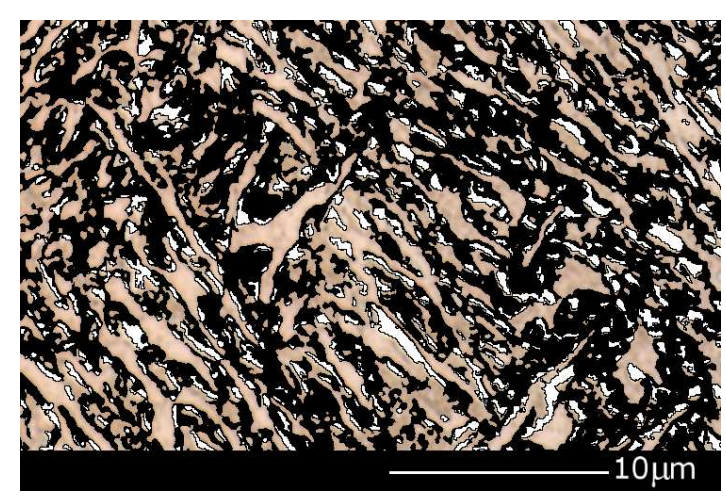

(b)

Figure 4.17: Optical micrographs of (a) equiaxed-750 and (b) lamellar-925 microstructures with phases masked. M/RA is white, bainite is black. 
Table 4.7 shows the RA carbon content in the equiaxed-750 microstructure and the lamellar-925 microstructure. The carbon content calculated from each of the four austenite peaks are all higher in the lamellar-925 microstructure than in the equiaxed-750 microstructure. The error provided is the $95 \%$ confidence interval.

Table 4.7: Carbon content in the austenite phase of equiaxed-750 and lamellar-925 microstructures.

\begin{tabular}{ccccc}
\hline & \multicolumn{4}{c}{ Carbon content by diffraction peak (wt.\%C) } \\
Sample & $(111) \gamma$ & $(200) \gamma$ & $(220) \gamma$ & $(311) \gamma$ \\
\hline Equiaxed-750 & $0.31 \pm 0.01$ & $1.51 \pm 0.01$ & $1.13 \pm 0.01$ & $1.04 \pm 0.01$ \\
Lamellar-925 & $1.77 \pm 0.01$ & $1.93 \pm 0.01$ & $1.43 \pm 0.01$ & $1.32 \pm 0.01$ \\
\hline
\end{tabular}

\subsubsection{Tensile Behaviour and Work Hardening Response}

The uniaxial tensile data is given in Table 4.8 and engineering stress-strain curves are presented in Figure 4.18. The two microstructures have very similar UTS values, the equiaxed-750 microstructure has a UTS of about 711MPa and the lamellar925 microstructure has a UTS of about 740MPa. However, the equiaxed-750 microstructure still exhibits a lower value of uniform elongation than the lamellar-925 microstructure even with similar strengths. Additionally, discontinuous yielding behaviour is observed in the equiaxed-750 microstructure.

A representative sample of each microstructural variant was used to calculate the work hardening rate $(d \sigma / d \epsilon)$ as a function of true strain, shown in Figure 4.19. Similar to the results in Section 4.1.2, the work hardening rate of the equiaxed-750 microstructure is higher than the lamellar-925 microstructure at lower strains. The $d \sigma / d \epsilon$ curve for the lamellar-925 microstructure is very similar to the work hardening curve for the lamellar-875 microstructure. However, unlike the equiaxed-875 


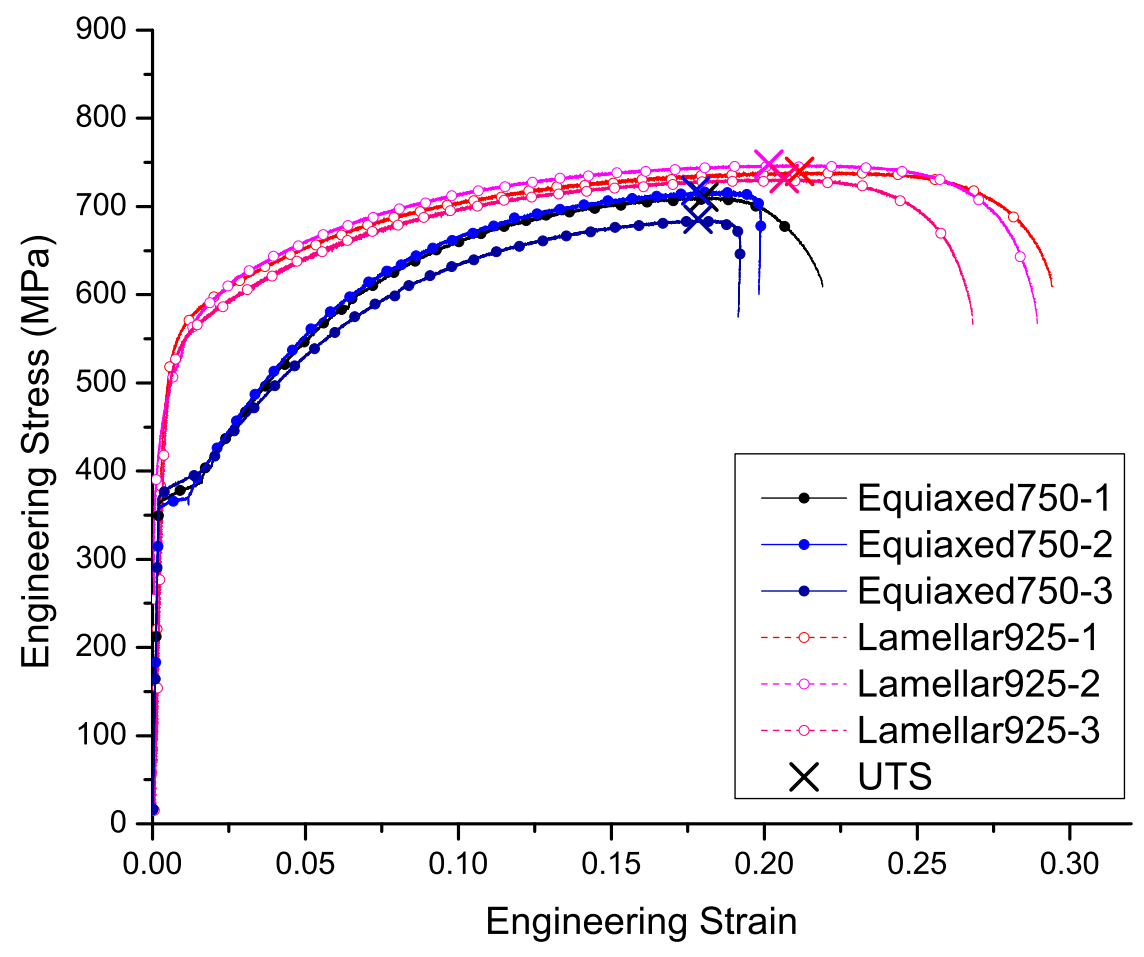

Figure 4.18: Engineering stress-strain curves for equiaxed-750 and lamellar-925 microstructures.

Table 4.8: Tensile properties of equiaxed-750 and lamellar-925 microstructures.

\begin{tabular}{ccccc}
\hline Sample & $\begin{array}{c}\text { Yield Strength } \\
(\mathrm{MPa})\end{array}$ & $\begin{array}{c}\text { UTS } \\
(\mathrm{MPa})\end{array}$ & $\begin{array}{c}\text { Engineering Strain } \\
\text { at UTS }\end{array}$ & $\begin{array}{c}\mathrm{UTS} \times \mathrm{El} \\
(\mathrm{MPa} \%)\end{array}$ \\
\hline Equiaxed750-1 & 368 & 711 & 0.180 & 15600 \\
Equiaxed750-2 & 362 & 718 & 0.178 & 14200 \\
Equiaxed750-3 & 377 & 685 & 0.178 & 13100 \\
Lamellar925-1 & 515 & 740 & 0.212 & 21700 \\
Lamellar925-2 & 539 & 748 & 0.202 & 21600 \\
Lamellar925-3 & 514 & 732 & 0.207 & 19600 \\
\hline
\end{tabular}




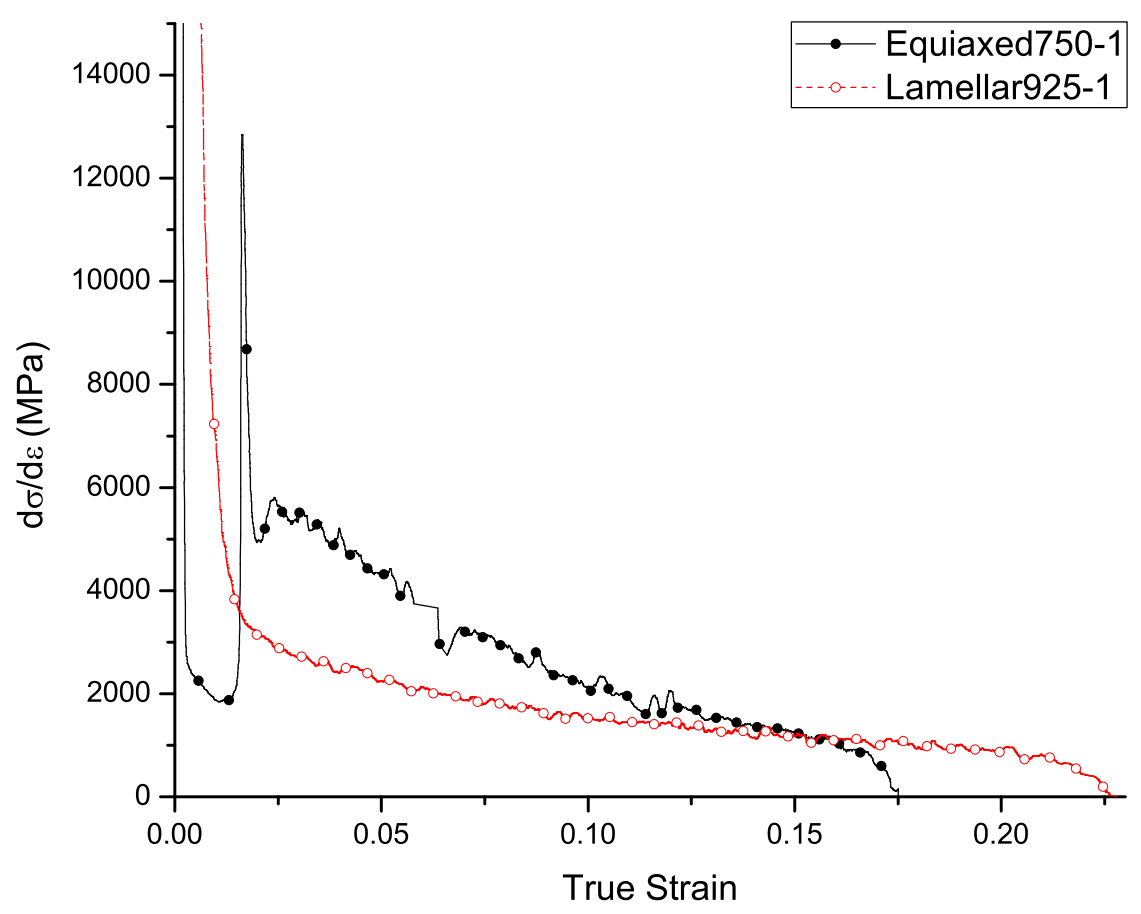

Figure 4.19: Work hardening rate of equiaxed-750 and lamellar-925 microstructures as it varies with true strain. 
microstructure, the equiaxed-750 microstructure exhibits a noticeable drop followed by a large spike in the work hardening rate around 0.01-0.02 strain. This fluctuation in work hardening rate is indicative of discontinuous yielding. At these low values of strain less than 0.025 , the equiaxed-750 microstructure shows considerably weaker work hardening properties than the equiaxed-875 microstructure, which suggests that continuous yielding would be preferred over discontinuous yielding behaviour.

The work hardening rate was also analyzed using the instantaneous $n$ values, plotted against true strain in Figure 4.20. With the exception of the spike in the equiaxed-750 microstructure around 0.01 strain as a result of discontinuous yielding, the work hardening plot shows a very similar shape to the plot for microstructures with similar volume fractions of RA (Figure 4.10). The equiaxed-750 microstructure has a higher maximum work hardening value than the lamellar-925 microstructure. The equiaxed-750 work hardening response is also exhausted at earlier strains than the lamellar-925 microstructure, where the lamellar-925 microstructure exhibits a flatter, more sustained work hardening curve up to higher strains.

\subsubsection{Retained Austenite Transformation Behaviour}

Based on magnetic measurements on a set of interrupted tensile tests, the transformation of RA in the equiaxed-750 microstructure and the lamellar-925 microstructure was determined and is shown in Figure 4.21, Table 4.9 and Table 4.10. The transformation behaviour appears very similar to the behaviour observed in the equiaxed-875 and lamellar-875 microstructures, where the shapes of the curves are the same but the lamellar-925 microstructure has a shallower slope than the equiaxed-750. Furthermore, it appears that even at the point of failure, about $20 \%$ of the initial RA 


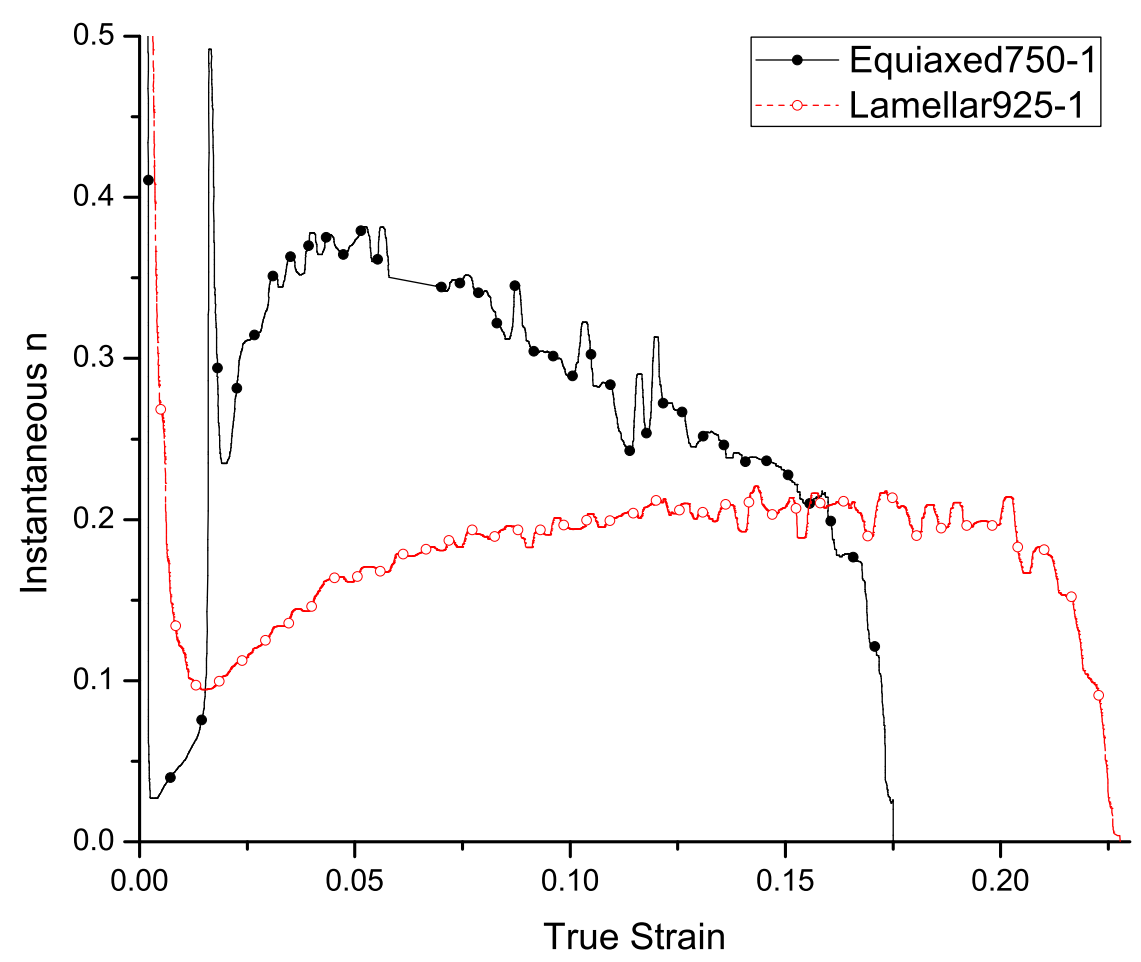

Figure 4.20: Instantaneous work hardening exponent for equiaxed-750 and lamellar-925 microstructures as it varies with true strain. 


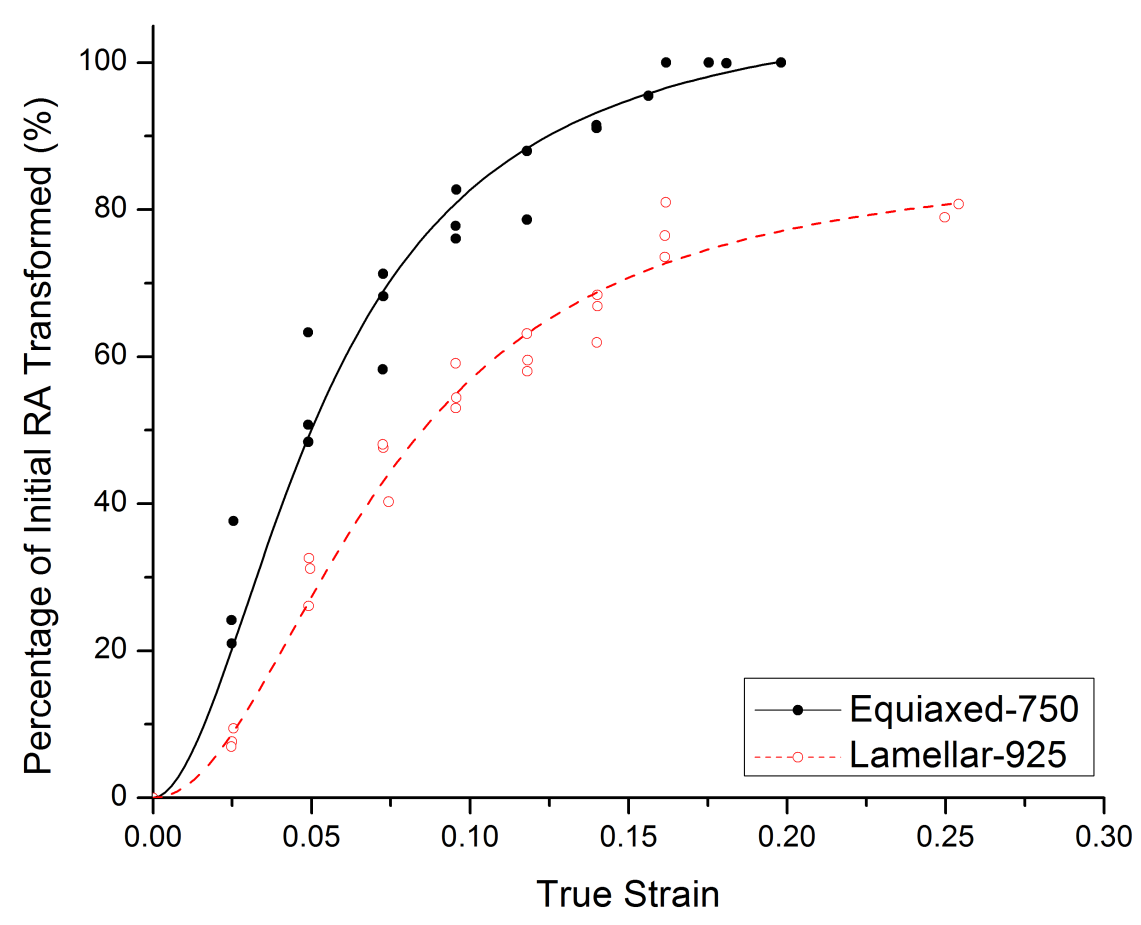

Figure 4.21: Percentage of initial RA transformed for equiaxed-750 and lamellar-925 microstructures as it varies with true strain. 
Table 4.9: Interrupted tensile test samples for the equiaxed-750 microstructure.

\begin{tabular}{lcc}
\hline Sample Name & True Strain & $\begin{array}{c}\text { Percentage of Initial } \\
\text { RA Transformed }(\%)\end{array}$ \\
\hline Equiaxed750e2.5-1 & 0.025 & 21.0 \\
Equiaxed750e2.5-2 & 0.025 & 37.6 \\
Equiaxed750e2.5-3 & 0.025 & 24.2 \\
\hline Equiaxed750e5-1 & 0.049 & 50.8 \\
Equiaxed750e5-2 & 0.049 & 48.4 \\
Equiaxed750e5-3 & 0.049 & 63.3 \\
\hline Equiaxed750e7.5-1 & 0.072 & 58.3 \\
Equiaxed750e7.5-2 & 0.073 & 68.2 \\
Equiaxed750e7.5-3 & 0.073 & 71.3 \\
\hline Equiaxed750e10-1 & 0.095 & 76.1 \\
Equiaxed750e10-2 & 0.095 & 77.8 \\
Equiaxed750e10-3 & 0.096 & 82.7 \\
\hline Equiaxed750e12.5-1 & 0.118 & 88.0 \\
Equiaxed750e12.5-2 & 0.118 & 78.6 \\
\hline Equiaxed750e15-2 & 0.140 & 91.5 \\
Equiaxed750e15-3 & 0.140 & 91.1 \\
\hline Equiaxed750e17.5-1 & 0.162 & 100 \\
Equiaxed750e17.5-3 & 0.156 & 95.5 \\
\hline Equiaxed750efail-1 & 0.181 & 100 \\
Equiaxed750efail-2 & 0.198 & 100 \\
Equiaxed750efail-3 & 0.175 & 100 \\
\hline & &
\end{tabular}


Table 4.10: Interrupted tensile test samples for the lamellar-925 microstructure.

\begin{tabular}{lcc}
\hline Sample Name & True Strain & $\begin{array}{c}\text { Percentage of Initial } \\
\text { RA Transformed (\%) }\end{array}$ \\
\hline Lamellar925e2.5-1 & 0.025 & 7.6 \\
Lamellar925e2.5-2 & 0.025 & 7.0 \\
Lamellar925e2.5-3 & 0.025 & 9.4 \\
\hline Lamellar925e5-1 & 0.050 & 31.2 \\
Lamellar925e5-2 & 0.049 & 32.6 \\
Lamellar925e5-3 & 0.049 & 26.1 \\
\hline Lamellar925e7.5-1 & 0.073 & 47.6 \\
Lamellar925e7.5-2 & 0.072 & 48.1 \\
Lamellar925e7.5-3 & 0.074 & 40.3 \\
\hline Lamellar925e10-1 & 0.096 & 54.4 \\
Lamellar925e10-2 & 0.095 & 59.1 \\
Lamellar925e10-3 & 0.095 & 53.0 \\
\hline Lamellar925e12.5-1 & 0.118 & 59.5 \\
Lamellar925e12.5-2 & 0.118 & 63.1 \\
Lamellar925e12.5-3 & 0.118 & 58.0 \\
\hline Lamellar925e15-1 & 0.140 & 62.0 \\
Lamellar925e15-2 & 0.140 & 68.4 \\
Lamellar925e15-3 & 0.140 & 66.9 \\
\hline Lamellar925e17.5-1 & 0.162 & 81.0 \\
Lamellar925e17.5-2 & 0.161 & 73.5 \\
Lamellar925e17.5-3 & 0.161 & 76.5 \\
\hline Lamellar925efail-1 & 0.250 & 79.0 \\
Lamellar925efail-2 & 0.254 & 80.8 \\
\hline
\end{tabular}


volume fraction in the lamellar-925 microstructure remains untransformed, much like the case in the lamellar-875 microstructure.

\subsection{UTS $\times$ El Values}

The UTS $\times$ El value was calculated for all of the samples that were tested and plotted against the respective volume fractions of RA, shown in Figure 4.22. A general trend can be seen where increasing the amount of RA in the microstructure increases the $\mathrm{UTS} \times \mathrm{El}$ value. This relationship between $\mathrm{UTS} \times \mathrm{El}$ and the initial volume fraction of RA is consistent with behaviour seen in previous studies where larger volume fractions of RA have better mechanical properties and a more desirable combination of strength and ductility. Both the equiaxed microstructures and the lamellar microstructures are plotted on the same graph, and the lamellar microstructure tends to have higher values of UTS $\times$ El than the equiaxed microstructure at any given volume fraction of RA. 


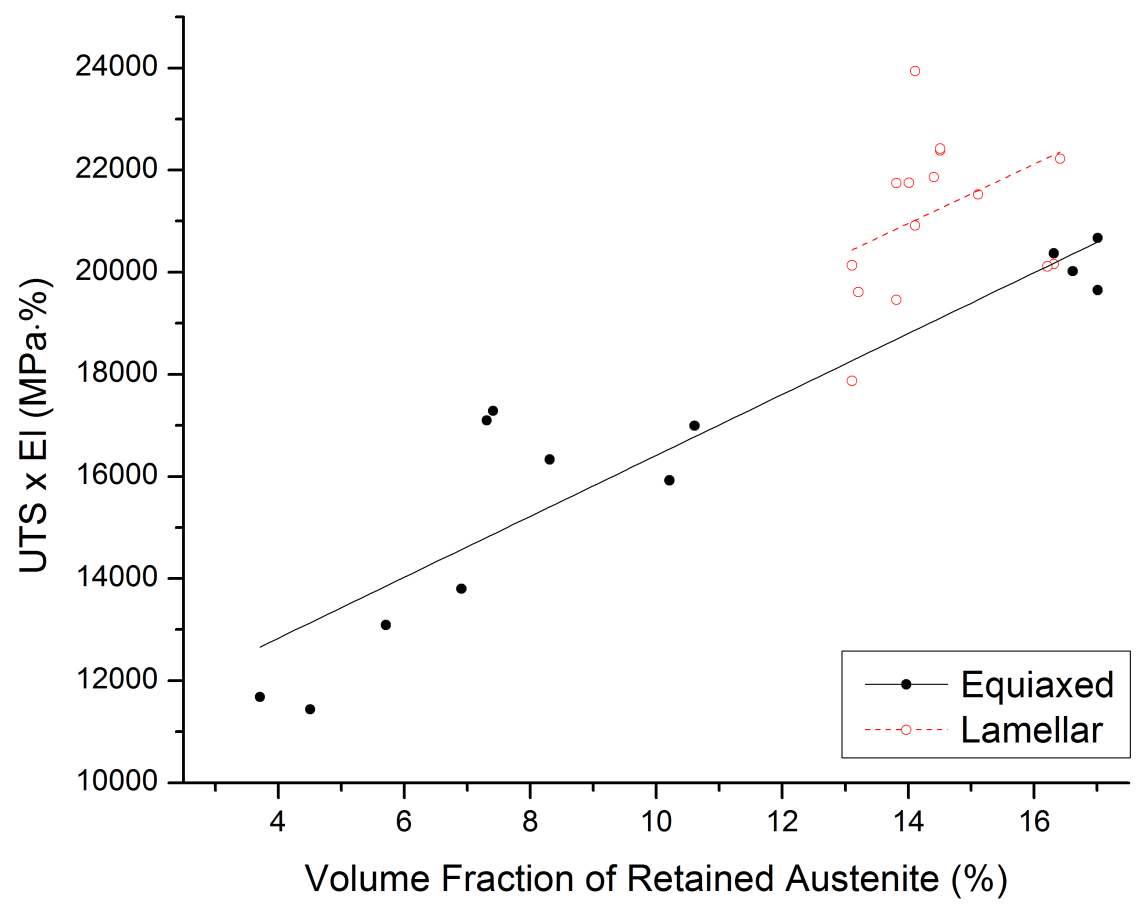

Figure 4.22: UTS $\times$ El values for samples with various volume fractions of RA. 


\section{Chapter 5}

\section{Discussion}

This chapter discusses the experimental results and their significance with reference to previous literature. The discussion is separated into five main sections covering the microstructural evolution of the TRIP steel variants, RA volume fraction measurement techniques, the relationship between tensile behaviour and the TRIP effect, RA stability, and a comparison of the results with a silicon-alloyed TRIP steel.

\subsection{Microstructural Evolution}

The initial heat treatment path for the microstructural variants was chosen based on the parameters that provided the maximum amount of RA in the equiaxed microstructure, the details of which can be found in Appendix A. Each processing variable (intercritical annealing time, intercritical annealing temperature, bainite hold time and bainite hold temperature) has a window that provides the maximum amount of RA that can be retained in the microstructure at room temperature because these variables influence many factors, including the amount of austenite formed during 
heat treatment, amount of bainite formed and carbon distribution within the microstructure [34, 37, 39, 100-102]. Because the microstructural evolution of the steel is so dependent on these variables, it will be discussed for each microstructural variant individually.

\subsubsection{Equiaxed-875 Microstructure}

The equiaxed-875 heat treatment produced a microstructure consisting of ferrite, bainite and martensite/retained austenite. The ferrite consists of equiaxed grains that were formed during the intercritical anneal. The austenite grains that grew during the intercritical anneal were partially consumed by bainite during the bainite hold step of the heat treatment. Any remaining austenite at this point was then retained at room temperature as small equiaxed or blocky grains at ferrite or bainite grain boundaries, although some of the austenite may have transformed into martensite during the water quench to room temperature. According to magnetic measurements, the resulting microstructure had $16.5 \% \mathrm{RA}$. The RA carbon content ranged from $0.65 \mathrm{wt} . \% \mathrm{C}$ to $1.33 w t . \% \mathrm{C}$ depending on the XRD peak that was used in the calculations. This particular microstructure is considered the conventional microstructure and is the one that is typically used in the automotive industry.

\subsubsection{Lamellar-875 Microstructure}

While the lamellar-875 microstructure has the same phases present as the equiaxed875 microstructure (ferrite, bainite and M/RA), the morphology and spatial distributions of phases are completely different. Before the standard two-step heat treatment, the steel was first heated to the fully austenitic region and held at this temperature 
to ensure that austenite comprised the entire microstructure. The steel was then quenched to room temperature to produce fine martensite. Subsequently, the steel was re-heated for the intercritical anneal where the martensite transforms into a mixture of ferrite and austenite.

The dislocations in the martensitic structure act as a driving force for recrystallization like the deformation from cold-rolling in the equiaxed-875 microstructure [88]. However, the morphology of the martensite laths is quite stable and remain (somewhat) unchanged after heat treatment such that the prior martensite lath boundaries can still be observed in the final lamellar-875 microstructure, suggesting that recrystallization did not occur. Transmission electron microscopy (TEM) studies show supporting evidence that the ferrite in the lamellar microstructure consist of recovered subgrains (i.e. the ferrite grains have not undergone recrystallization) [4]. Although the lath martensite structure has a high dislocation density, the driving force for recrystallization is lower than in cold-rolled ferrite [103]. This difference in driving force is a result of the dislocation arrangement - the dislocations due to the martensitic transformation are fairly uniform whereas the dislocations introduced by cold-rolling are inhomogeneous, resulting in bands or cell structures, which act as effective nucleation sites for recrystallization [104].

During the bainite hold, the bainite grows into the remaining austenite. Carbon is partitioned into the austenite during this step to stabilize it at room temperature [21]. The resulting microstructure has elongated grains of ferrite separated by M/RA and bainite grains that lie along prior martensite lath boundaries. Most of the M/RA grains are elongated, needle-like and surrounded by bainite, although there are a few larger blocky M/RA grains that can be observed, which is similar to results found in previous literature [105]. There is about $16.3 \% \mathrm{RA}$ in the final microstructure 
according to magnetic measurements, and the carbon content in the RA phase is higher than in the equiaxed-875 microstructure (1.23wt.\%C-1.77wt.\%C).

\subsubsection{Equiaxed-750 Microstructure}

The equiaxed-750 microstructure was produced in a similar manner to the equiaxed875 microstructure, except with a lower intercritical annealing temperature. At low intercritical annealing temperatures, the microstructure mostly consists of ferrite and a small amount of carbon-rich austenite [36]. The low intercritical annealing temperature and fairly short hold time may not be sufficient for the cementite in the initial ferrite/pearlite microstructure to fully dissolve $[3,106]$. Cementite is a specific carbide $\left(\mathrm{Fe}_{3} \mathrm{C}\right)$ in the steel, and its dissolution into austenite depends on the diffusion of carbon; hence, the rate is lower at lower annealing temperatures [17]. Consequently, the carbides that are present in the equiaxed-750 microstructure are either a result of cementite not being completely dissolved during the intercritical anneal or precipitation during cooling to the bainite temperature range. The carbon that is trapped in the carbides is not available to be partitioned into the remaining austenite during the bainite hold, thus destabilizing the austenite [10]. As a result, less RA is retained in the final microstructure.

The final equiaxed-750 microstructure is made up of blocky grains of M/RA in a matrix of ferrite with carbides spread throughout the matrix. According to magnetic measurements, the equiaxed-750 microstructure consisted of $12.4 \%$ RA. However, the accuracy of this measurement is affected by the presence of carbides. Carbides have a lower magnetic saturation than ferrite, thus reducing the overall magnetic saturation of the specimen [75]. This effect, however, was not taken into account during the 
analysis of the measurements so the reduction in the magnetic saturation is assumed to be due to the presence of RA, which results in an overestimation in the volume fraction of RA.

The carbon content in the RA phase was also expected to be lower than in any of the other microstructural variants tested because the carbon is trapped in the carbides. The RA carbon content was found to be between $0.31 \mathrm{wt} . \% \mathrm{C}$ and $1.51 \mathrm{wt} . \% \mathrm{C}$. XRD measurements are also affected by the presence of carbides because carbides produce reflections that interfere with the ferrite and austenite diffraction peaks [96]. Several carbide peaks were observed in the diffraction pattern of the specimen; however their intensities were so low that they could be considered background noise in the data. It is possible that the RA volume fraction measurements calculated from the integrated intensities of the diffraction peaks were affected by the carbide reflections, but the carbon content measurements were derived from the relative positions of the peaks, which appeared to be unaffected by the carbide diffraction pattern.

\subsubsection{Lamellar-925 Microstructure}

Similar to the lamellar-875 microstructure, the lamellar-925 microstructure followed the three-step heat treatment with an austenitizing step, an intercritical anneal and a bainite hold. The main difference is that the lamellar-925 microstructure had a higher intercritical annealing temperature, which means there is more austenite with a lower carbon content in the microstructure during the intercritical anneal. And because the thermodynamic driving force for nucleation decreases as the austenite carbon content increases, more bainite is able to form in austenite with a lower 
carbon content [58]. Consequently, the lamellar-925 microstructure has more bainite than the lamellar-875 microstructure. The M/RA grains are mostly elongated, although there are a few equiaxed RA grains. The bainite and M/RA are predominantly located at prior martensite lath boundaries, and most of the M/RA grains are surrounded by bainite. Again, the more blocky RA grains were the ones located near ferrite grains, which has been observed elsewhere [105]. Magnetic and XRD measurements revealed that the lamellar-925 microstructure had about 14.0\% RA with an austenite carbon content ranging from $1.32 \mathrm{wt} . \% \mathrm{C}$ to $1.93 \mathrm{wt} . \% \mathrm{C}$.

\subsubsection{Texture}

Although all of the microstructural variants originated from the same cold-rolled sheet material, the texture is slightly different between the equiaxed and lamellar microstructures. The values of integrated intensity for each individual peak were normalized against an expected theoretical intensity and compared between the microstructural variants. All ferrite peaks followed similar trends in the microstructural variants, where the (110) $\alpha$ peak had the lowest intensity of the three peaks and (211) $\alpha$ had the highest. However, the austenite showed a slightly different trend in the equiaxed-875 microstructures when compared to the lamellar-875 microstructures. Specifically, the (111) $\gamma$ peak had a significantly higher intensity in the equiaxed-875 microstructure than the lamellar-875 microstructure and the $(220) \gamma$ peak was much lower in the equiaxed-875 microstructure. These two peaks in the microstructural variants are shown in Figure 5.1. Similar trends were also observed in the equiaxed750 microstructure and the lamellar-925 microstructure. 


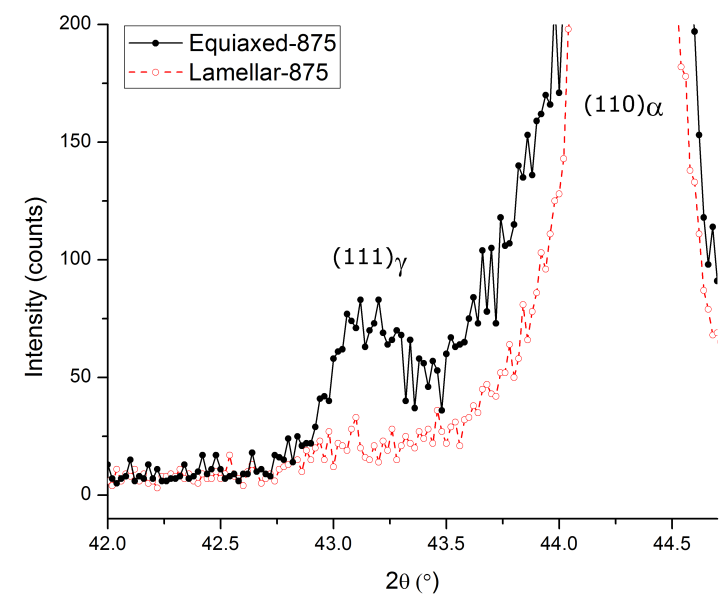

(a)

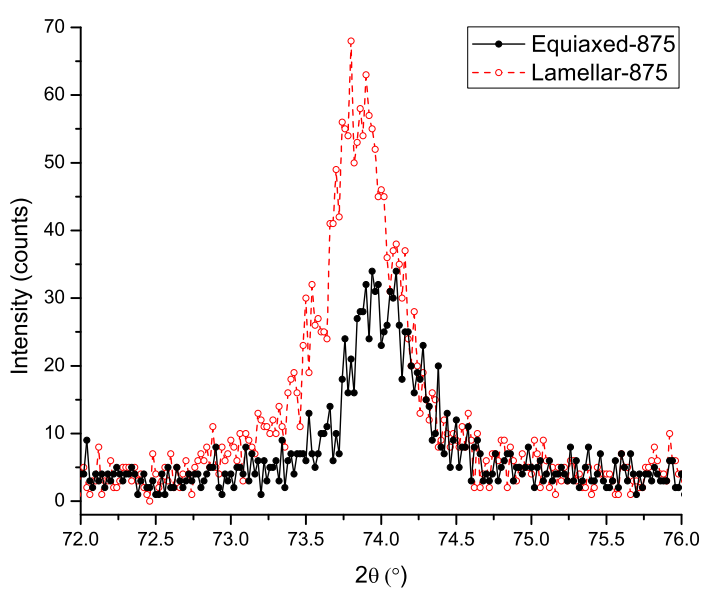

(b)

Figure 5.1: X-ray diffraction pattern for (a) the (111) $\gamma$ peak and (b) the $(220) \gamma$ peak in the equiaxed-875 and lamellar-875 microstructures.

\subsection{Retained Austenite Volume Fraction Measurement Techniques}

Magnetic measurements were the primary means of measuring the RA volume fraction in this investigation. However, XRD measurements were also conducted on a few samples for comparison. Both methods were able to show similar trends in the microstructures, but there were some discrepancies between results of the two techniques. The XRD measurements were consistently 4\%-5\% lower than the magnetic measurements, which is an effect that has been observed in previous studies that compare XRD and magnetic measurements $[42,75,95]$. The XRD results may be lower than the magnetic results due to the sample preparation procedure where some RA may have transformed during the grinding and polishing procedure [42]. This discrepancy between the two RA measurement techniques must therefore be taken 
into account when comparing volume fractions of RA that are quoted in previous literature.

The XRD measurements tended to have larger uncertainty values than the magnetic measurements; this difference in standard deviation has also been observed in previous studies [95]. The large XRD experimental error is mainly due to the sample texture and consequently the calculated values varied from peak to peak. The uncertainty associated with XRD measurements would be significantly smaller if the measurements were conducted on a sample with a randomly-oriented texture because the results themselves are very reproducible [96]. One way to reduce the texture effects would be to perform an average of the intensities for a large number of diffraction peaks; however, this method cannot be used for heavily textured materials [107]. A better alternative to this method is to simultaneously tilt and rotate the specimen in the path of the beam [108]. This maneuvering allows for many orientations of the specimen to be brought into position for diffraction and to make a contribution to the diffracted intensity. However, this technique is not easy to perform because the surface of the specimen needs to be completely flat so that the surface is exactly in the plane defined by the incident and reflected beams.

$\mathrm{XRD}$ is a surface technique that measures a very small area whereas magnetic measurements samples a much larger volume for the bulk properties [95]; the sample volume for XRD is on the order of hundreds of cubic microns versus the sample volume of hundreds of cubic millimeters for the magnetic measurements. The smaller sample volume in the XRD method could also lead to higher uncertainties because the RA is not distributed homogenously throughout the steel - the spatial variation within the microstructure would affect the XRD measurements depending on where the specimen was tested. Moreover, the MSAT measurements were a result of averaging 
about thirty samples, whereas the XRD measurements are only for one. The XRD results would most likely produce a much larger uncertainty if more samples were tested because of sample-to-sample variation.

Magnetic measurements tend to be easier to conduct because they do not require a lot of sample preparation, only that any oxides are removed from the surface. XRD, on the other hand, requires a significant amount of sample preparation in terms of grinding and polishing, ensuring that the surface is as stress-free as possible and that the centre-line of the sheet sample is measured. The drawback to magnetic measurements is that they can only be used for volume fraction measurements, where diffraction data can be used to determine many other material properties, such as the carbon content, texture and internal stresses.

The volume fractions of RA can also be determined using optical micrographs, although it is generally agreed that this method has low accuracy when compared to the many other techniques that are commonly used, such as XRD, magnetic measurements and Mössbauer spectroscopy [109]. In most cases, the optical contrast of bainite, martensite, RA and carbides is not sufficient to obtain an accurate result. The accuracy decreases even further when there is less than $10 \% \mathrm{RA}$ in the microstructure or when the RA is in the form of a thin film between ferrite laths [110]. 


\subsection{Tensile Behaviour and Retained Austenite Transformation Behaviour}

\subsubsection{Variants with Similar Volume Fractions of Retained Austenite}

As described in Section 4.1.2, the equiaxed-875 microstructure exhibited a higher UTS than the lamellar-875 microstructure, an interesting tensile response since both microstructural variants have the same initial volume fraction of RA. The lamellar875 microstructure also has a higher volume fraction of stronger phases (i.e. martensite and bainite) than the equiaxed-875 microstructure, which should help to increase the strength due to the composite strengthening effect that is typically observed in these multi-phase steels [36]. A possible reason that the lamellar-875 microstructure has a lower UTS value is that $20 \%$ of the initial RA volume fraction remains untransformed after failure of the sample. In other words, the percentage of RA that is actively contributing via the TRIP effect is lower in the lamellar-875 microstructure versus the equiaxed-875 microstructure.

This $20 \%$ of the initial RA volume fraction that does not transform under mechanical deformation is considered to be over-stabilized, and many other studies have reported similar observations $[8,18,45,111,112]$. Specifically, Mark et al. [8] observed approximately $2 \%$ RA remaining after tensile deformation in both their equiaxed microstructure and their acicular (lamellar) microstructure. The majority of these studies investigated silicon-alloyed TRIP steels, although there are a few studies that have also observed this phenomenon in aluminum-alloyed TRIP steels, with compositions of about $1.8 \mathrm{wt} . \% \mathrm{Al}-0.2 \% \mathrm{Si}[111,112]$. All of these studies had results showing 
evidence of some over-stabilized RA with anywhere from $20 \%$ to about $50 \%$ RA remaining after deformation. All of these volume fraction measurements were conducted either using X-ray or neutron diffraction and the initial volume fraction of RA in the samples ranged from about $6 \%$ to $10 \%$. On the other hand, in TRIP steels with compositions of $1.5 \mathrm{wt} . \% \mathrm{Si}$ and $1 \mathrm{wt} . \% \mathrm{Al}-0.5 \mathrm{wt} . \% \mathrm{Si}$, cases where $100 \%$ of the RA transforms during mechanical deformation have been observed $[67,113]$. In contrast to the results presented by Mark et al., specimens of silicon-alloyed TRIP steels were reported to have complete transformation of the RA after deformation in both the equiaxed and the lamellar microstructures [113]. These studies used XRD and magnetic measurements to determine the volume fraction of RA and had samples with initial RA volume fractions ranging from $10 \%$ to $18 \%$. Consequently, there does not appear to be a definite trend differentiating those samples that had over-stabilized RA versus those that did not in terms of their chemical composition, measurement technique and heat treatment path.

A possible explanation for this untransformed RA effect is the orientation of the RA grains and the texture of the RA phase. Studies have observed evidence of the orientation of a RA grain affecting its transformation behaviour, where certain orientations such as the $<100>$ direction along the loading direction transform preferentially $[111,114,115]$. Figure 5.2 shows a schematic of the angle between the normal to the diffracting plane and the direction of the applied stress $(\eta)$ and its effect on the RA volume fraction as a function of applied strain. Figure 5.2b shows some variation in the initial volume fraction of RA, indicating the presence of a texture for the RA. Most notably, values of $\eta$ such as $0^{\circ}$ or $90^{\circ}$ show significantly more mechanicallyinduced transformation of RA than angles such as $45^{\circ}$ or $60^{\circ}$. And generally, the $45^{\circ}$ or $60^{\circ}$ angles are the ones that are closest to those of conventional XRD setups [114], 


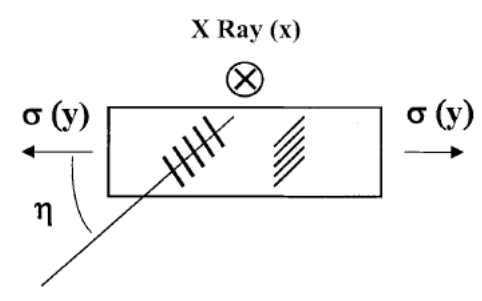

(a)

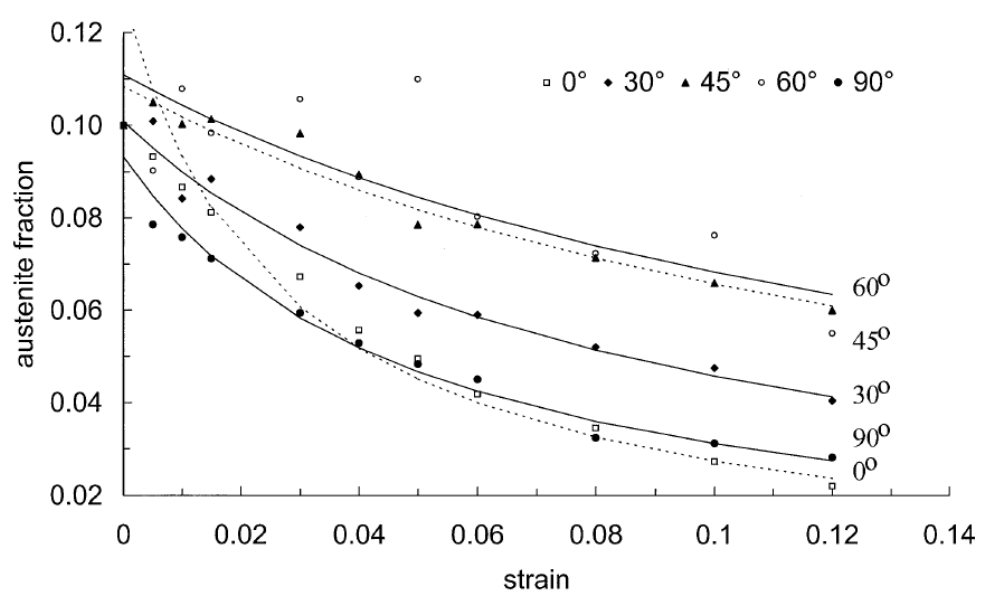

(b)

Figure 5.2: (a) Schematic showing the definition of $\eta$ and (b) the RA fraction as a function of applied strains for various values of $\eta$. The point labelled $\mathrm{X}$-ray is the X-ray source, $\sigma(y)$ is the applied stress, and the parallel lines are the diffracting planes [114].

which could be a reason as to why so many previous studies have shown evidence of over-stabilized RA. However, the results shown for lamellar-875 microstructure in the present work cannot be explained by the orientation of the sample in the diffraction experimental setup because the measurements were conducted via magnetic means. Hence, the over-stabilized RA in the lamellar-875 microstructure is due to microstructural stabilizing effects such as RA grain size or orientation of the RA grains. To explore this subject in more detail, the sample should be mechanically tested in several different orientations. Uniaxial tensile tests were only conducted in the rolling direction (RD) of the sheet, but testing in the transverse or at $45^{\circ}$ to the RD may lead to more or less RA transforming during deformation.

The lamellar-875 microstructure has a higher UTS $\times$ El value than the equiaxed875 microstructure as calculated from the engineering stress-strain curves (Figure 4.8) despite the fact that the two microstructural variants have the same initial volume 
fraction of RA. Taking into account the $20 \%$ of initial RA that remains untransformed after deformation, the lamellar-875 microstructure actually has a lower volume fraction of RA that actively participates in the TRIP effect. This result suggests that the UTS $\times$ El value is in fact more heavily influenced by the RA stability, or the RA-tomartensite transformation rate, than the volume fraction of RA alone, which agrees with previous literature [67].

The work hardening behaviour of a TRIP steel can be directly related to the RAto-martensite transformation rate. The transformation rate can be calculated from the RA transformation curves in Figure 4.11 by fitting the data with a growth function and subsequently taking the derivative. The transformation kinetics are more commonly fitted using an exponential function [67]. However, an exponential function does not describe the RA transformation behaviour very well at very small strains; an exponential fit would suggest that the highest RA transformation rate would in fact occur at next to zero applied strain. Furthermore, studies have shown that the transformation kinetics appear more distinctly sigmoidal in shape for higher temperature tests [116]. Thus, a Weibull function was chosen to fit the RA transformation curves because it is the growth function most similar to the exponential function previously used by Shi et al. [67]. A Weibull function is of the form:

$$
y=A\left(1-e^{-(b(x-c))^{d}}\right) .
$$

The calculated transformation rate and values for instantaneous $n$ are plotted against true strain in Figure 5.3. These two plots show a few very distinctive similarities. Firstly, the peak height of the equiaxed-875 microstructure is larger than that of the lamellar-875 microstructure for both the transformation rate and the work hardening rate plots. Secondly, the strains at which the peaks occur correspond for 


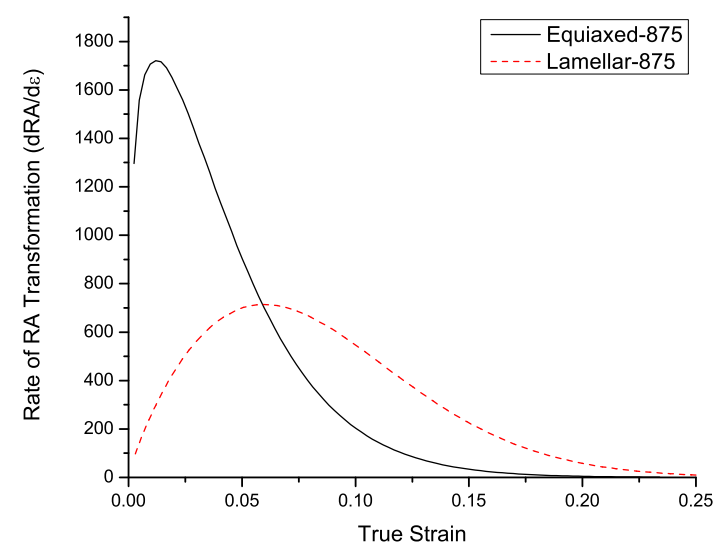

(a)

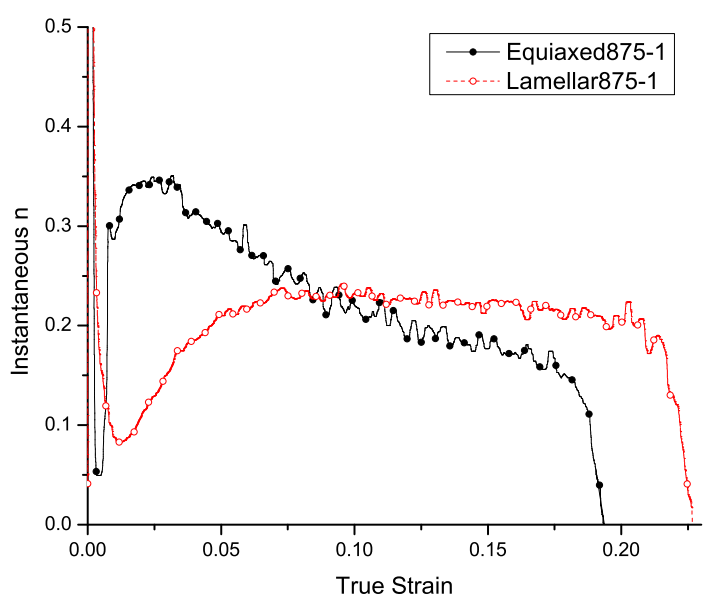

(b)

Figure 5.3: Relationship between (a) transformation rate and (b) instantaneous $n$ as plotted against true strain for equiaxed-875 and lamellar-875 microstructures.

both the transformation rate and the work hardening rate. This correspondence suggests that a higher transformation rate is directly related to a higher work hardening rate. Additionally, the decaying slope of the transformation rate after the peak value is steeper in the equiaxed-875 microstructure than the lamellar-875 microstructure. A similar trend can be seen in the instantaneous $n$ plot where the equiaxed-875 microstructure has a higher negative slope than the lamellar-875 microstructure, which exhibits a very flat, almost horizontal slope. And finally, the strains at which the transformation rate drops essentially to zero are the same values at which the work hardening response is exhausted. Such a strong correspondence between these two plots indicates that the RA transformation rate in TRIP steels directly influences the work hardening behaviour. 


\subsubsection{Variants with Similar Ultimate Tensile Strengths}

The uniaxial stress-strain curves of the equiaxed-750 microstructure and the lamellar925 microstructure exhibit two distinctive shapes. Specifically, the equiaxed-750 microstructure exhibits discontinuous yielding and has a steeper slope while having a slightly lower UTS and lower total elongation. This tensile behaviour can mostly be attributed to the carbides and the lack of bainite in the equiaxed-750 microstructure. Carbides in the microstructure destabilize the RA, leading to less austenite retained in the initial microstructure as well as unstable RA that will transform at earlier strains [10]. This reduced TRIP effect, coupled with the lack of the stronger bainite phase in the microstructure, leads to the lower strength and lower ductility [71].

The lower intercritical annealing temperature led to the appearance of discontinuous yielding, which is an effect that has been reported in previous studies with TRIP steels [117]. Discontinuous yielding is related to an insufficient mobile dislocation density in the microstructure $[118,119]$. Gibbs et al. [117] found that samples heat treated at lower intercritical annealing temperatures exhibited discontinuous yielding and lower UTS values. The defined yield point is also usually followed by an initial increase in the work hardening rate. Additionally, bainite has a significantly higher dislocation density than ferrite because of the shear mechanism by which bainite is formed [58]. Consequently, the absence of any bainite phase and its associated dislocations may contribute to the discontinuous yielding behaviour in the equiaxed-750 microstructure.

The shape of the engineering stress-strain curves can be better examined us-

ing plots of the work hardening rate, either $d \sigma / d \epsilon$ or instantaneous $n$. Focusing on instantaneous $n$ plotted against true strain in Figure 5.4b, the equiaxed-750 
microstructure shows very good work hardening properties up to strains of about 0.15 , despite having a relatively low UTS and a low uniform elongation value. The rate of RA transformation was also calculated from a growth function fitted to the magnetic RA measurements and plotted against true strain alongside the plot of instantaneous $n$ in Figure 5.4a. According to these graphs, the equiaxed-750 microstructure exhibits very high values of work hardening rate (between 0.36 and 0.2 ) until it reaches failure, which corresponds with the high RA transformation rate. The maximum value of $n_{\text {inst }}$ occurs around a strain of 0.05 , which is the same value of strain at which the maximum transformation rate occurs. Both the work hardening rate and the RA transformation rate begin to deteriorate soon thereafter, but appear to out-perform the lamellar-925 microstructure until a strain of 0.15. In contrast, the lamellar-925 microstructure has a lower maximum RA transformation rate and the decaying slope

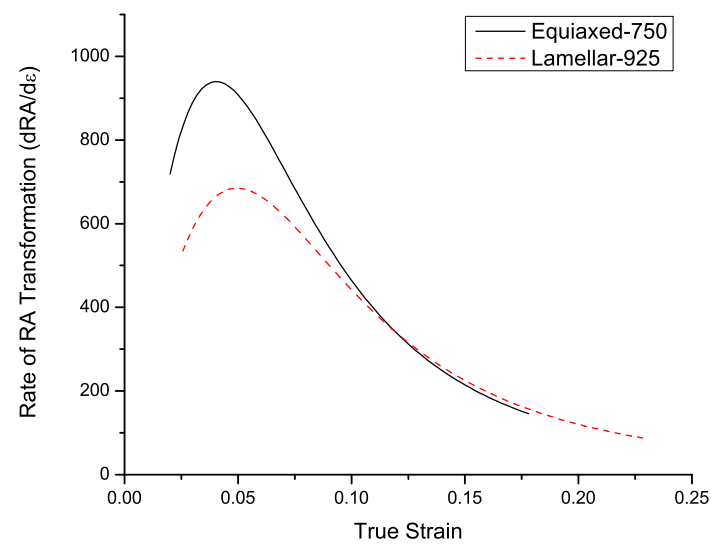

(a)

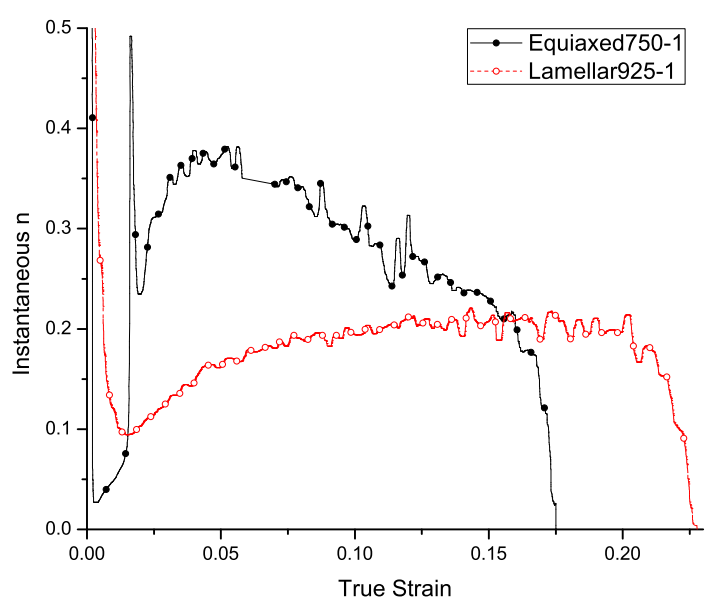

(b)

Figure 5.4: Relationship between (a) transformation rate and (b) instantaneous work hardening exponent, $n_{\text {inst }}$, as plotted against true strain for equiaxed-750 and lamellar-925 microstructures. 
is much gentler than the equiaxed-750 microstructure, which agrees with the very flat, sustained work hardening behaviour that plateaus around a value of 0.2.

Over-stabilized RA was also observed in the lamellar-925 microstructure, where about $20 \%$ of the initial RA remained untransformed even after failure of the sample. Similar to the lamellar-875 microstructure, this is most likely due to microstructural factors affecting the RA stability or the orientation of the RA grains within the microstructure because certain grain orientations are more susceptible to mechanicallyinduced deformation [115]. These microstructural factors will be discussed in greater detail in Section 5.4.

\subsection{Microstructural Effects on Retained Austenite Stability}

\subsubsection{Variants with Similar Volume Fractions of Retained Austenite}

The equiaxed-875 microstructure and the lamellar-875 microstructure had the same volume fractions of RA but their microstructures led to a difference in RA stability, which dictates the transformation behaviour and the work hardening rate. The effects of certain microstructural features on the RA stability will be examined using results from image analysis.

The RA stability was examined through the RA-to-martensite transformation rate, that is, RA with higher stability has a slower, more gradual transformation rate. The equiaxed-875 microstructure exhibits a faster rate of transformation when compared to the lamellar-875 microstructure. Furthermore, all of the RA transforms 
during tensile deformation in the equiaxed-875 samples whereas the lamellar-875 samples have about $20 \%$ of the RA that remains untransformed even at failure. These differences are most likely due to a combination of several factors, including the size, aspect ratio and carbon content of the RA grains, as well as the spatial distribution of phases within the microstructure.

Grain size affects the thermal stability of each RA grain because of its effect on lowering the $\mathrm{M}_{s}$ temperature and having fewer defects to act as nucleation sites [48]. This effect can even be observed qualitatively in some micrographs with very large M/RA islands and very small M/RA grains. Figure 5.5 has two SEM micrographs that show several large M/RA grains next to a few small ones in an undeformed specimen. The very large islands distinctly show the substructure indicating that it is the martensite phase whereas the smaller islands are smooth and thus RA [85]. The large grains have already transformed to martensite even in the undeformed state and are therefore less thermally stable than the smaller islands which have not yet undergone transformation.

The grain size is a large factor affecting RA stability, but the image analysis results show that the M/RA grain size distributions in the equiaxed-875 microstructure and the lamellar-875 microstructure are very similar (refer to Figure 4.4). Because the two microstructural variants have such a similar M/RA grain size distribution, grain size does not appear to be one of the main contributing factors to the greater RA stability in the lamellar-875 microstructures.

Apart from the RA grain size, the morphology of the grains also has an effect on the stability. Specifically, more elongated RA islands are more stable because many small martensite laths are needed to compensate for the grain shape, which increases the interfacial energy component of the martensite transformation [52, 55]. Image 


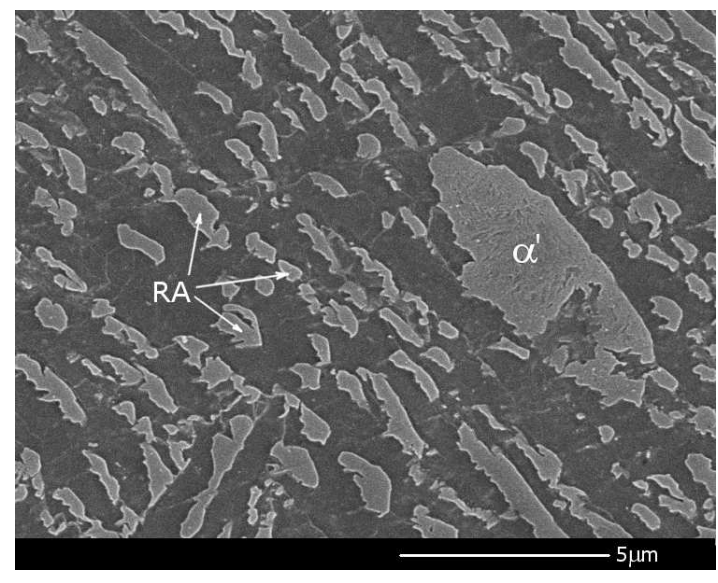

(a)

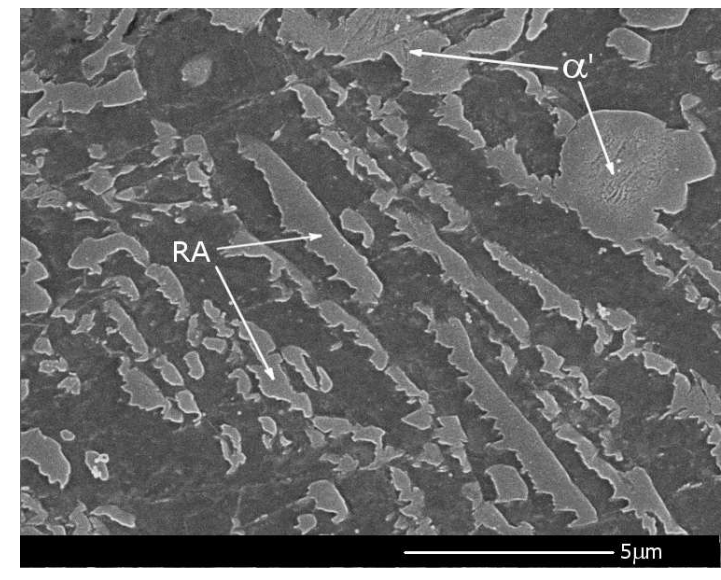

(b)

Figure 5.5: SEM micrographs showing small RA grains and large martensite grains in an undeformed specimen. $\alpha^{\prime}$ is martensite and RA is retained austenite.

analysis was conducted on optical micrographs of the equiaxed-875 microstructure and the lamellar-875 microstructure to determine the aspect ratios of the M/RA grains. In Figure 4.5, the distributions of the aspect ratios show that the lamellar875 microstructure has more M/RA grains with high aspect ratios, which would contribute to the higher RA stability that is observed.

The two microstructural variants also exhibit different spatial distributions of phases, specifically the bainite phase (refer to Figure 4.7). RA grains surrounded by a hard bainite phase will be more stable than those surrounded by soft ferrite grains because the RA would experience less load, and therefore, transform later in the deformation process due to a stress shielding effect [57]. The equiaxed-875 microstructure has some blocky M/RA grains that are surrounded by ferrite and some that are surrounded by bainite whereas the majority of the M/RA grains in the lamellar-875 microstructure are surrounded by bainite, especially the more needle-like RA. Similar observations have also been reported elsewhere where the more needle-like RA is 
predominantly surrounded by bainite while blocky RA is typically located between other phases $[105,120]$. The bainite surrounding the RA grains in the lamellar-875 microstructure would help to stabilize the RA in comparison to the equiaxed-875 microstructure.

Finally, the chemical stability of the austenite phase is often considered to be one of the most important factors controlling RA stability because of its effect on the thermal stability, or $\mathrm{M}_{s}$ temperature [53]. In particular, the carbon content of the RA was measured in the microstructural variants and reported in Table 4.2. Although each of the austenite diffraction peaks had different absolute values of carbon, the relative carbon content could still be compared between the equiaxed-875 microstructure and the lamellar-875 microstructure. Each of the four diffraction peaks were compared to the same peak in the other variant. In doing so, the lamellar-875 microstructure was observed to have RA with a higher carbon content than the equiaxed-875 microstructure, thus helping the RA phase to be more stable. It should also be taken into consideration that the RA carbon content may not be the same between individual grains. The carbon content is not homogeneous throughout the microstructure and XRD measurements only provide an average value of the carbon content within all of the RA grains for a sample [95]. The chemical stability of RA varies from grain to grain depending on where it is located within the microstructure, so XRD measurements can only be used for a general comparison. For a good representation of the local RA chemical stability, other techniques like TEM would be required [121].

The comparison between the equiaxed-875 microstructure and the lamellar-875 microstructure indicate that several factors contribute to the higher RA stability in the lamellar-875 microstructure: the higher RA aspect ratio, the surrounding bainite phase and the higher carbon content. All three of these factors are contributing 
to the difference in RA stability and these microstructural effects may have led to the $20 \%$ over-stabilized RA in the lamellar-875 microstructure. The lamellar-875 microstructure has about $11 \%$ of the M/RA grains with an aspect ratio greater than 4.5, a value above which the RA is expected to not transform [53]. The carbon content of the RA in the lamellar-875 microstructure is below $1.8 \mathrm{wt} . \% \mathrm{C}$ so all of the RA is expected to transform if only the austenite carbon content is considered [60]. Each individual effect alone is not enough to explain the large percentage of untransformed RA, but the combination of the three factors could be sufficient to stabilize the RA to the extent observed.

\subsubsection{Variants with Similar Ultimate Tensile Strengths}

It is a little more difficult to compare the RA stability of the equiaxed-750 microstructure and the lamellar-925 microstructure because there are so many variables that are different between the two variants. Not only is the ferrite matrix a different morphology, but the volume fractions of RA are also different, as well as the phases that are present in the microstructure. Nevertheless, the same four stabilizing factors will be discussed for these two variants just as it was for the equiaxed-875 and lamellar-875 microstructures in Section 5.4.1.

The grain size distribution of the M/RA grains were determined using image analysis of the equiaxed-750 and lamellar-925 microstructures, shown in Figure 4.14. The resulting histogram shows that the lamellar-925 microstructure tends to have smaller M/RA grains than the equiaxed-750 microstructure, with the majority of the $\mathrm{M} / \mathrm{RA}$ grains having a grain diameter less than $0.5 \mu \mathrm{m}$. RA grains that are smaller will have fewer sites for martensite nucleation and are therefore less likely to undergo 
the RA-to-martensite transformation, making smaller grains more stable [52]. The smaller grains in the lamellar-925 microstructure would help to promote increased RA stability when compared to the equiaxed-750 microstructure.

Furthermore, the lamellar-925 microstructure has more elongated M/RA grains than the equiaxed-750 microstructure (shown in Figure 4.15). This is important because the stability of RA grains is related to their aspect ratios. Because of the nature of the martensitic transformation, elongated grains raise the interfacial energy component of the energy required for the transformation, making these grains more stable [55]. Thus, the higher amount of elongated RA grains in the lamellar-925 microstructure would contribute to an overall higher RA stability.

The bainite phase is considered to be stronger than ferrite due to its higher carbon content and dislocation density [58]. Hence, the presence of bainite in the lamellar925 microstructure helps to increase the strength of the steel. Bainite can also help to further stabilize the RA when it is located near RA grains because of a stress shielding effect where the bainite will carry most of the load and yield later in the deformation process than ferrite [57]. The equiaxed-750 microstructure does not contain any bainite phase, so the matrix is completely comprised of ferrite. The soft ferrite phase will yield at fairly low strains and consequently shed the load onto the RA, leading to earlier transformation during deformation.

The equiaxed-750 microstructure has RA with much lower carbon content than the lamellar-925 microstructure (refer to Table 4.7). Most likely, the low RA carbon content in the equiaxed-750 microstructure is a result of the carbides that formed in the ferrite matrix. The carbides trap the carbon that would have otherwise been in the austenite phase [10]. Consequently, the RA in the equiaxed-750 microstructure has a higher $\mathrm{M}_{s}$ temperature and is less thermodynamically stable. It is also expected 
that the RA of the lamellar-925 microstructure has a slightly higher carbon content than the lamellar-875 microstructure because it has a lower volume fraction of RA. Carbon is generally distributed within the austenite phase that remains during heat treatment processing, so of two steels with the same chemical composition, the one with less RA will have a higher carbon concentration in that phase.

In exploring the RA stability of these two microstructural variants, it was found that the lamellar-925 microstructure had many factors contributing to its higher RA stability in comparison to the equiaxed-750 microstructure. The grain size effect, aspect ratio, spatial distribution of bainite and the RA carbon content all promoted more stable RA in the lamellar-925 microstructure. These factors have also led to about $20 \%$ of the initial RA volume fraction being over-stabilized. If RA grains above an aspect ratio of 4.5 do not contribute largely to the TRIP effect, then about $14 \%$ of the M/RA grains in the lamellar-925 microstructure could be considered overstabilized [53]. The carbon content of the lamellar-925 microstructure is also bordering the ideal RA carbon concentration of less than $1.8 \mathrm{wt} . \% \mathrm{C}$, where the (111) $\gamma$ peak and the $(200) \gamma$ peak give calculated carbon contents of $1.77 \mathrm{wt} . \% \mathrm{C}$ and $1.93 \mathrm{wt} . \% \mathrm{C}$, respectively [60]. Thus, it is expected that some of the over-stabilized RA is caused by the high RA carbon content. The large volume fraction of over-stabilized RA cannot be accounted for by considering each individual stabilizing factors alone; rather, it is more likely a result of the combined effect of all of them.

\subsection{Aluminum- versus Silicon-Alloyed TRIP Steel}

To examine how the performance of this aluminum-alloyed composition of TRIP steel compares with the traditional silicon-alloyed composition, the results from a 
previous study were considered [113]. This previous work investigated the equiaxed and the lamellar microstructures in a silicon-alloyed TRIP steel. Representative engineering stress-strain curves of the equiaxed-875 microstructure and the lamellar875 microstructure were plotted on the same graph as the equiaxed and lamellar microstructures in the silicon TRIP steel, shown in Figure 5.6 and Table 5.1. For clarity, the equiaxed microstructure and the lamellar microstructure in the siliconalloyed TRIP steel will be referred to as Si-equiaxed and Si-lamellar microstructures, respectively.

As expected, there are several differences that can be directly attributed to the difference in chemical composition. The silicon TRIP steels have higher ultimate tensile strengths and lower elongation values due to the silicon's tendency to solid-solution strengthen the ferrite matrix [22]. When comparing the Si-equiaxed microstructure and the equiaxed-875 microstructure, the expected trade-off between strength and ductility is observed. However, the UTS $\times$ El values remain fairly constant, indicating that the strength-ductility balance is not affected, which is a result that has also been reported in previous studies [122]. Most notably, the lamellar-875 microstructure appeared to out-perform the Si-lamellar microstructure, with an increase of about $5000 \mathrm{MPa} \%$ in the UTS $\times \mathrm{El}$ value. Both of these variants have approximately the same UTS values, but the lamellar-875 microstructure had a significantly higher uniform elongation, with a strain of about 0.238 at UTS, whereas the silicon equiaxed microstructure had a strain of about 0.182 . 


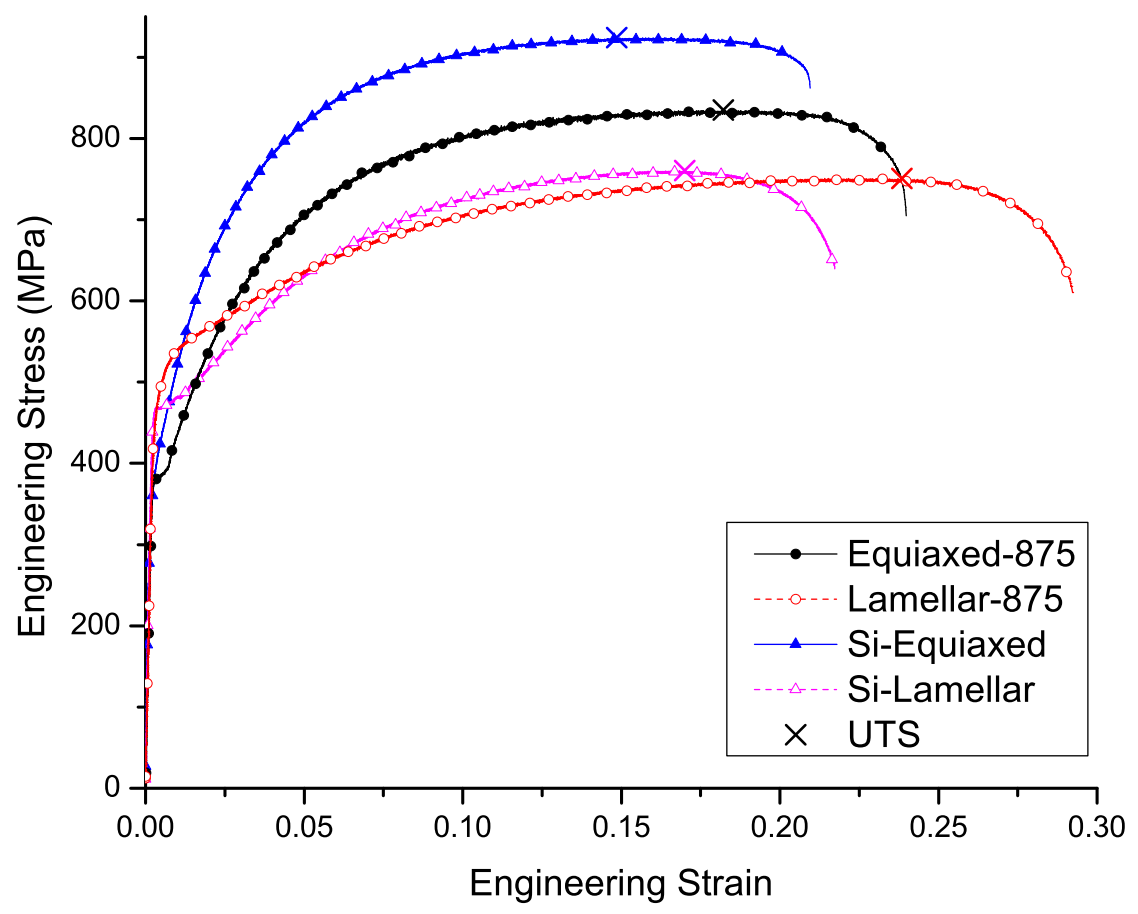

Figure 5.6: Representative engineering stress-strain curves for equiaxed-875, lamellar-875, Si-equiaxed and Si-lamellar microstructures.

Table 5.1: Tensile properties of samples of an aluminum TRIP steel and a silicon TRIP steel.

\begin{tabular}{cccccc}
\hline Sample & $\begin{array}{c}\text { Yield Strength } \\
(\mathrm{MPa})\end{array}$ & $\begin{array}{c}\text { UTS } \\
(\mathrm{MPa})\end{array}$ & $\begin{array}{c}\text { Engineering Strain } \\
\text { at UTS }\end{array}$ & $\begin{array}{c}\text { UTS } \times \text { El } \\
(\mathrm{MPa} \%)\end{array}$ & $\begin{array}{c}\% \mathrm{RA} \\
\%\end{array}$ \\
\hline Equiaxed-875 & 388 & 840 & 0.184 & 20700 & 16.5 \\
Lamellar-875 & 494 & 751 & 0.238 & 22000 & 16.3 \\
Si-Equiaxed & 406 & 924 & 0.149 & 19400 & 13.7 \\
Si-Lamellar & 470 & 760 & 0.170 & 16500 & 10.1 \\
\hline
\end{tabular}


The RA-to-martensite transformation behaviour for the same four variants were also plotted against true strain in Figure 5.7. The two equiaxed microstructures exhibit very similar RA transformation behaviours, although the equiaxed-875 microstructure does show a slightly slower transformation rate. Once again, the most distinctive difference appears between the lamellar-875 microstructure and the $\mathrm{Si}$ lamellar microstructure. The lamellar-875 microstructure exhibits a significantly slower RA transformation rate (or more stable RA) than the Si-lamellar microstructure. Furthermore, $20 \%$ of the RA remains untransformed after deformation in the lamellar-875 microstructure, whereas $100 \%$ of the Si-lamellar RA transforms. Taking into account the $20 \%$ of the RA that does not transform in the lamellar-875 microstructure, there is still about 13\% RA that actively contributes to the TRIP effect. This 13\% RA is still greater than the initial volume fraction of RA available in the Si-lamellar microstructure, which has only $10.1 \%$. Hence, it follows that the higher initial volume fraction of RA and the more stable RA contribute to the better mechanical properties of the lamellar-875 microstructure in comparison to the Si-lamellar microstructure.

The aluminum-alloyed TRIP steels were not only able to achieve comparable properties to the traditional silicon-alloyed TRIP steels, but they appear to improve upon those properties, particularly the increase in the ductility. This outcome suggests that the aluminum TRIP steels can provide a feasible option for replacing the silicon compositions. 


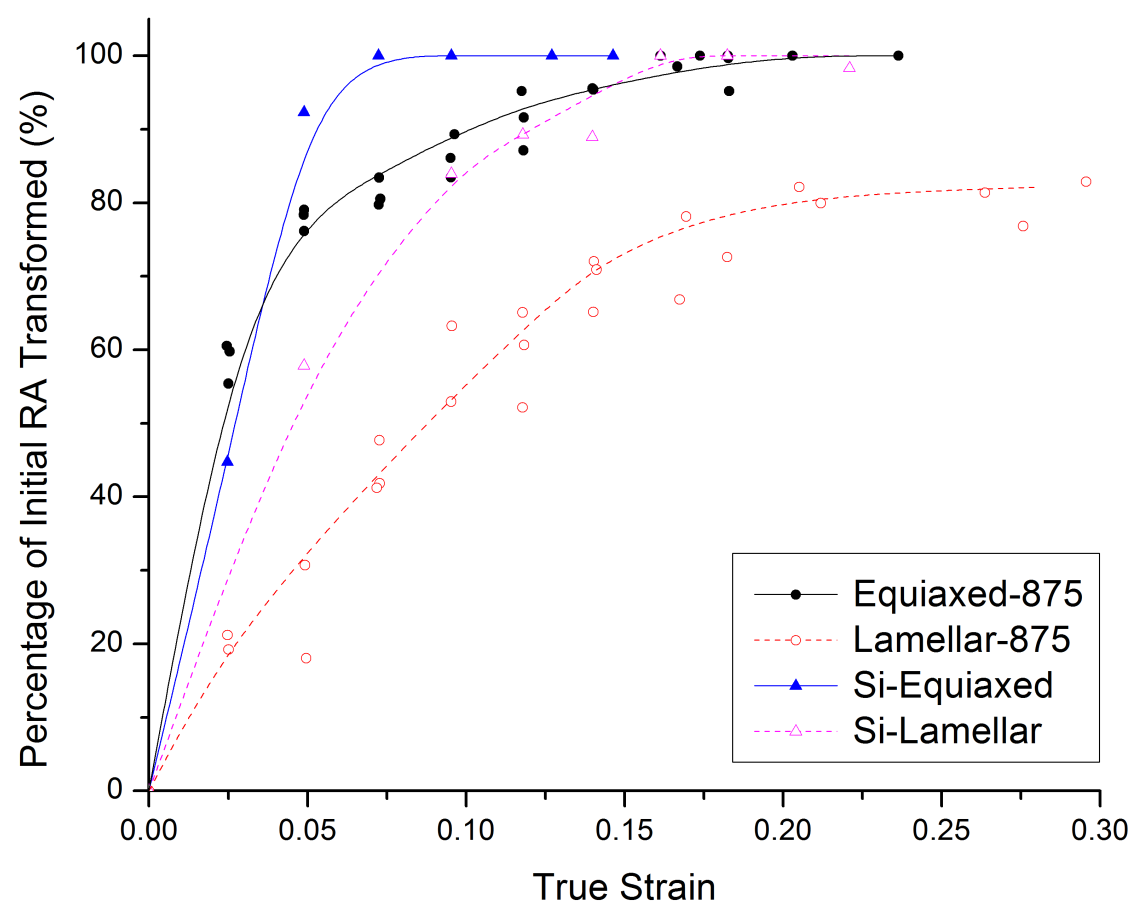

Figure 5.7: Percentage of initial RA transformed in equiaxed and lamellar microstructures for aluminum and silicon-alloyed TRIP steels. 


\section{Chapter 6}

\section{Conclusions and Recommendations}

The scope of this thesis focused on microstructural effects on uniaxial tensile properties and RA-to-martensite transformation behaviour in an aluminum-alloyed TRIP steel. Specifically, two distinct microstructural variants were studied. The equiaxed microstructure has a matrix of equiaxed ferrite grains separated by bainite and islands of M/RA. In contrast, the lamellar microstructure consists of elongated grains of ferrite separated by bainite, martensite and RA grains that are primarily located at prior martensite lath boundaries.

A set of samples was produced where the equiaxed and lamellar microstructures had similar initial volume fractions of RA, labelled as the equiaxed-875 microstructure and the lamellar-875 microstructure. The microstructures were characterized using microscopy, magnetic measurements and XRD. Interrupted uniaxial tensile tests and ex-situ magnetic measurements were conducted to examine the mechanical behaviour and the RA-to-martensite transformation behaviour. The same experimental procedure was also conducted on a set of samples with similar ultimate tensile strengths (equiaxed-750 microstructure and lamellar-925 microstructure). This second set was 
examined to provide a better comparison of mechanical properties and formability.

\subsection{Conclusions}

- The work hardening response is directly related to the RA-to-martensite transformation rate, where a higher RA transformation rate results in a higher work hardening rate. The graphs of the RA transformation rate and instantaneous $n$ as a function of true strain (Figures 5.3 and 5.4) exhibit a very strong correspondence. The relative heights and the strains at which the maxima occur are the same for both the transformation rate and the work hardening rate plots. The strains at which the transformation rate drops to zero are the same values at which the work hardening rate is exhausted.

- Both the lamellar-875 microstructure and the lamellar-925 microstructure exhibit a slower RA-to-martensite transformation rate than the equiaxed-875 microstructure and the equiaxed-750 microstructure. The higher RA stability that is characteristic of the lamellar microstructures results in a work hardening response that is more constant during uniform elongation and can therefore be sustained to higher values of strain. The instantaneous $n$ curves appear flatter and exhibit high $n_{\text {inst }}$ values even at high values of strain just before necking and failure. On the other hand, the equiaxed microstructures have a lower RA stability and consequently exhibit work hardening rates that are high at low strains, but are then quickly exhausted during uniform elongation. These results indicate that the lamellar microstructure has potential for use in formed components where further work hardening may be required after the initial forming process (such as in an automobile crash scenario), and should therefore be a focus for future work. 
- The product of UTS and total percent elongation provides a measure of the strength-ductility balance in TRIP steels and is usually directly related to the volume fraction of RA. However, the UTS $\times$ El values calculated for the lamellar microstructures are generally higher than the values for the equiaxed microstructures at any given volume fraction of RA (refer to Figure 4.22). This difference suggests that RA stability also has an effect on the UTS $\times$ El value where the slower RA-to-martensite transformation rate observed in the lamellar microstructures are promoting a better combination of strength and ductility.

- There are several microstructural factors that affect the RA stability, including RA grain size, RA grain aspect ratio, RA carbon content, and spatial distribution of the ferrite and bainite phases. However, there were two factors that appeared to be distinctly characteristic of the lamellar microstructure. Both the lamellar875 microstructure and the lamellar-925 microstructure contained more elongated M/RA grains than the equiaxed microstructures and had M/RA grains that were primarily surrounded by bainite. The lamellar microstructures mostly consisted of needle-like M/RA grains that lay on prior martensite lath boundaries. These grains were the ones predominantly surrounded by bainite. A few blocky M/RA grains were also observed in the lamellar microstructures, and they tended to be located near ferrite grains.

- RA can also be over-stabilized, a phenomenon observed in both the lamellar875 microstructure and the lamellar-925 microstructure. Approximately $20 \%$ of the RA in the lamellar microstructures was over-stabilized, and therefore, remained untransformed even at failure. This most likely occurred because of the many factors that contributed to stabilizing the RA, such as the ones discussed in 
Section 5.4 or the RA grain orientation with respect to the direction of applied load. The over-stabilized RA is not a desired effect because this untransformed RA does not contribute to improving the work hardening response, which means the TRIP steel does not benefit from having this RA in the microstructure.

- The results indicate that an aluminum-alloyed TRIP steel can achieve properties on par with, or better than, the traditional silicon compositions. Aluminum-alloyed TRIP steels typically have lower UTS and higher uniform elongation values than their silicon-alloyed counterparts, but the UTS $\times$ El values show that the strengthductility balance did not deteriorate. In the case of the lamellar microstructure, the aluminum-alloyed TRIP steel was also able to improve upon the properties, particularly in regards to increasing the ductility. The improvement in ductility is most likely due to the higher volume fraction of RA and the increased RA stability in the aluminum-alloyed lamellar microstructure. These results show that the aluminum compositions have potential as a feasible replacement for conventional silicon compositions in industry.

\subsection{Recommendations for Future Work}

Several suggestions for elaborating on the work of this thesis were mentioned during discussion of the results. Some recommendations for future work include:

- Uniaxial tensile tests that are conducted in different directions other than the RD of the sheet to explore how the RA grain orientations affect its mechanical stability. These tests would allow for a better explanation of the over-stabilized RA that was observed in the lamellar-875 and lamellar-925 microstructures. 
- Mechanical testing that studies a strain path other than uniaxial tension, such as compression, bending, in-plane plane strain or hole expansion tests to explore how the mechanical response and RA-to-martensite transformation behaviour is affected by a more complex strain path.

- High strain rate testing to investigate the effect of strain rate on both the mechanical response and the RA transformation behaviour. Previous literature has investigated the effect of high strain rates on the equiaxed TRIP microstructure, and reported that TRIP steels have a positive strain rate dependence; higher strain rates lead to higher yield strengths, higher strengths and higher energy absorption [123-125].

- RA volume fraction measurements using XRD where the sample is simultaneously tilted and rotated in the path of the X-ray beam. This experimental setup would better mitigate the effect of texture and provide a more accurate result.

- A full texture analysis of the specimens to better explore its effects on the RA transformation.

- In-situ neutron diffraction measurements to monitor the RA-to-martensite transformation and to examine load partitioning between the various microstructural phases during deformation.

- Measurements to determine the local carbon content of RA grains using methods such as TEM. The carbon content in the RA phase is not homogeneous throughout the microstructure, and local carbon concentration measurements would provide more detail on the stability of individual RA grains. 


\section{CHAPTER 6. CONCLUSIONS AND RECOMMENDATIONS}

- Investigation of variants with starting microstructures other than ferrite/pearlite (such as the equiaxed microstructure) and martensite (as in the case for the lamellar microstructure), such as tempered martensite. Goel et al. [44] observed excellent properties in a dual-phase steel that had a starting structure of tempered martensite, and a similar microstructural variant could be designed for TRIP steels.

- Examination of the fracture properties and damage mechanisms in TRIP steels, specifically its relationship to the RA-to-martensite transformation. Some work has been conducted on this topic, but only considering the equiaxed microstructure $[46,126,127]$. 


\section{References}

[1] H Helms and U Lambrecht. The potential contribution of light-weighting to reduce transport energy consumption. International Journal of Life Cycle Analysis, (Special 12):58-64, 2007.

[2] WorldAutoSteel. Advanced High Strength Steel (AHSS) Application Guidelines. Technical Report v. 4.1, 2009.

[3] B C De Cooman. Structure-properties relationship in TRIP steels containing carbidefree bainite. Current Opinion in Solid State $\&$ Materials Science, 8(3-4):285-303, 2004 .

[4] A Mark. Microstructural Effects on the Stability of Retained Austenite in Transformation Induced Plasticity steels. PhD thesis, Queen's University, January 2008.

[5] WorldSteel Association. An Advanced High-Strength Steel Family Car, 2011.

[6] R Geyer. Parametric assessment of climate change impacts of automotive material substitution. Environmental Science \& Technology, 42(18):6973-6979, 2008.

[7] L Zhao, J Sietsma, and S van der Zwaag. Phase transformations and microstructural evolution in aluminium-containing TRIP steels. In P Neumann, D Allen, and E Tenckhoff, editors, Materials/Steels, volume 7 of Steels and Materials for Power Plants, pages 77-82, Weinheim, 1999. Wiley-VCH Verlag GmbH \& Co.

[8] A Mark, M Westphal, D Boyd, J McDermid, and D Embury. Microstructural design of multiphase advanced high strength steels. Canadian Metallurgical Quarterly, 48(3):237-245, 2009.

[9] S Thibaud, N Boudeau, and J C Gelin. TRIP steel: Plastic behaviour modelling and influence on functional behaviour. Journal of Materials Processing Technology, 177(1-3):433-438, 2006.

[10] W Bleck. Using the TRIP effect - the dawn of a promising group of cold formable steels. In B C De Cooman, editor, International conference on TRIP-aided high strength ferrous alloys, pages 13-23. GRIPS, 2002. 
[11] S M K Hosseini, A Zarei-Hanzaki, E Essadiqi, and S Yue. Effect of prior austenite characteristics on mechanical properties of thermomechanically processed multiphase TRIP assisted steels. Materials Science and Technology, 24(11):1354-1361, 2008.

[12] S Chatterjee, H S Wang, J R Yang, and H K D H Bhadeshia. Mechanical stabilisation of austenite. Materials Science and Technology, 22(6):641-644, 2006.

[13] P J Jacques, Q Furnemont, T Pardoen, and F Delannay. On the role of martensitic transformation on damage and cracking resistance in trip-assisted multiphase steels. Acta Materialia, 49(1):139-152, 2001.

[14] L Kaufman and M Hillert. Thermodynamics of Martensitic Transformations. In G B Olson and W S Owen, editors, Martensite, volume 1, pages 41-58. ASM International, 1992.

[15] B C De Cooman, L Barbe, J Mahieu, D Krizan, L Samek, and M De Meyer. Mechanical properties of low alloy intercritically annealed cold rolled trip sheet steel containing retained austenite. Canadian Metallurgical Quarterly, 43(1):13-24, 2004.

[16] H Takechi. Transformation hardening of steel sheet for automotive applications. JOMJournal of the Minerals Metals \& Materials Society, 60(12):22-26, 2008.

[17] R W K Honeycombe and H K D H Bhadeshia. Steels: Microstructure and Properties, volume 3. Butterworth-Heinemann, 2006.

[18] M R Berrahmoune, S Berveiller, K Inal, A Moulin, and E Patoor. Analysis of the martensitic transformation at various scales in TRIP steel. Materials Science and Engineering A-Structural Materials Properties Microstructure and Processing, 378(12):304-307, 2004.

[19] S J Kim, C G Lee, I Choi, and S Lee. Effects of heat treatment and alloying elements on the microstructures and mechanical properties of 0.15 wt pct $\mathrm{C}$ transformationinduced plasticity-aided cold-rolled steel sheets. Metallurgical and Materials Transactions A-Physical Metallurgy and Materials Science, 32(3):505-514, 2001.

[20] S Traint, E Werner, A Pichler, and P Stiaszny. Low-alloyed dual-phase and multiphase steel strip. In P Neumann, D Allen, and E Tenckhoff, editors, Materials/Steels, volume 7 of Steels and Materials for Power Plants, pages 71-76, Weinheim, 1999. Wiley-VCH Verlag GmbH \& Co.

[21] P J Jacques, E Girault, T Catlin, N Geerlofs, T Kop, S van der Zwaag, and F Delannay. Bainite transformation of low carbon Mn-Si TRIP-assisted multiphase steels: influence of silicon content on cementite precipitation and austenite retention. Materials Science and Engineering A-Structural Materials Properties Microstructure and Processing, 273:475-479, 1999. 
[22] E Girault, A Mertens, P J Jacques, Y Houbaert, B Verlinden, and J Van Humbeeck. Comparison of the effects of silicon and aluminum on the tensile behaviour of multiphase TRIP-assisted steels. Scripta Materialia, 44(6):885-892, 2001.

[23] Q Furnemont, M Kempf, P J Jacques, M Goken, and F Delannay. On the measurement of the nanohardness of the constitutive phases of TRIP-assisted multiphase steels. Materials Science and Engineering A-Structural Materials Properties Microstructure and Processing, 328(1):26-32, 2002.

[24] C N Jing, D W Suh, C S Oh, Z C Wang, and S J Kim. Effects of phosphorous addition on mechanical properties and retained austenite stability of $0.15 \mathrm{C}-1.5 \mathrm{Mn}$ 1.5Al TRIP-aided cold rolled steels. Metals and Materials International, 13(1):13-19, 2007.

[25] E M Bellhouse, A I M Mertens, and J R McDermid. Development of the surface structure of TRIP steels prior to hot-dip galvanizing. Materials Science and Engineering A-Structural Materials Properties Microstructure and Processing, 463(1-2):147-156, 2007.

[26] J Mahieu, S Claessens, and B C De Cooman. Galvanizability of high-strength steels for automotive applications. Metallurgical and Materials Transactions A-Physical Metallurgy and Materials Science, 32(11):2905-2908, 2001.

[27] I B Timokhina. The Microstructure and Mechanical Properties of Thermomechanically Processed TRansformation Induced Plasticity (TRIP) Steels. PhD thesis, Deakin University, 2003.

[28] M Gomez, C I Garcia, and A J Deardo. The role of new ferrite on retained austenite stabilization in Al-TRIP steels. ISIJ International, 50(1):139-146, 2010.

[29] P J Jacques, E Girault, A Mertens, B Verlinden, J Van Humbeeck, and F Delannay. The developments of cold-rolled TRIP-assisted multiphase steels. Al-alloyed TRIPassisted multiphase steels. ISIJ International, 41(9):1068-1074, 2001.

[30] M Soliman and H Palkowski. On factors affecting the phase transformation and mechanical properties of cold-rolled transformation-induced-plasticity-aided steel. Metallurgical and Materials Transactions A-Physical Metallurgy and Materials Science, 39A(10):2513-2527, 2008.

[31] P J Jacques. Transformation-induced plasticity for high strength formable steels. Current Opinion in Solid State $\&$ Materials Science, 8(3-4):259-265, 2004.

[32] K W Andrews. Empirical formulae for calculation of some transformation temperatures. Journal of the Iron and Steel Institute, 203:721-727, 1965.

[33] A A Gorni. Steel Forming and Heat Treating Handbook, volume 19 January. Sao Vicente, Brazil, 2002. 
[34] L Zhao, J Moreno, S Kruijver, J Sietsma, and S van der Zwaag. Influence of intercritical annealing temperature on phase transformations in a high aluminum TRIP steel. In B C De Cooman, editor, International conference on TRIP-aided high strength ferrous alloys, pages 141-145. GRIPS, 2002.

[35] A Ali, M Ahmed, F H Hashmi, and A Q Khan. Incomplete reaction phenomenon in high-strength bainitic steels. Metallurgical Transactions A-Physical Metallurgy and Materials Science, 24(10):2145-2150, 1993.

[36] P J Jacques, X Cornet, P Harlet, J Ladriere, and F Delannay. Enhancement of the mechanical properties of a low-carbon, low-silicon steel by formation of a multiphased microstructure containing retained austenite. Metallurgical and Materials Transactions A-Physical Metallurgy and Materials Science, 29(9):2383-2393, 1998.

[37] F G Caballero and H K D H Bhadeshia. Very strong bainite. Current Opinion in Solid State 85 Materials Science, 8(3-4):251-257, 2004.

[38] S Traint, A Pichler, K Hauzenberger, P Stiaszny, and E Werner. Influence of silicon, aluminium, phosphorus and copper on the phase transformations of low alloyed TRIPsteels. In B C De Cooman, editor, International conference on TRIP-aided high strength ferrous alloys, pages 121-128. GRIPS, 2002.

[39] A Z Hanzaki, P D Hodgson, and S Yue. The influence of bainite on retained austenite characteristics in Si-Mn TRIP steels. ISIJ International, 35(1):79-85, 1995.

[40] A N Vasilakos and G N Haidemenopoulos. The stability of retained austenite in lowalloy TRIP steels. In P Neumann, D Allen, and E Tenckhoff, editors, Materials/Steels, volume 7 of Steels and Materials for Power Plants, pages 213-218, Weinheim, 1999. Wiley-VCH Verlag GmbH \& Co.

[41] K Sugimoto, M Misu, M Kobayashi, and H Shirasawa. Effects of second phase morphology on retained austenite morphology and tensile properties in a TRIP-aided dual-phase steel sheet. ISIJ International, 33(7):775-782, 1993.

[42] B Lawrence. The Effect of Phase Morphology and Volume Fraction of Retained Austenite on the Formability of Transformation Induced Plasticity Steels. Master's thesis, Queen's University, January 2010.

[43] K Sugimoto, T Iida, J Sakaguchi, and T Kashima. Retained austenite characteristics and tensile properties in a TRIP type bainitic sheet steel. ISIJ International, 40(9):902-908, 2000.

[44] N C Goel, J P Chakravarty, and K Tangri. The influence of starting microstructure on the retention and mechanical stability of austenite in an intercritically annealed low-alloy dual-phase steel. Metallurgical Transactions A-Physical Metallurgy and Materials Science, 18(1):5-9, 1987. 
[45] P J Jacques, J Ladriere, and F Delannay. On the influence of interactions between phases on the mechanical stability of retained austenite in transformation-induced plasticity multiphase steels. Metallurgical and Materials Transactions A-Physical Metallurgy and Materials Science, 32(11):2759-2768, 2001.

[46] G Lacroix, T Pardoen, and P J Jacques. The fracture toughness of TRIP-assisted multiphase steels. Acta Materialia, 56(15):3900-3913, 2008.

[47] E Jimenez-Melero, N H van Dijk, L Zhao, J Sietsma, S E Offerman, J P Wright, and $\mathrm{S}$ van der Zwaag. Martensitic transformation of individual grains in low-alloyed TRIP steels. Scripta Materialia, 56(5):421-424, 2007.

[48] J J Wang and S van der Zwaag. Stabilization mechanisms of retained austenite in transformation-induced plasticity steel. Metallurgical and Materials Transactions APhysical Metallurgy and Materials Science, 32(6):1527-1539, 2001.

[49] J H Ryu, D I Kim, H S Kim, H K D H Bhadeshia, and D W Suh. Strain partitioning and mechanical stability of retained austenite. Scripta Materialia, 63(3):297-299, 2010 .

[50] E Jimenez-Melero, N H van Dijk, L Zhao, J Sietsma, S E Offerman, J P Wright, and $\mathrm{S}$ van der Zwaag. Characterization of individual retained austenite grains and their stability in low-alloyed TRIP steels. Acta Materialia, 55(20):6713-6723, 2007.

[51] J C Fisher, J H Hollomon, and D Turnbull. Kinetics of the austenite-martensite transformation. Transactions of the American Institute of Mining and Metallurgical Engineers, 185(10):691-700, 1949.

[52] S Chatterjee. Transformations in TRIP-assisted Steels: Microstructure and Properties. PhD thesis, University of Cambridge, 2006.

[53] A Basuki and E Aernoudt. Influence of rolling of TRIP steel in the intercritical region on the stability of retained austenite. Journal of Materials Processing Technology, 90:37-43, 1999.

[54] K Sugimoto, N Usui, M Kobayashi, and S Hashimoto. Effects of volume fraction and stability of retained austenite on ductility of TRIP-aided dual-phase steels. ISIJ International, 32(12):1311-1318, 1992.

[55] A Mark, M A Gharghouri, and Boyd J D. Retained austenite stability in model TRIP steel microstructures: II Deformation induced transformation behaviour. Paper submitted for publication.

[56] Q Furnemont, P Jacques, T Pardoen, F Lani, S Godet, P Harlet, K T Conlon, and F Delannay. The macro- and micromechanics of TRIP-assisted multiphase steels, experiments and modelling. In B C De Cooman, editor, International conference on TRIP-aided high strength ferrous alloys, pages 39-43. GRIPS, 2002. 
[57] I B Timokhina, P D Hodgson, and E V Pereloma. Effect of microstructure on the stability of retained austenite in transformation-induced-plasticity steels. Metallurgical and Materials Transactions A-Physical Metallurgy and Materials Science, $35 \mathrm{~A}(8): 2331-2341,2004$.

[58] H K D H Bhadeshia. Bainite in Steels. The Institute of Materials, London, 1992.

[59] G Reisner, E A Werner, P Kerschbaummayr, I Papst, and F D Fischer. The modeling of retained austenite in low-alloyed TRIP steels. JOM-Journal of the Minerals Metals E Materials Society, 49(9):62-83, 1997.

[60] M De Meyer, D Vanderschueren, and B C De Cooman. The influence of the substitution of $\mathrm{Si}$ by $\mathrm{Al}$ on the properties of cold rolled $\mathrm{C}-\mathrm{Mn}-\mathrm{Si}$ TRIP steels. ISIJ International, 39(8):813-822, 1999.

[61] M De Meyer, D Vanderschueren, K De Blauwe, and B C De Cooman. The characterization of retained austenite in TRIP steels by X-ray diffraction. In Mechanical Working and Steel Processing Conference, volume 37 of 41 st Mechanical Working and Steel Processing Conference Proceedings Iron $\&$ steel society: Mechanical working and steel processing conference proceedings, pages 483-491, 1999.

[62] S S Hansen and R R Pradhan. Structure-property relationships and continuous yielding behavior in dual-phase steels. Journal of Metals, 32(12):30, 1980.

[63] Y Sakuma, D K Matlock, and G Krauss. Intercritically annealed and isothermally transformed 0.15-Pct-C steels containing 1.2-Pct Si-1.5-Pct Mn and 4 Pct Ni .1. Transformation, microstructure, and room-temperature mechanical-properties. Metallurgical Transactions A-Physical Metallurgy and Materials Science, 23(4):1221-1232, 1992.

[64] N J Kim and G Thomas. Effects of morphology on the mechanical behavior of a dual phase Fe/2Si/0.1C steel. Metallurgical Transactions A-Physical Metallurgy and Materials Science, 12:483-489, 1981.

[65] J Mahieu, J Maki, B C De Cooman, and S Claessens. Phase transformation and mechanical properties of Si-free CMnAl transformation-induced plasticity-aided steel. Metallurgical and Materials Transactions A-Physical Metallurgy and Materials Science, 33(8):2573-2580, 2002.

[66] A Z Hanzaki. Transformation Characteristics of Si-Mn TRIP Steels After Thermomechanical Processing. PhD thesis, McGill University, 1994.

[67] J Shi, X Sun, M Wang, W Hui, H Dong, and W Cao. Enhanced work-hardening behavior and mechanical properties in ultrafine-grained steels with large-fractioned metastable austenite. Scripta Materialia, 63:815-818, 2010. 
[68] Y Tomota, H Tokuda, Y Adachi, M Wakita, N Minakawa, A Moriai, and Y Morii. Tensile behavior of TRIP-aided multi-phase steels studied by in situ neutron diffraction. Acta Materialia, 52(20):5737-5745, 2004.

[69] S Oliver, T B Jones, and G Fourlaris. Dual phase versus TRIP strip steels: Comparison of dynamic properties for automotive crash performance. Materials Science and Technology, 23(4):423-431, 2007.

[70] R Petrov, L Kestens, A Wasilkowska, and Y Houbaert. Microstructure and texture of a lightly deformed TRIP-assisted steel characterized by means of the EBSD technique. Materials Science and Engineering A-Structural Materials Properties Microstructure and Processing, 447(1-2):285-297, 2007.

[71] J Van Slycken, P Verleysen, J Degrieck, J Bouquerel, and B C De Cooman. Dynamic response of aluminium containing TRIP steel and its constituent phases. Materials Science and Engineering A-Structural Materials Properties Microstructure and Processing, 460:516-524, 2007.

[72] H Paruz and D V Edmonds. The strain-hardening behavior of dual-phase steel. Materials Science and Engineering A-Structural Materials Properties Microstructure and Processing, 117:67-74, 1989.

[73] W M Sing and K P Rao. Influence of material properties on sheet-metal formability limits. Journal of Materials Processing Technology, 48(1-4):35-41, 1995.

[74] B D Cullity. Quantitative Analysis: Direct Comparison Method. In Elements of X-Ray Diffraction, volume 1, pages 391-396. Addison-Wesley, Reading, MA, 1956.

[75] L Zhao, N H van Dijk, E Bruck, J Sietsma, and S van der Zwaag. Magnetic and X-ray diffraction measurements for the determination of retained austenite in TRIP steels. Materials Science and Engineering A-Structural Materials Properties Microstructure and Processing, 313(1-2):145-152, 2001.

[76] C G Li, Q D Zhou, G S Song, and Z S Fang. Influence of carbon content of martensitic matrix and retained austenite on wear of martensitic ductile iron. Wear, 162:75-82, 1993.

[77] A M Beese and D Mohr. Identification of the direction-dependency of the martensitic transformation in stainless steels using in situ magnetic permeability measurements. Hyperfine Interactions, 50(7), 2010.

[78] A M Beese, D Mohr, and P O Santacreu. Isotropic phase transformation in anisotropic stainless steel 301LN sheets. In Petr Sittner, Vaclav Paidar, Ludek Heller, and Hanus Seiner, editors, European Symposium on Martensitic Transformations, 2009.

[79] A E Berkowitz and E Kneller. Magnetism and Metallurgy, volume 1. Academic Press, New York, 1969. 
[80] R M Bozorth. Ferromagnetism. D van Nostrad Company Inc, New York, 1961.

[81] F E Luborsky, J D Livingston, and G Y Chin. Magnetic Properties of Metals and Alloys. In Physical Metallurgy, volume 4, pages 2558-2560. Elsevier Science, Amsterdam, 1996.

[82] R W Cahn and P Haasen. Physical Metallurgy, volume 3. Elsevier, Amsterdam, 1983.

[83] Omega Engineering Inc. Wire color codes and limits of error. http://www.omega. com/techref/colorcodes.html. Accessed: 15/04/2012.

[84] D A Porter and K E Easterling. Interstitial Diffusion. In Phase Transformations in Metals and Alloys, volume 2, pages 63-75. CRC Press, USA, 1981.

[85] E Girault, P J Jacques, P Harlet, K Mols, J Van Humbeeck, E Aernoudt, and F Delannay. Metallographic methods for revealing the multiphase microstructure of TRIPassisted steels. Materials Characterization, 40(2):111-118, 1998.

[86] F S LePera. Improved etching technique to emphasize martensite and bainite in high-strength dual-phase steel. Journal of Metals, 32(3):38-39, 1980.

[87] G Vander Voort. Metallography: Principles and Practice, volume 4 of Materials Science and Engineering Series. ASM International, New York, 1999.

[88] W D Callister. Materials Science and Engineering: An Introduction, volume 6. John Wiley \& Sons, Inc., 2003.

[89] J F Kielkopf. New approximation to Voigt function with applications to spectral-line profile analysis. Journal of the Optical Society of America, 63(8):987-995, 1973.

[90] S Enzo, G Fagherazzi, A Benedetti, and S Polizzi. A profile-fitting procedure for analysis of broadened X-ray-diffraction peaks. 1. Methodology. Journal of Applied Crystallography, 21:536-542, 1988.

[91] R A Young and D B Wiles. Profile shape functions in Rietveld refinements. Journal of Applied Crystallography, 15:430-438, 1982.

[92] D J Dyson and B Holmes. Effect of alloying additions on lattice parameter of austenite. Journal of the Iron and Steel Institute, 208:469-474, 1970.

[93] R Ruhl and M Cohen. Splat quenching of iron-carbon alloys. Transactions of the Metallurgical Society of AIME, 245:241-251, 1969.

[94] E M Bellhouse and J R McDermid. Effect of continuous galvanizing heat treatments on the microstructure and mechanical properties of high Al-low Si transformation induced plasticity steels. Metallurgical and Materials Transactions A, 41(6):14601473, June 2010. 
[95] P J Jacques, S Allain, O Bouaziz, A De, A F Gourgues, B M Hance, Y Houbaert, J Huang, A Iza-Mendia, S E Kruger, M Radu, L Samek, J Speer, L Zhao, and $\mathrm{S}$ van der Zwaag. On measurement of retained austenite in multiphase TRIP steels results of blind round robin test involving six different techniques. Materials Science and Technology, 25(5):567-574, 2009.

[96] ASTM. E975-03 Standard Practice for X-Ray Determination of Retained Austenite in Steel with Near Random Crystallographic Orientation 1. Technical Report Reapproved 2008, 2010.

[97] ASTM. E8M-09 Standard Test Methods for Tension Testing of Metallic Materials. Technical Report C, 2010.

[98] G R Speich and K A Taylor. Tempering of Ferrous Martensites. In G B Olson and W S Owen, editors, Martensite, volume 1, pages 243-275. ASM International, 1992.

[99] ASTM. E112-10 Standard Test Methods for Determining Average Grain Size. Technical report, 2011.

[100] S Ganguly, S Datta, P P Chattopadhyay, and N Chakraborti. Designing the multiphase microstructure of steel for optimal TRIP effect: A multiobjective genetic algorithm based approach. Materials and Manufacturing Processes, 24(1):31-37, 2009.

[101] O Matsumura, Y Sakuma, and H Takechi. Retained austenite in 0.4 C-Si-1.2 Mn steel sheet intercritically heated and austempered. ISIJ International, 32(9):10141020, 1992.

[102] R Blonde, E Jimenez-Melero, N H van Dijk, E Bruck, L Zhao, J Sietsma, and S van der Zwaag. Microstructural control of the austenite stability in low-alloyed TRIP steels. Solid-Solid Phase Transformations in Inorganic Materials Solid State Phenomena. 2011.

[103] M Kehoe and P M Kelly. Role of carbon in strength of ferrous martensite. Scripta Metallurgica, 4(6):473-476, 1970.

[104] M Tokizane, N Matsumura, K Tsuzaki, T Maki, and I Tamura. Recrystallization and formation of austenite in deformed lath martensitic structure of low-carbon steels. Metallurgical Transactions A-Physical Metallurgy and Materials Science, 13(8):13791388, 1982.

[105] K Sugimoto, A Kanda, R Kikuchi, S Hashimoto, T Kashima, and S Ikeda. Ductility and formability of newly developed high strength low alloy TRIP-aided sheet steels with annealed martensite matrix. ISIJ International, 42(8):910-915, 2002.

[106] G Krauss. Steels: Processing, Structure, and Performance. ASM International, 2005. 
[107] R Gullberg and Lagnebor R. X-ray determination of the volume fraction of phase in textured materials. Transactions of the Metallurgical Society of AIME, 236(10):1482$1485,1966$.

[108] R L Miller. Volume fraction analysis of phase in textured alloys. Transactions of the ASM, 61(3):592-597, 1968.

[109] M X Zhang, P M Kelly, L K Bekessy, and J D Gates. Determination of retained austenite using an X-ray texture goniometer. Materials Characterization, 45(1):3949, 2000.

[110] R L Miller. A rapid X-ray method for the determination of retained austenite. Transactions of the ASM, 57(4):892-899, 1964.

[111] E Jimenez-Melero, N H van Dijk, L Zhao, J Sietsma, J P Wright, and S van der Zwaag. In situ synchrotron study on the interplay between martensite formation, texture evolution and load partitioning in low-alloyed TRIP steels. Materials Science and Engineering A-Structural Materials Properties Microstructure and Processing, 528(21):6407-6416, 2011.

[112] R Blonde, E Jimenez-Melero, L Zhao, J P Wright, E Bruck, S van der Zwaag, and $\mathrm{N} \mathrm{H}$ van Dijk. High-energy X-ray diffraction study on the temperature-dependent mechanical stability of retained austenite in low-alloyed TRIP steels. Acta Materialia, 60(2):565-577, 2012.

[113] J Chiang, B Lawrence, J D Boyd, and A K Pilkey. Effect of microstructure on retained austenite stability and work hardening of TRIP steels. Materials Science and Engineering: A, 528(13-14):4516-4521, May 2011.

[114] S van der Zwaag, L Zhao, S O Kruijver, and J Sietsma. Thermal and mechanical stability of retained austenite in aluminum-containing multiphase TRIP steels. ISIJ International, 42(12):1565-1570, 2002.

[115] S Kruijver, L Zhao, J Sietsma, E Offerman, N H van Dijk, L Margulies, E Lauridsen, S Grigull, H Poulsen, and S van der Zwaag. In situ observations on the austenite stability in TRIP-steel during tensile testing. In B C De Cooman, editor, International conference on TRIP-aided high strength ferrous alloys, pages 25-29. GRIPS, 2002.

[116] G B Olson and M Azrin. Transformation behavior of TRIP steels. Metallurgical Transactions A-Physical Metallurgy and Materials Science, 9(5):713-721, 1978.

[117] P J Gibbs, E De Moor, M J Merwin, B Clausen, J G Speer, and D K Matlock. Austenite stability effects on tensile behavior of manganese-enriched-austenite transformation-induced plasticity steel. Metallurgical and Materials Transactions APhysical Metallurgy and Materials Science, 42A(12):3691-3702, 2011. 
[118] A Pierman, C Tekoglu, T Pardoen, and P J Jacques. Nucleation, growth and coalescence of voids in dual phase steels: from model microstructures to microstructure based modelling. In Proceedings of the 12th International Congress on Fracture, July 2009 .

[119] T Sakaki, K Sugimoto, and T Fukuzato. Role of internal stress for continuous yielding of dual-phase steels. Acta Metallurgica, 31(10):1737-1746, October 1983.

[120] A Basuki and E Aernoudt. Effect of deformation in the intercritical area on the grain refinement of retained austenite of 0.4C trip steel. Scripta Materialia, 40(9):10031008, 1999.

[121] A Kammouni, W Saikaly, M Dumont, C Marteau, X Bano, and A Charai. A methodology suitable for TEM local measurements of carbon concentration in retained austenite. Materials Characterization, 59(9):1307-1311, 2008.

[122] K Sugimoto, B Z Yu, Y Mukai, and S Ikeda. Microstructure and formability of aluminum bearing TRIP-aided steels with annealed martensite matrix. ISIJ International, 45(8):1194-1200, 2005.

[123] J Van Slycken, P Verleysen, J Degrieck, L Samek, and B C De Cooman. High-strainrate behavior of low-alloy multiphase aluminum- and silicon-based transformationinduced plasticity steels. Metallurgical and Materials Transactions A-Physical Metallurgy and Materials Science, 37A(5):1527-1539, 2006.

[124] F Latourte, Z Feinberg, L F Mori, G B Olson, and H D Espinosa. Shear and tensile plastic behaviour of austenitic steel TRIP-120 compared with martensitic steel HSLA100. International Journal of Fracture, 162(1-2):187-204, 2010.

[125] J Van Slycken, P Verleysen, J Degrieck, J Bouquerel, and B C De Cooman. Crashworthiness characterization and modelling of high-strength steels for automotive applications. Proceedings of the Institution of Mechanical Engineers Part D-Journal of Automobile Engineering, 220(D4):391-400, 2006.

[126] K S Choi, W N Liu, X Sun, and M A Khaleel. Microstructure-based constitutive modeling of TRIP steel: Prediction of ductility and failure modes under different loading conditions. Acta Materialia, 57(8):2592-2604, 2009.

[127] V Uthaisangsuk, U Prahl, and W Bleck. Modelling of damage and failure in multiphase high strength DP and TRIP steels. Engineering Fracture Mechanics, 2010.

[128] S Curtze, V T Kuokkala, M Hokka, and P Peura. Deformation behavior of TRIP and DP steels in tension at different temperatures over a wide range of strain rates. Materials Science and Engineering A-Structural Materials Properties Microstructure and Processing, 507(1-2):124-131, 2009. 


\section{REFERENCES}

[129] H W Luo, L Zhao, S O Kruijver, J Sietsma, and S van der Zwaag. Effect of intercritical deformation on bainite formation in Al-containing TRIP steel. ISIJ International, 43(8):1219-1227, 2003.

[130] L Li, B C De Cooman, P Wollants, Y L He, and X D Zhou. Effect of aluminum and silicon on transformation induced plasticity of the TRIP steel. Journal of Materials Science $\&$ Technology, 20(2):135-138, 2004.

[131] S Papaefthymiour, W Bleck, S Kruijver, J Sietsma, L Zhao, and S van der Zwaag. Influence of intercritical deformation on microstructure of TRIP steels containing Al. Materials Science and Technology, 20(2):201-206, 2004.

[132] E Emadoddin, A Akbarzadeh, and Gh Daneshi. Effect of cold rolling reduction and intercritical annealing temperature on the bulk texture of two TRIP-aided steel sheets. Journal of Materials Processing Technology, 203(1-3):293-300, July 2008. 


\section{Appendix A}

\section{Optimizing Heat Treatment}

\section{Parameters}

The transformation temperature $\mathrm{Ac}_{1}$ was estimated to be $701.4^{\circ} \mathrm{C}$ using the $\mathrm{An}$ drews formula [32] and $\mathrm{Ac}_{3}$ was estimated to be $948.3^{\circ} \mathrm{C}$ using the Park formula [33]. These two transformation temperatures, which predict the temperatures bounding the intercritical region, were used as a starting point for designing a set of preliminary heat treatments to determine a heat treatment schedule that would produce the maximum volume fraction of RA. Heat treatments for aluminum-alloyed TRIP steels that were outlined in literature were also used as a guideline to help focus the scope of this investigation [128-132]. The heat treatment schedule used to produce the equiaxed microstructure is the standard two-step heat treatment that is shown schematically in Figure 3.1a. The lamellar microstructure was produced following the same heat treatment path, but with an additional step of austenitizing and quenching the sample before intercritical annealing. The diagram of the lamellar heat treatment path is shown in Figure 3.1b. 
Four main parameters were investigated in the preliminary heat treatments: intercritical annealing temperature and time, and the bainite hold temperature and time. In particular, the intercritical annealing temperature in the equiaxed microstructure was explored in greater detail than the other parameters. The values of each parameter that were tested are listed in Table A.1. To simplify this process, only a few combinations of these heat treatment parameters were tested. Each of the temperatures and times were tested systematically so that there was only one variable at a time, while the other parameters remained constant. These preliminary heat treatments were evaluated using magnetic measurements to determine the volume fraction of retained austenite. The best heat treatment was determined as the one with the highest volume fraction of RA in the microstructure. This evaluation criterion was

Table A.1: Parameters that were tested in the preliminary heat treatments.

\begin{tabular}{lc}
\hline Heat Treatment Parameter & Values \\
\hline & $800^{\circ} \mathrm{C}$ \\
& $825^{\circ} \mathrm{C}$ \\
Intercritical annealing temperature & $850^{\circ} \mathrm{C}$ \\
& $875^{\circ} \mathrm{C}$ \\
& $900^{\circ} \mathrm{C}$ \\
& $925^{\circ} \mathrm{C}$ \\
& $950^{\circ} \mathrm{C}$ \\
\hline \multirow{2}{*}{ Intercritical annealing time } & $120 \mathrm{~s}$ \\
& $300 \mathrm{~s}$ \\
Bainite hold temperature & $600 \mathrm{~s}$ \\
\hline & $400^{\circ} \mathrm{C}$ \\
Bainite hold time & $450^{\circ} \mathrm{C}$ \\
& $500^{\circ} \mathrm{C}$ \\
\hline
\end{tabular}


chosen because high volume fractions of RA are directly related to good mechanical properties (i.e.: highest UTS, highest percent elongation, high work hardening rate) $[4,42]$. The results of these heat treatments are summarized in Figure A.1.

Figure A.1a shows a plot of how the volume fraction of RA is affected by the intercritical annealing temperature. While the intercritical annealing temperature was varied, the other parameters were kept constant at an intercritical annealing time of $300 \mathrm{~s}$, a bainite hold time of $100 \mathrm{~s}$ and a bainite hold temperature of $450^{\circ} \mathrm{C}$. This parameter was tested more thoroughly for the equiaxed microstructure than for the lamellar microstructure. A maximum volume fraction of RA was achieved at an intercritical annealing temperature of $875^{\circ} \mathrm{C}$ for both microstructures, although the peak is more pronounced in the equiaxed microstructure. The horizontal error bars on the graph represent the uncertainty associated with the thermocouple that was used. The vertical error bars represent the standard deviation of the 10 measurements that were averaged for each of the plotted points.

Figure A.1b shows the effect of varying the bainite hold temperature. This investigation of the bainite hold temperature was conducted with three different temperatures in both the equiaxed and the lamellar microstructure variants. An intercritical anneal of $875^{\circ} \mathrm{C}$ for 300 s was used and the bainite hold time was held constant at 100s. Both microstructures exhibited a clear peak for the maximum volume fraction of RA produced at a bainite hold temperature of $450^{\circ} \mathrm{C}$.

Similarly, the time parameters of the heat treatments were also varied systematically. Figure A.1c shows the results of heat treatments with three intercritical annealing times. The intercritical annealing temperature was held constant at $875^{\circ} \mathrm{C}$ and a bainite hold of $450^{\circ} \mathrm{C}$ for 100 s was used. Varying the intercritical annealing time did not result in a distinct peak in the volume fraction of RA, but rather had fairly 


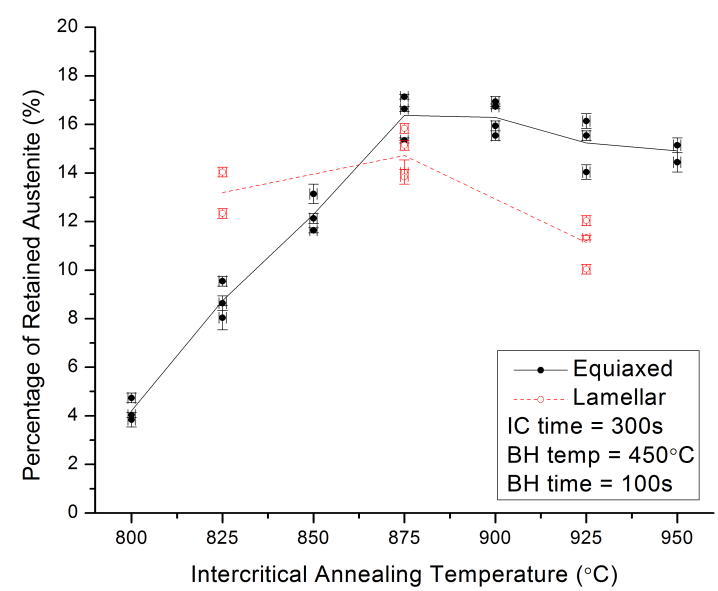

(a)

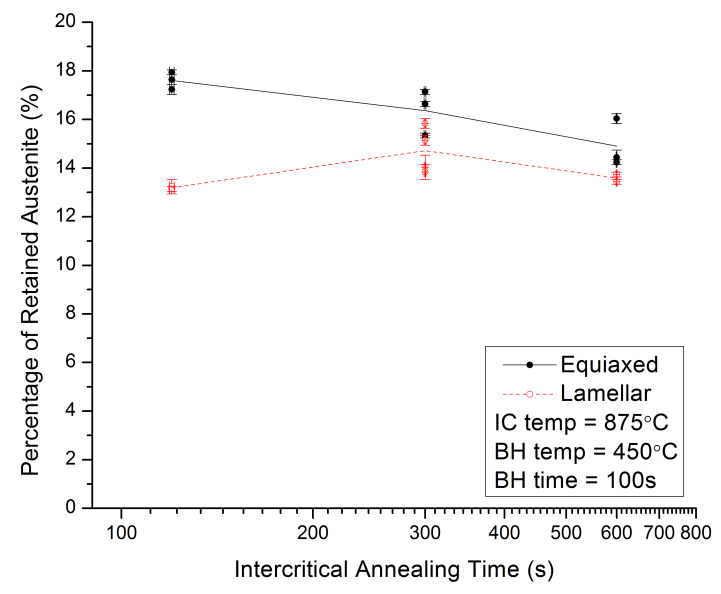

(c)

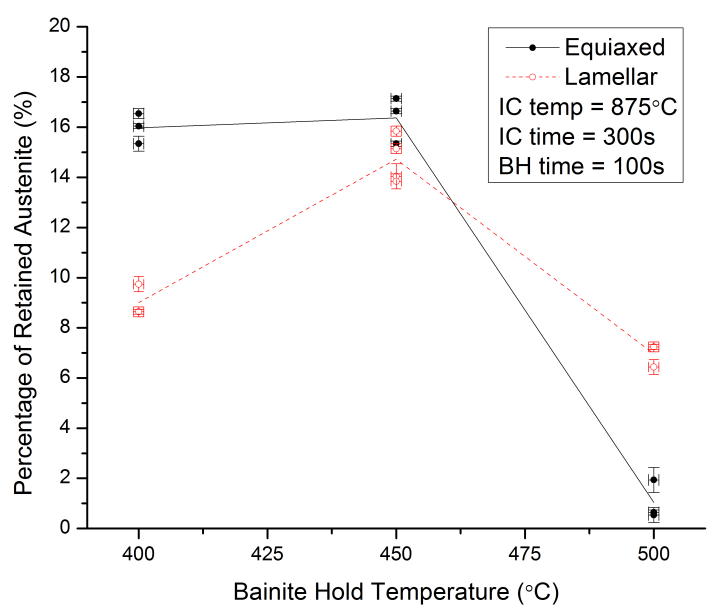

(b)

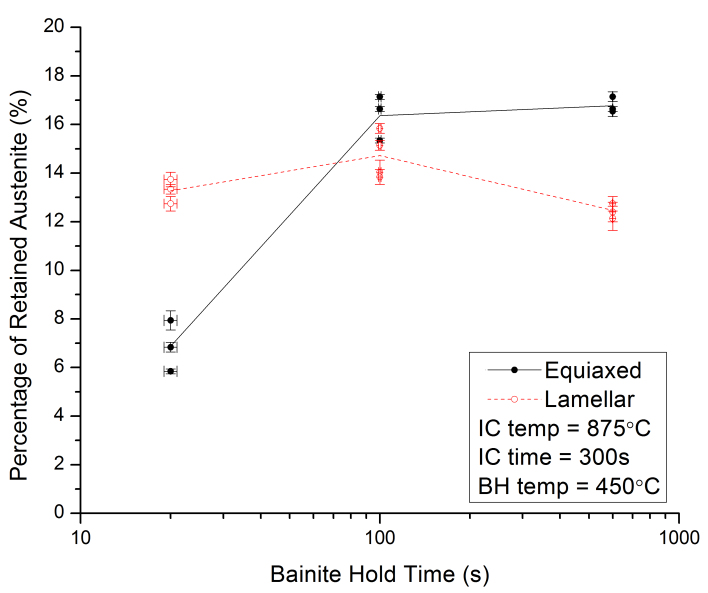

(d)

Figure A.1: Effect of (a) intercritical annealing temperature, (b) bainite hold temperature, (c) intercritical annealing time and (d) bainite hold time on volume fraction of RA. 
constant values for all of the samples tested. There was a slight trend that could be observed but the measurements were all within $4 \%-5 \%$ of each other.

And finally, three bainite hold times were tested for each microstructure variant and the results are summarized in Figure A.1d. The intercritical anneal was held constant at $875^{\circ} \mathrm{C}$ for $300 \mathrm{~s}$ and the bainite hold temperature was $450^{\circ} \mathrm{C}$. Similar to the intercritical annealing time, the bainite hold time also does not appear to affect the volume fraction of RA significantly, with the exception of the drop in RA volume fraction for the equiaxed microstructure at a bainite hold time of 20s. These results suggest that the time parameters of the heat treatment path do not influence the volume fraction of RA as much as the temperatures do. Alternatively, this lack of a clear peak in Figures A.1c and A.1d could be because the range in the times that were tested was not large enough.

Thus, the schedule for the two-step heat treatment was chosen to be an intercritical anneal at $875^{\circ} \mathrm{C}$ for 300 s followed by a bainite hold at $450^{\circ} \mathrm{C}$ for 100 s for both microstructural variants. This combination produced the microstructural variants with the highest volume fraction of RA as well as similar volume fractions to one another. These two variants were labelled the equiaxed-875 microstructure and the lamellar-875 microstructure. 


\section{Appendix B}

\section{Heat Treatments to Produce Similar UTS Values}

In order to produce microstructural variants having similar UTS values, the original heat treatments were varied and tested using uniaxial tensile tests. The initial heat treatment used to produce the equiaxed-875 and lamellar-875 microstructures followed the heat treatment schedule of an intercritical anneal at $875^{\circ} \mathrm{C}$ for 300 s followed by a bainite hold at $450^{\circ} \mathrm{C}$ for $100 \mathrm{~s}$. Because the intercritical annealing temperature was found to have the largest effect on the volume fraction of RA in the microstructure (according to Appendix A), this was expected to lead to the largest change in mechanical properties so this parameter was chosen for testing.

Five intercritical annealing temperatures in the range of $750^{\circ} \mathrm{C}-925^{\circ} \mathrm{C}$ were chosen to be tested for the equiaxed microstructure. Four temperatures between $825^{\circ} \mathrm{C}$ and $950^{\circ} \mathrm{C}$ were tested for the lamellar microstructure. The intercritical hold time of 300 s and the bainite hold of $450^{\circ} \mathrm{C}$ for 100 s was kept constant throughout this entire study. Three specimens for each intercritical annealing temperature were tested in 
uniaxial tension to compare the UTS values. Figure B.1 shows representative engineering stress-strain curves for each of the intercritical annealing temperatures that were tested and Table B.1 provides the results for the individual tensile tests. This tensile data is summarized in Figure B.2 as the UTS values as a function of intercritical annealing temperature. The samples were named according to their intercritical annealing temperatures. For instance, the equiaxed $775-1$ sample follows the equiaxed heat treatment path with an intercritical annealing temperature of $775^{\circ} \mathrm{C}$, and is specimen number 1.

Specifically, an intercritical annealing temperature of $750^{\circ} \mathrm{C}$ was chosen for the equiaxed microstructure because it exhibited a lower UTS than the lamellar microstructures that were tested. This tensile response was very different from the other equiaxed microstructural variants that all had higher UTS values than the lamellar microstructural variants. An effort was made to choose an intercritical annealing temperature for the lamellar microstructure that produced the closest UTS value while still considering the time constraints on this project. Thus, an intercritical annealing temperature of $750^{\circ} \mathrm{C}$ was chosen for the equiaxed microstructure and $925^{\circ} \mathrm{C}$ was chosen for the lamellar microstructure. These two variants were labelled the equiaxed-750 microstructure and the lamellar-925 microstructure. 


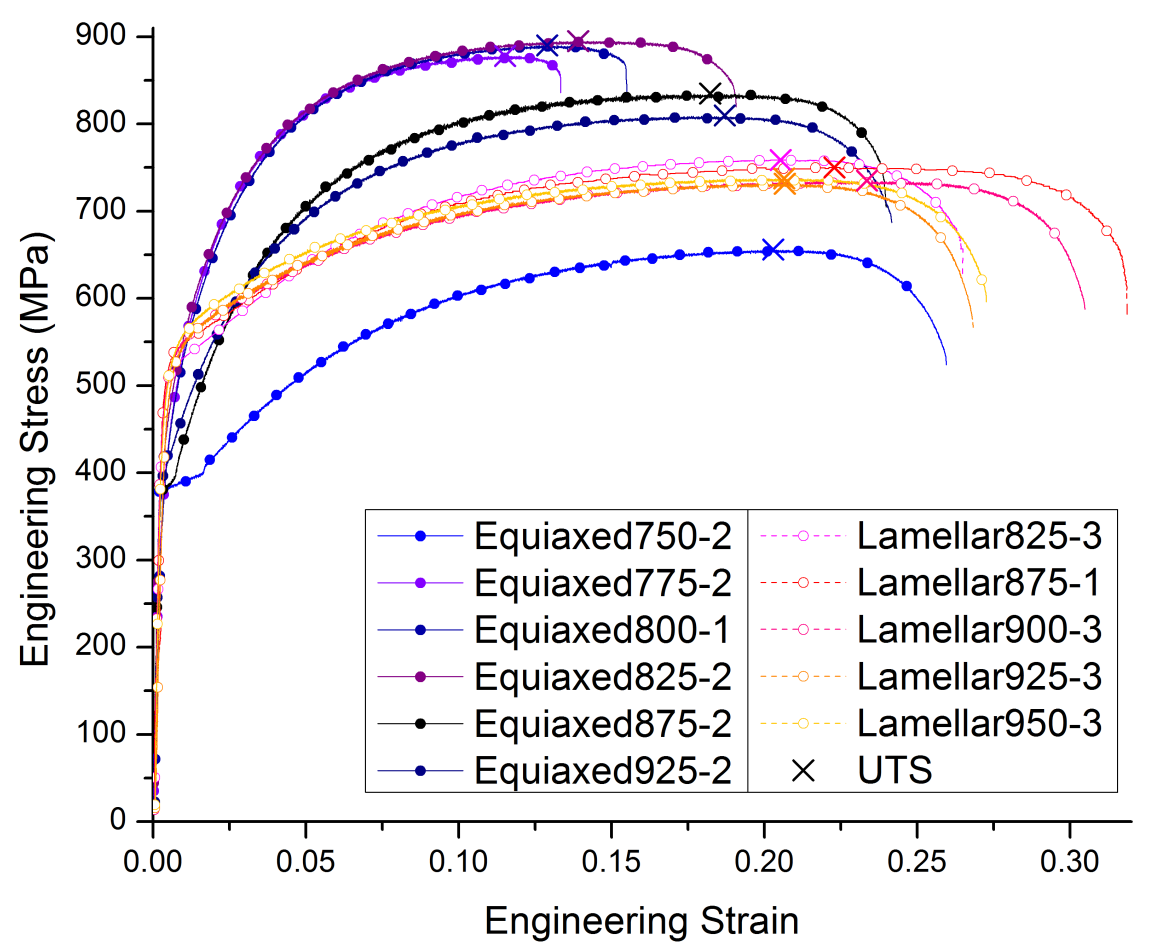

Figure B.1: Representative engineering stress-strain curves of samples with different intercritical annealing temperatures. 
Table B.1: Ultimate tensile strengths of samples with different intercritical annealing temperatures.

\begin{tabular}{cccc}
\hline Sample & $\begin{array}{c}\text { UTS } \\
(\mathrm{MPa})\end{array}$ & Sample & $\begin{array}{c}\text { UTS } \\
(\mathrm{MPa})\end{array}$ \\
\hline Equiaxed750-1 & 669 & Lamellar825-1 & 778 \\
Equiaxed750-2 & 656 & Lamellar825-2 & 764 \\
Equiaxed750-3 & 680 & Lamellar825-3 & 760 \\
Equiaxed775-1 & 867 & Lamellar875-1 & 750 \\
Equiaxed775-2 & 878 & Lamellar875-2 & 758 \\
Equiaxed775-3 & 874 & Lamellar875-3 & 750 \\
Equiaxed800-1 & 890 & Lamellar900-1 & 739 \\
Equiaxed800-2 & 885 & Lamellar900-2 & 738 \\
Equiaxed800-3 & 905 & Lamellar900-3 & 735 \\
Equiaxed825-1 & 901 & Lamellar925-1 & 740 \\
Equiaxed825-2 & 895 & Lamellar925-2 & 727 \\
Equiaxed825-3 & 914 & Lamellar925-3 & 732 \\
Equiaxed875-1 & 848 & Lamellar950-1 & 750 \\
Equiaxed875-2 & 835 & Lamellar950-2 & 742 \\
Equiaxed875-3 & 840 & Lamellar950-3 & 738 \\
Equiaxed925-1 & 815 & & \\
Equiaxed925-2 & 810 & & \\
Equiaxed925-3 & 813 & & \\
\hline
\end{tabular}




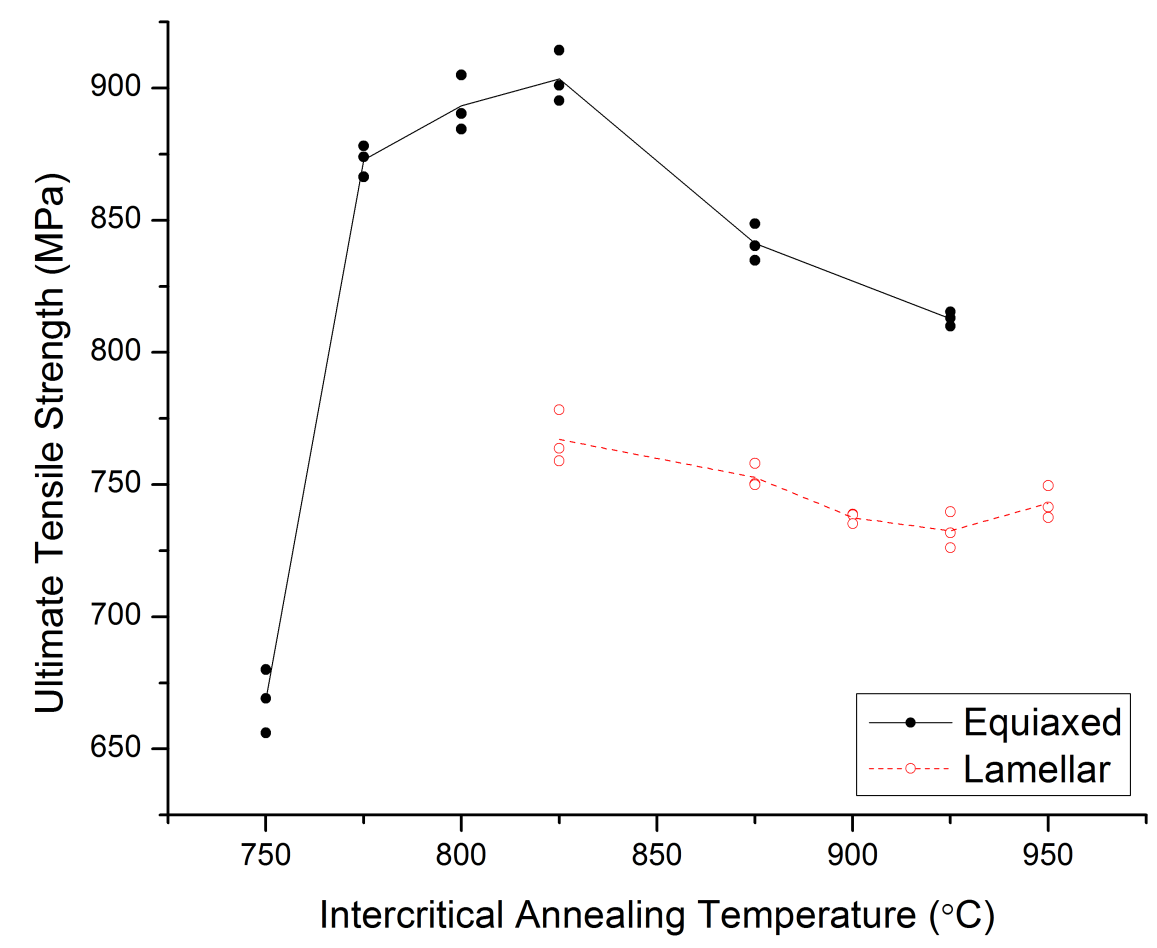

Figure B.2: Ultimate tensile strength versus intercritical annealing temperature for the two microstructural variants. 


\section{Appendix $\mathrm{C}$}

\section{Calibration of Heat Treatment Equipment}

\section{C.1 Heating Rates}

The heating rates for the tube furnace were monitored using a thermocouple attached to a sample that was the same size as the coupons used for the tensile specimens. This was done to determine how long it took for the sample to reach the intercritical annealing temperature of $875^{\circ} \mathrm{C}$. That way, the annealing time could be adjusted accordingly so that the specimen is held at the target temperature for the desired amount of time. The heating curve temperature data that was collected is shown in Figure C.1.

$\mathrm{Ac}_{1}$ is the temperature at which austenite begins to form in the steel, so the sample was considered to be at-temperature upon reaching the theoretical $\mathrm{Ac}_{1}$ temperature. This value was calculated to be $701.4^{\circ} \mathrm{C}$ using the Andrews formula [32]. The average time it took to reach the $\mathrm{Ac}_{1}$ transformation temperature from room temperature 
was $18 \mathrm{~s}$. Because the heating time was so short, the intercritical annealing time was not adjusted and the 300s hold was measured starting from the time of insertion.

The cooling rate between the intercritical anneal and the bainite hold was controlled based on the timing of transferring the sample by hand. A reasonable effort was made to keep this timing constant, however there is some variability introduced during this step of the heat treatment process and there is potential for improvement in the experimental setup.

\section{C.2 Temperature Gradients}

The temperature in the tube furnace was calibrated so that the target temperature was achieved at the centre of the tube and the sample was placed with the centre of the sample at that location. However, there is a temperature gradient within the furnace so the sample is subjected to slightly lower temperatures at the edges of the sample than in the centre. The temperature gradient along the tube was measured using a thermocouple and is shown in Figure C.2. Due to the flow of argon in the tube, one side of the sample had a slightly lower temperature than the other. The sample has a length of $100 \mathrm{~mm}$ so the edges of the sample are heat treated at a temperature that is about $10^{\circ} \mathrm{C}$ lower than the centre of the sample.

Similarly, the temperature in the salt bath was examined at various depths using a thermocouple. Because the salt bath is fairly large, the temperature was found to be very uniform. The temperature of the salt at different depths were within $2^{\circ} \mathrm{C}$ of the set point. 


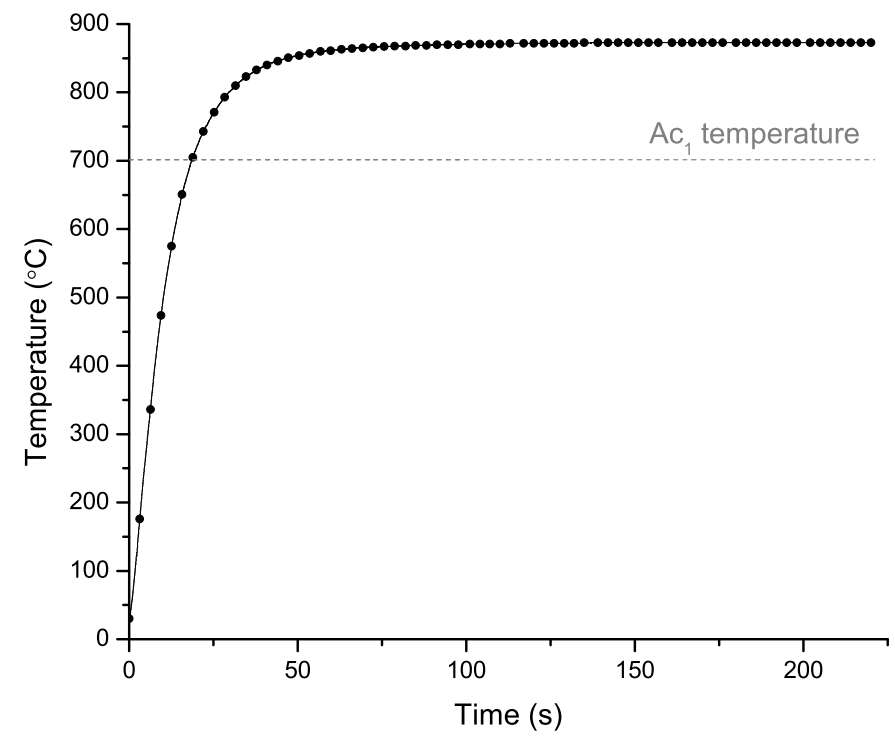

Figure C.1: Temperature data for the heating rate in the tube furnace with a set point of $875^{\circ} \mathrm{C}$.

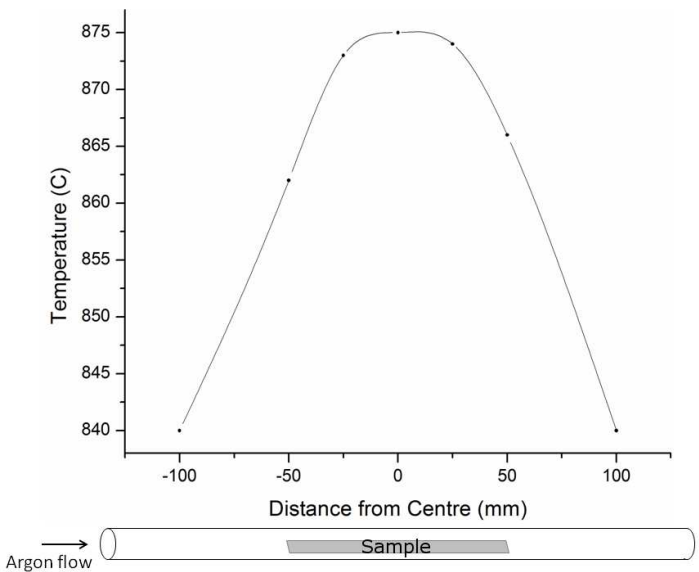

(a)

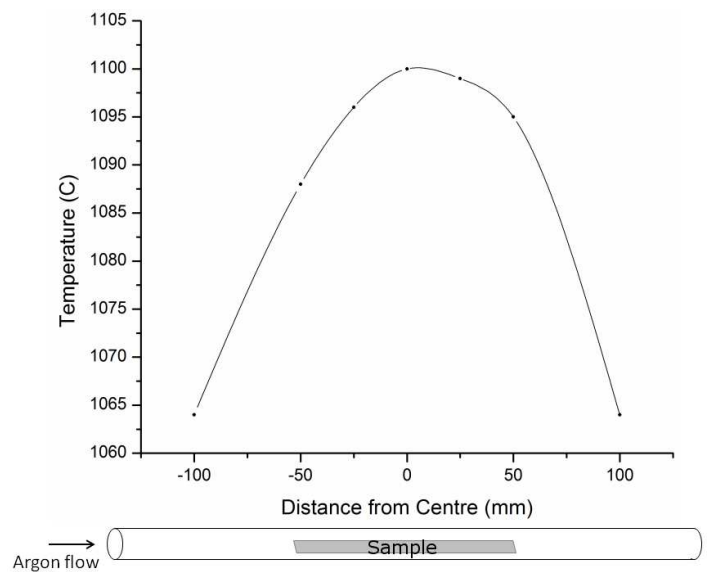

(b)

Figure C.2: Temperature gradient in tube furnace at set points of (a) $875^{\circ} \mathrm{C}$ and (b) $1100^{\circ} \mathrm{C}$. The diagrams below the plots represent the location of the sample within the tube furnace and the direction of argon flow. 